\title{
A hermeneutic phenomenological examination of the lived experience of incarceration for those with autism
}

Claire Newman

Submitted for the degree of

Master of Nursing (Hons)

University of Technology Sydney 


\section{Certificate of Authorship/Originality}

I certify that the work in this thesis has not previously been submitted for a degree nor has it been submitted as part of requirements for a degree except as fully acknowledged within the text.

I also certify that the thesis has been written by me. Any help that I have received in my research work and the preparation of the thesis itself has been acknowledged. In addition, I certify that all information sources and literature used are indicated in the thesis.

Signature of Student 


\section{Acknowledgements}

I would like to thank the participants of this study for their time and generosity in sharing their experiences. Thank you also to the JH\&FMHN and CSNSW staff who assisted with the identification of participants and who enabled data collection to take place.

I would also like to thank my supervisors, Andrew Cashin and Cheryl Waters, for sharing their knowledge and expertise, and offering their continued support, patience and encouragement. And to my manager, Karen Patterson, for her generous support especially in the latter stages of the completion of this thesis.

Finally, a special thanks to my parents and sister, Cheryl, Dave \& Karla Newman, and my friends, for their ongoing encouragement, and to Bruno, Joey, Izzy, Skyla and my other furry, scaly and feathered family and friends for the unconditional support and enjoyment throughout this journey. 


\section{Contents}

List of Appendices $\quad \mathrm{V}$

List of Tables \& Figures vi vi

Glossary of Acronyms vii

Abstract viii

$\begin{array}{ll}\text { Chapter 1: Introduction } & 1\end{array}$

Chapter 2: Literature review 4

2.1 What is autism? 4

2.2 Diagnosis of autism 5

$\begin{array}{ll}2.3 \text { Prevalence of autism } & 8\end{array}$

$\begin{array}{ll}2.4 \text { Causes of autism } & 10\end{array}$

2.5 Impaired communication 18

2.6 Impaired social skills 26

2.7 Repetitive behaviours and narrow interests $\quad 29$

2.8 Autism and anxiety 31

2.9 Autism and offending behaviour 34

2.10 Prevalence of autism in offender populations 39

2.11 What is known about the experience of incarceration 42

2.11.1 Prison and the general experience of incarceration 43

2.11.2 The experience of incarceration for those with autism 52

Chapter 3: Methodology 56

Chapter 4: Methods $\quad 65$

4.1 Study participants $\quad 65$

4.2 Procedures 66

4.2.1 Recruitment 66

$\begin{array}{ll}\text { 4.2.2 Data collection } & 67\end{array}$

$\begin{array}{ll}\text { 4.2.3 Data analysis } & 70\end{array}$

$\begin{array}{ll}4.3 \text { Ethical considerations } & 71\end{array}$

$\begin{array}{ll}\text { Chapter 5: Findings } & 77\end{array}$

$\begin{array}{ll}5.1 \text { Deprivation of attempts to regain control } & 78\end{array}$

5.2 Being constantly present in an unpredictable environment 86

5.3 Strangeness and incomprehension of prison routines and rules 91

5.4 Negotiating the social world of prison 93 
5.5 Coping with social-related demands through self-isolation $\begin{array}{ll}\text { and avoidance } & 100\end{array}$

$\begin{array}{ll}\text { Chapter 6: Discussion } & 107\end{array}$

6.1 Participant experience and what is known about autism 107

6.2 Comparing participant experience with the neurotypical experience $\begin{array}{ll}\text { of incarceration } & 121\end{array}$

$\begin{array}{ll}\text { 6.3 Limitations } & 129\end{array}$

6.4 Recommendations and conclusion 132

$\begin{array}{ll}\text { Appendices } & 137\end{array}$

$\begin{array}{ll}\text { References } & 145\end{array}$ 


\section{List of appendices}

I Comic visual aid: What it is like to have autism and be in prison?

II Approvals from ethics committees

III Participant information sheet

IV Participant consent form

V Publications arising from this thesis 


\section{List of tables}

Table 1: Gene abnormalities potentially associated with autism

\section{List of figures}

Figure 1: Illustrated model of anxiety experienced by incarcerated persons who have autism 


\section{Glossary of acronyms}

$\begin{array}{ll}\text { ADI-R } & \text { Autism Diagnostic Interview - Revised } \\ \text { ADOS } & \text { Autism Diagnostic Observation Scale } \\ \text { ASD } & \text { Autism Spectrum Disorder } \\ \text { CSNSW } & \text { Correctional Services New South Wales } \\ \text { DSM } & \text { Diagnostic and Statistical Manual } \\ \text { ICD } & \text { International Classification of Diseases } \\ \text { JH\&FMHN } & \text { Justice Health \& Forensic Mental Health Network } \\ \text { MHOAT } & \text { Mental Health Outcomes and Assessment Tool } \\ \text { MMR } & \text { Measles, Mumps and Rubella Vaccine } \\ \text { PAS } & \text { Patient Administration System } \\ \text { PDD-nos } & \text { Pervasive Developmental Disorder not otherwise specified } \\ \text { NSW } & \text { New South Wales } \\ \text { UK } & \text { United Kingdom } \\ \text { US } & \text { United States }\end{array}$




\begin{abstract}
The experiences of incarceration for those with autism are largely unknown. As a result there is paucity in the research literature to inform appropriate service provision for incarcerated persons with autism. This study aimed to examine and interpret the lived experience of adults with autism who were incarcerated in the New South Wales correctional system, Australia. A hermeneutic phenomenological approach, underpinned by the philosophy of Martin Heidegger and Hans-Georg Gadamer, was utilised in this research. Participants were interviewed with sensitivity to the information processing style of those with autism using modified techniques for using a hermeneutic phenomenological approach with study participants who have autism. Interviews were audio-recorded and recordings transcribed to create a text for interpretative analysis. The lived experience of incarceration for the participants of this study was about being in an unpredictable environment characterised by everchanging routines, incomprehensible rules and unpredictable complex social situations. Experiencing anxiety was a prominent theme and stemmed from being deprived of their ability to create predictability in their environment, and the confusion and distress experienced by being forced to comply with actions that were in conflict with their logic. The environment further allowed participants to isolate themselves and avoid social interactions as a form of maladaptive coping with the social-related demands of incarceration. From dialoguing the findings with existing literature it was clear that aspects of study participants' experience of incarceration were comparable to what would be experienced by incarcerated persons who do not have autism. However much of the anxiety experienced by participants in the current study related directly to the incompatibleness of their autism-related impairments and the prison environment and would therefore be unique to prisoners who have autism or autism-like traits. Recommendations for improvements in service provision for incarcerated persons with autism are made and areas for future research suggested.
\end{abstract}




\section{Introduction}

Autism is a developmental disorder estimated to affect up to $1.6 \%$ of the population (Baron-Cohen et al. 2009). Autism is characterised by a triad of impairment in communication skills and social functioning, and restricted and stereotyped patterns of behaviour. These impairments are most notably characterised by difficulties with pragmatic language, inability to interpret complex social situations, social misunderstandings, and behavioural inflexibility. The behavioural characteristics of autism, that constitute the triad of impairment, have been theorised to relate to weak central coherence, deficits in theory of mind ability, and executive dysfunction. The behavioural characteristics of autism form the basis of criteria utilised in the diagnosis of autism. The construct of autism is applicable to three discrete entities in the Diagnostic and Statistical Manual of Mental Disorders (DSM-IV-TR)(APA 2000). The diagnostic entities of Autistic Disorder, Asperger's Disorder and Pervasive Developmental Disorder not otherwise specified (PDD-nos) are considered to be autism. The term 'autism' will be used throughout this thesis to represent these disorders.

It has been postulated through a small number of case studies that the behavioural characteristics of autism may predispose such persons to engage in offender behaviour (Barry-Walsh \& Mullen 2004; Everall \& LeCouter 1990; Kohn et al. 1998; Mawson, Grounds \& Tantam 1985; Murrie et al. 2002; Murphy 2010b; Realmuto \& Ruble 1999; Schwartz-Watts 2005; Woodbury-Smith et al. 2005; Woodbury-Smith et al. 2010). Despite a relation between autism and offending behaviour being unsubstantiated in current literature a number of studies examining the prevalence of autism in mentally disordered offender populations imply a higher prevalence rate of autism in comparison to the general population (Hare et al. 1999; Scragg \& Shah 1994; Siponmaa et al. 2001). However there is a paucity of research to determine the prevalence of autism in the mainstream prison population. Issues related to the likelihood of individuals with autism in this population group being undiagnosed or misdiagnosed is likely to make accurate prevalence rates unattainable (Cashin \& Newman 2009; Gómez de la Cuesta 2010). However available evidence does support the notion that persons with autism are represented in the custodial system. 
Prisons are known to be environments designed to confine and deprive their occupants liberty and privacy where, underlying a hierarchical-based social order, is a prisoner subculture in which bullying and victimisation is known to be rife (Ashkar \& Kenny 2008; Doyle 2003; Korn 2004; Ireland 2000; South \& Wood 2006). The incarceration experience of prisoners with autism is largely unknown, despite reasonable postulation that their communication and social impairments would render such individuals vulnerable to high rates of exploitation and abuse in the prison environment (Dein \& Woodbury-Smith 2010). This is supported by a small UK case study of two individuals with Asperger's Disorder whose experiences were dominated by confrontations with others and isolation as a form of avoidance of, or protection from, being bullied (Paterson 2008). The impact of the unpredictable nature of prison and prison routines on incarcerated prisoners with autism are also unknown. An understanding of the experience and research in this area is required to inform the development of appropriate services to support those with autism who are incarcerated.

The current study aimed to examine the lived experience of incarceration for persons with autism in New South Wales (NSW), Australia. The methodology utilised in this study was that of hermeneutic phenomenology, as a methodology focused on examining human experiences as they are lived. Hermeneutic phenomenology, outlined in chapter three of this thesis, aims to make explicit the meaning of the experience under investigation through interpretation of text created from the narratives of those being studied (Geanellos 1998). Martin Heidegger defined and made explicit the importance of meaning in his phenomenological study related to the meaning of Being: "That which has been articulated as such in interpretation and sketched out beforehand in the understanding in general as something articulable, is the meaning” (Heidegger 1927/1962, p. 154). The meaning of the lived experienced cannot be detached from the world of the person for whom it is being experienced, as human experience is embedded within a historical and social context (Crotty 1998; Geanellos 1998). This reflects the ontological nature of hermeneutic phenomenology. The philosophical underpinnings of hermeneutic phenomenology are required to be integrated into the method of data collection and analysis of a hermeneutic phenomenological study. The methods of the current study are outlined in chapter 
four of this thesis. Methodological approaches in the current study were also considered with sensitivity to the information processing style of those with autism and modified interview techniques for use in interviewing persons with autism participating in hermeneutic phenomenological research, stated by Newman, Cashin and Waters (2010) were employed.

The final chapters of this thesis detail the results of the study (chapter five) and a discussion of the interpretation of the participants' incarceration experience in relation to its relevance to the triad of impairment (chapter six). Within the discussion (chapter six) the interpretation of the participants' incarceration experiences are also dialogued with existing literature to understand whether incarceration is uniquely experienced by those with autism. Finally future directions for research and recommendations to improve service provision for incarcerated persons with autism are discussed. 


\section{Literature Review}

\subsection{What is autism?}

The term 'autism' was derived from the Greek word autos, meaning 'self', and first used by the Swiss Psychiatrist Dr. Eugen Bleuler in 1911, who theorised 'autism' to be a form or symptom of Schizophrenia reflecting egocentric thinking and a withdrawal from the external world (Feinstein 2010). The term 'autism' was not used as it is in its present sense until the 1940s when the characteristics of autism were first described in detail by Leo Kanner (1894-1981), an Austrian born psychiatrist working in Baltimore. In a seminal paper titled 'Autistic disturbances of affective contact', Kanner (1943) described eleven children who displayed severe social deficits detailing “the children's inability to relate themselves in the ordinary way to people and situations from the beginning of life” (Kanner 1943, p. 242). Kanner described the children's' unusual behaviors such as dislike to changes in routine, unusual language, sensory problems and savant skills. Kanner referred to this pattern of behaviour as 'early infantile autism', and emphasised an onset of before 30 months of age.

At the same time Viennese pediatrician Hans Asperger (1906-1980) was submitting his thesis on "Die Autistischen Psychopathen im kindesalter" (Autistic Psychopathy in Childhood) (Asperger 1944), translated into English by Uta Firth in full and published in 1991 (Firth 1991, pp. 37-92), in which he described children who made inappropriate social approaches, who were clumsy and inept but had average or above intelligence and good vocabulary although only used to talk about a narrow range of special interests. However as Asperger's work, written during the Second World War, contained pro-Nazi vocabulary it was interpreted and consequently discounted as Nazi-propaganda by the international community (Feinstein 2010). Asperger’s work continued to go unrecognised until Lorna Wing, an English Psychiatrist, published an account of his work in 1981 (Wing 1981). Wing and her colleagues, through clinical work and epistemological based research, first identified the similarities between Kanner's autism and Asperger's Syndrome in the late 1970s (Wing \& Gould 1979). They developed the concept of 'autistic spectrum disorders', reflecting that the 
features of autism may occur at varying degrees of severity (Wing \& Potter 2002). Wing and Gould at this time introduced the features of autistic spectrum disorders as a 'triad of impairment' in social interaction, communication and imagination, with repetitive activities replacing imaginative symbolic interests (Wing \& Gould 1979).

\subsection{Diagnosis of autism}

In the absence of biological markers and definitive diagnostic tests for autism diagnostic constructs have historically been defined by the presence of behavioural characteristics. Kanner's original diagnostic formation of autism was based on behavioural features of autism that included obsessive desire for sameness and a profound lack of affective contact (Feinstein 2010). As research with individuals with autism progressed throughout the 1960s and 1970s there was recognition there were many individuals with autistic-like impairments that didn’t fully meet Kanner's original diagnostic critieria for autism (Feinstein 2010). Therefore Wing and Gould (1979) introduced the concept of a spectrum of autistic disorders (ASDs) to reflect the wide variance in the presentation of autism.

Current diagnostic criteria provided in the Diagnostic and Statistical Manual of Mental Disorders, $4^{\text {th }}$ edition text revised, (DSM-IV-TR) list the three diagnostic entities that constitute autism: Autistic Disorder, Asperger's Disorder and Pervasive Developmental Disorder not otherwise specified (PDD-nos) (APA 2000). These disorders are known collectively as Pervasive Developmental Disorders along with two other neurological disorders, Rett's Disorder and Childhood Disintegrative Disorder, which are not considered autism. Similarly the International Classification of Mental and Behavioural Disorders, $10^{\text {th }}$ edition (ICD-10) indicate subgroups of pervasive developmental disorders that include Childhood Autism, Atypical Autism, Asperger's Syndrome and pervasive developmental disorders, unspecified (WHO 1992).

Whilst PDD-nos is a diagnosis used for sub-threshold behaviours across the triad of impairment, differentiating between Autistic Disorder and Asperger’s Disorder is a contentious issue. The criteria for Autistic Disorder specifies that there must be present a certain number of characteristics within the categories of impaired social 
interaction and communication, and restricted, repetitive and stereotyped patterns of behaviours, with abnormal functioning in at least one category prior to the age of three years (APA 2000). If the individual's intelligence is average or above, where there was no significant delay in cognitive development, and speech developed in a chronologically expected manner then Asperger's Disorder is given as the diagnosis as opposed to Autistic Disorder. As the criteria for Autistic Disorder must not be met in order for an individual to meet the criteria for Asperger's Disorder, it has been argued that a diagnosis of Asperger’s Disorder is not possible (Cashin 2006). Vague wording and unclear definitions in current diagnostic manuals make differentiating diagnostic criteria between subgroups extremely difficult. This is evidenced in the wide range of modified diagnostic definitions used across studies involving participants with Asperger’s Disorder.

The ability to draw distinctions between Asperger's Disorder and other forms of autism was first questioned more than three decades ago by German psychiatrist, Dr. Gerhard Bosch (Bosch 1970). In this book Bosch included a section in the appendix titled ‘The differences between Asperger and Kanner syndromes' in which clear distinctions between the two syndromes were questioned (Bosch 1970). The contentious issue of the validity of Asperger's Disorder as a separate construct has been discussed in recent literature also. For example, Ghaziuddin (2010) argued that there is clinical utility in the diagnosis of Asperger's Disorder as those with this disorder differ to those who met the diagnostic criteria for Autistic Disorder in communication style, social impairment, idiosyncratic interests, and in age of onset. However, evidence for discrete phenotypes was not supported in a recent German study of 140 children and adolescents (Kamp-Becker et al. 2010). In this study participants who had varying diagnoses that included: Asperger's Disorder $(n=52)$; high-functioning autism ( $n=44)$; atypical autism $(n=8)$; and other diagnoses $(n=36)$, when clustered could not be distinguished by their diagnosis in either early or current symptomatology or in neuropsychological behaviours (Kamp-Becker et al. 2010). The Autism Diagnostic Observation Scale (ADOS) and the Autism Diagnostic InterviewRevised (ADI-R) was used to identify symptom variability and severity, the Vineland Adaptive Behaviour Scales to assess adaptive behaviour in communication, daily living skills and socialisation, and the Neuropsychological Test Battery was used to measure intelligence, emotion recognition, Theory of Mind, spatial perception, 
executive functioning and attention (Kamp-Becker et al. 2010). Similarly, no significant difference was found in ADI-R scores, or in language comprehension or expression, in 34 adults with autism compared to 42 adults with Asperger's Disorder (Howlin 2003). There is arguably little benefit or clinical value to an individual being diagnostically assigned to specific subgroup, especially as they are likely to fit the criteria for different subgroups as their development changes throughout their life.

Unsurprisingly the relevance of subgroups of autism in diagnostic manuals has also been questioned (Wing, Gould \& Gillberg 2011). It is of interest that the criteria for diagnosing autism will again be refined in the DSM-V scheduled for publication in 2013. The DSM-V proposes a diagnostic term of Autistic Disorder with the removal of previously used subgroups including Asperger’s Disorder (APA 2010). Further proposed changes include three criteria: 1 . social and communication problems; 2. restricted behaviour; 3. symptoms present in early childhood (Wing, Gould \& Gillberg 2011). This has lead to debate in the literature including the risk of previously undiagnosed adults with autism being unable to receive a diagnosis in the absence of informants to meet the third criterion (Ghaziuddin 2010; Wing, Gould \& Gillberg 2011). Therefore the reliability, and relevance, of subcategorising autism in diagnostic manuals is uncertain. Health professionals, rather than commit to a specific diagnosis where there is uncertainty, will often use the term 'Autistic Spectrum Disorder' (Baird, Cass \& Slonims 2003). It is of interest to note that this term is not listed in either internationally used diagnostic manuals (DSM or ICD), rather subcategories of autism are collectively referred to as Pervasive Development Disorders.

Diagnosis is made by observation of behaviours in structured and unstructured situations, medical history taking and a detailed examination of developmental history (Baird, Cass \& Slonims 2003; Wing \& Potter 2002). This lengthy process is fraught with difficulties where the diagnostic entities of autism are difficult to define as the impairments experienced by people with autism are variable in nature and change in the presentation of these impairments occurs over time (Baird, Cass \& Slonims 2003). Additionally the diagnostic process is further complicated by difficulties in obtaining detailed and reliable developmental histories, as whilst this is an achievable task during childhood, for many adults detail of developmental history are unclear to 
support differentiation between diagnostic subcategories of autism. Further the presence of, or misdiagnosis with, mental health disorders such as anxiety, depression, obsessive compulsive disorder or schizophrenia, add additional complications in the diagnostic process (Royal College of Psychiatrists 2006; Wing \& Potter 2002).

The wide variation in the presentation of autism has lead to autism being viewed as a spectrum disorder where one might possess a subgroup of autism depending on where on the spectrum their presenting behaviours are at time of diagnosis. This subjective means of sub-grouping autism in combination with the vague wording and unclear definitions in diagnostic manuals has lead to the critical questioning of the value of diagnostic subgroups of autism and a review of current diagnostic criteria. However, until such time, current diagnostic criteria is based on the triad of impairment.

\subsection{Prevalence of autism}

There have been a number of epidemiological based studies attempting to determine the prevalence of autism or autism spectrum disorders. However the comparability of the findings from these studies is difficult due to varying methodologies and diagnostic terms and criteria used. From a review of 32 epidemiological surveys of autism between 1966 and 2001 Fombonne (2003) estimated the prevalence of Autistic Disorder to be between $0.09 \%$ and $0.11 \%$ of the population, and $0.025 \%$ for Asperger's Disorder although acknowledged epidemiological studies of Asperger's Disorder were sparse at time of review. Whilst these figures are now considered conservative based on recent studies, Fombonne’s review clearly illustrated a rising trend in prevalence estimates of autism with estimates for autistic disorder as low as $0.007 \%$ in 1970 rising up to $0.4 \%$ in 2001 in one study.

Several factors are considered to account for the steady increase in the prevalence estimate of autism in the general population. Firstly, as recognised by Fombonne (2003) this increase is representative of the prevalence estimate only rather than the incidence of autism, and most likely reflects changes in the concepts and definitions of autism. However it is possible that the incidence of autism has also increased (Wing \& Potter 2002). Other suggested factors include increased awareness amongst 
professionals and the lay public, deinstitutionalisation of mental health facilities, improved recognition and detection, changes in diagnostic methods and concepts, recognition that autism can co-exist with other psychiatric or developmental conditions and epidemiological studies employing different methodologies (Baird, Cass \& Slonims 2003; Baron-Cohen et al. 2009; Eyal et al. 2010; Feinstein 2010; Wing \& Potter 2002).

The national prevalence of autism in Australia is largely unknown due to the inconsistencies in calculation. Autism prevalence estimates in Australia have ranged from $0.08 \%$ in Western Australia to $0.4 \%$ in Victoria (Williams et al. 2008). From the examination of existing data provided by the primary Commonwealth, State and Territory agencies using nationally collected data between 2003-2004, prevalence ranges were $0.09-1.5 \%$ for $0-5$ years old, $0.1-0.4 \%$ for $6-12$ year old, and $0.08-0.2 \%$ for 13-16 years old (Williams et al. 2008).The estimated prevalence of autism among Australian children provided in this review varied considerably depending on the data source with Centrelink data being the most comprehensive single source of national information. A recent and comprehensive report produced by the Australian Advisory Board on Autism Spectrum Disorders (2007) used the Commonwealth Government's Centrelink data to estimate a prevalence of 1 in every 160 children (0.6\%) aged 6-12 years with Autistic Disorder, Asperger’s Disorder, or Pervasive Developmental Disorder not otherwise specified (PPD-nos), or as termed by the authors 'autism spectrum disorder' (ASD). This rise is consistent with the steady increase witnessed in international prevalence estimates of autism.

Similar prevalence rates of autism have been presented in the international literature. In the United States (US) 1 in 90 children (1.1\%) aged 3-17 years were estimated to have Autistic Disorder, Asperger's disorder, or PDD-nos based on parental reports in 2007 (Kogan et al. 2009). Similarly in the US the Centre for Disease Control and Prevention (2007) found a prevalence of 1 in 150 children (0.7\%) of 8 years of age to have an ASD (Autistic Disorder, Asperger's Disorder, or PDD-nos). A recent study in the United Kingdom (UK) estimated a similar prevalence rate (1\%) of known 'autismspectrum conditions' (using the International Classification of Diseases research criteria (WHO 1993)) in school children aged 5-9 years based on information drawn from the Special Educational Needs Register and confirmed cases identified through 
parental survey (Baron-Cohen et al. 2009). This study additionally determined a prevalence of (0.6\%) undiagnosed cases in the study sample by screening children who scored highly on the Childhood Autism Spectrum Test (CAST). This equates to a total prevalence of 157 per 10,000 (1.6\%). It is plausible that further cases may have been found if all schools in the sample area participated (children from nonresponding schools equated to 2876), and if a greater than $29 \%$ response rate on the CAST survey had been achieved.

\subsection{Causes of autism}

Whilst autism has been associated with abnormal brain development its aetiology remains uncertain. Kanner originally postulated that there was a psychogenic aetiology where parent-child relationships were a causal factor. In Kanner's original article he described the parents of his subjects as a group to be "very few warmhearted" and to be "limited in genuine interest in people” (Kanner 1943, p. 250). This theory was credited for many decades later largely as the result of Bruno Bettelheim's 1967 book titled 'The empty fortress: Infantile autism and the birth of self' in which parents were blamed for their child's autism. Bettelheim claimed infantile autism to be "a state of mind that develops in reaction to feeling oneself in an extreme situation, entirely without hope" (p.68) where the cognitive development of children with autism had been impeded by the child's intentions to withdraw their self either from their mother's emotional coldness or her negative feelings. Bettelheim described this as ‘pathogenic deprivation' or ‘pathogenic overstimulation' and may be a precipitating factor in the cause of autism when a child reacts to such in a sensitive way (Bettelheim 1967, p. 399). In his book, Bettelheim presented case studies of children with infantile autism whose mothers he described to have emotional attachment issues that were narcissistic, maternally ambivalent or simply ignored their child.

In the decade following the publication of Bettelheim's book a new theory of autism was postulated: the opioid excess theory. Panksepp (1979) hypothesised that autism was caused by endogenous overactivity of opiates in the brain system causing a disturbance that blocked psychosocial development in infants. Panksepp based his theory on the results of animal experiments where young animals showed similar 
symptoms to a child with autism when given low doses of morphine (Panksepp 1979). However Panskepp had the belief that autism was purely an emotional rather than cognitive disorder and was a result of an inability to appropriately respond to the sensory and social environment. It was further hypothesised by Sandyk and Gillman (1986) that dysfunction of the endogenous opioid system was potentially the cause of autism as the clinical characteristics of autism resembled the characteristic changes in mood, behaviour and attention when morphine is administered. It was later postulated that inadequately metabolised proteins from gluten and casein are absorbed across abnormally permeable dietary membranes resulting in opioid peptides that cross the blood-brain barrier intensifying opioid activity that would present itself in symptomatology characteristic of autism (Reichelt et al. 1991; Shattock \& Whiteley 2002). However, despite evidence of the blood-brain barrier physiologically functioning to restrict the permeation of substances such as opioid peptides due to their lipid solubility and molecular size (Witt \& Davis 2006), the role of the opioid theory in the aetiology of autism continues to influence a large portion of dietetic therapies for autism today.

The opioid excess theory was supported by studies that found excessive opioid peptides in the urine of children with autism (Reichelt et al. 1986; Reichelt et al. 1991). However, a more recent case control study of 65 boys with autism and 158 control boys, found no evidence of opioid peptiduria in the urine samples of those with autism (Cass et al. 2008). Nor have recent studies found children with autism to be at a greater risk of gastro-intestinal problems. For example, in a Canadian sample of 14 children aged 4 to 12 years with autism, no difference was found in small intestine permeability when compared to a control group of seven developmental normal siblings and eight developmentally normal unrelated children (Robertson et al. 2008). However the findings from this study should be considered in light of its small sample size and poor clarity of diagnostic inclusion criteria. Only children with DSMIV diagnosed 'autism' were included in the study; therefore it is unclear whether the authors were referring to the inclusion of children with Autistic Disorder only given the use of different nomenclature to what is used in the diagnostic manual referred to by the authors. 
Intervention studies examining the effectiveness of gluten and casein free diets have yielded mixed results. A Norwegian study by Knivsberg and colleagues (1995) examined the effects of a gluten-casein free diet in 15 participants aged 6 to 22 years with DSM-III-R diagnosed Pervasive Developmental Disorders. After one year all participants were described to have reduced symptomatology in that social, cognitive and communicative skills had improved, and 'remarkable progress' was noted at four years for those participants who continued the diet (Knivsberg et al. 1995). However, the reliability of these improvements is questionable as they were based on parental report and, as the parents were aware of their child being allocated to the glutencasein free diet group from the outset, the impact of the placebo affect cannot be ruled out. The results are further limited by the lack of certainty that participants' diet remained completely free from gluten and casein throughout the study period. The same authors later conducted a small-scale randomised control study to determine the effects of dietary intervention on 10 individuals with 'autistic syndromes' aged 5 to 10 years and again concluded significant improvement was found in the intervention group (Knivsberg et al. 2002). Further to this the behavioural improvements described in these studies can arguably be considered normal trajectory of improved behavioural symptoms of autism with or without dietary intervention. Conversely no significant findings were found in a randomised, double blind repeated measures crossover design study of 15 children with DSM-IV diagnosed Autistic Disorder (Elder et al. 2006). In this study the authors concluded that there was no significant difference in autistic symptoms or urinary peptide levels found between the intervention or control group despite parental-reported improvements in their children (Elder et al. 2006). To date there is insufficient empirical data to suggest diet is involved in the aetiology of autism (Lomangino 2010; Millward et al. 2008).

A possible link between immunological abnormalities and autism has also been a focus in autism related research for a number of decades. A recent review of the research relating to the immune system's role in the biology of autism concluded that recent findings link immunity to autism (Goines \& Van de Water 2010). Immunological abnormalities highlighted from the reviewed studies include: altered cytokine profiles (dysregulation of transforming growth factor beta, elevated plasma levels of macrophage inhibitory factor, and elevated plasma leptin levels); abnormal plasma immunoglobin levels (reduced IgG and IgM levels and increased IgG $_{4}$ levels); 
altered celluar immunity (reduced natural killer (NK) cell activity and altered macrophages); neuroinflammation (active inflammation in the central nervous system). The implications of these immunological abnormalities include altered neural development, dysregulation of the immune system, the central nervous system, and the endrocrone system, and autoimmunity disorders all of which may play a role in the aetiology of autism (Goines \& Van de Water 2010). However the authors have provided little critique of the papers included in their review with the exception of stating five referenced studies had large sample numbers. Further examination of the studies reveals that the review, on which the authors have based their conclusions, has a number of limitations that have not been addressed. Firstly of the 17 referenced studies only 11 different study samples were included (this is likely to be only 10 different study samples as two studies by the same author had similar participant numbers ( $n=72$ vs. $n=71$ ) but this is not confirmed due to failure by the author to include recruitment method details for either study). Six studies in fact reported from one study sample. Therefore despite different abnormalities being explored in different studies, if immunological abnormalities were identified in one study it is not surprising that further immunological abnormalities were found in the other studies using the same sample. Further, inconsistent inclusion criteria for participants included in the 'autism' groups of these studies are apparent. For example, only one of the studies referenced in this review had inclusion criteria of participants with DSM-IV diagnosed Autistic Disorder or Asperger's Disorder and a further two studies had the broader inclusion criteria of DSM-IV diagnosed Autistic Disorder, Asperger's Disorder and PDD-nos. The participants in the remaining reviewed studies included DSM-IV diagnosed ‘autism’ (n=9 referenced studies), DSM-IV diagnosed 'ASD' ( $\mathrm{n}=2$ referenced studies) and 'autism' or 'ASD' diagnosed using autism diagnostic interviews (ADI/ADOS). The majority of studies included in this review also had small sample numbers: six studies had sample numbers ranging from 8 to 20 participants with autism/ASD; six studies had sample numbers ranging from 35 to 75 participants with autism/ASD; and two studies had sample numbers ranging from 114 to 116 participants with autism/ASD. One genotyping study had 230 participants with non-DSM diagnosed participants with autism. Only one had had a large sample number of 1027 participants with DSM-IV or ICD-10 diagnosed autism (note the term 'autism' was used so it is unknown whether this sample included participants with sub-threshold behaviours i.e. diagnosed with PDD-nos). However these participants 
had all been referred for immune system evaluation by their clinicians so increased incidences of immunological abnormalities would be expected, and were compared to an insufficient number of controls ( $\mathrm{n}=113)$. It is also a further limitation that of the ten referenced studies reporting altered cytokine profiles in participants with autism, only two reported that the participants were free from psychotropic medication that is known to skew cytokine profiles due to a potential interaction with the immune system. Two of the ten studies identified that some of the participants in the autism group were taking psychotropic medication and the remaining six studies failed to disclose if their participants were taking psychotropic medication. A further bias was also identified in two studies that related directly to examining intolerance to dietary proteins. Therefore despite 'evidence' suggesting a possible link with autism and immunological abnormalities to date there is little empirical evidence to support that immunology plays a role in the aetiology of autism.

Other theories implicating the cause of autism have been discredited. In 1998 a study was published in the Lancet implicating a link between the Measles, Mumps and Rubella (MMR) vaccine and regressive autism (Wakefield et al. 1998). This link, at the time, was plausible given that the diagnostic trajectory of regressive autism coincided with the regression of development abilities and skills around same age as the MMR vaccine is given. In 2009 the US Vaccine Injury Compensation Program ruled there to be no conclusive evidence for a connection between autism and vaccines in a historic hearing of three cases of childhood autism in which significant evidence, medical records and scientific research was reviewed ('Vaccine court rules no connection between vaccines and autism’2009). In a review of studies evaluating or reviewing possible links with autism to the MMR vaccine between 1998 and 2009 $(n=20)$ no casual relationship between the MMR vaccine and autism had been found (Hensley \& Briars 2010). In 2010 Wakefield's original article was deemed fraudulent by the British General Medical Council on the basis of dishonest, unethical and callous practice by the authors, and was subsequently retracted by the Lancet (Deer 2011).

The relationship between autism and prenatal maternal exposures and postnatal birth complications has been explored as factors contributing to the aetiology of autism. In a systematic review of seven epidemiological studies examining prenatal and perinatal 
factors that affect the risk of autism Kolevzon, Gross and Reichenberg (2007) concluded parental age and obstetric conditions were associated with increased risk of autism. Advanced paternal age was found to be significantly correlated in three out of four studies that examined it and advanced maternal age was found in six of the seven studies that examined it. However, these findings were not considered significant when controlled for potential confounders (Kolovos, Gross \& Reichenberg 2007). Whilst foetal hypoxia and hypoxia-related obstetric conditions, such as maternal hypertension and prolonged labour, were positively trended with increased risk of autism in four of the seven studies reviewed, the only significant variables were a low Apgar score (a health assessment of a newborn immediately after birth) ( $\mathrm{n}=3$ studies), bleeding during pregnancy ( $\mathrm{n}=1$ study), and foetal distress ( $\mathrm{n}=1$ study) (Kolevzon, Gross \& Reichenberg 2007). Whilst attempts were made to increase the value of the review by including only studies with large population-based epidemiological samples, the conclusions drawn from the review were based on a limited number of studies, all of which used varying diagnostic criteria. A recent study, using a co-twincontrol design of 3715 same-sex discordant twin pairs in Sweden indicated that low birth weight was associated with higher risk of autistic traits (Losh et al. 2012). Participants were aged 9 to 12 years old and enrolled in the Child and Adolescent Twin Study of Sweden for which data collection took place between 1992 and 1998. Using the Autism - Tics, Attention-deficit hyperactivity disorder, and other Comorbidities (A-TAC) Inventory, ASD-like traits (language impairment, social dysfunction and restricted interests/ repetitive behaviours) and severity were assessed for in participants. The results from this study indicated that in discordant twin pairs ( $n=43$ twin pairs where there was $>400$ g or $15 \%$ difference in birth weight) lighter twins were significantly more likely $(\mathrm{p}<0.01)$ than the heavier twin to meet the ATAC criteria for ASD. As this occurrence affected both monozygotic twins (A-TAC score of 3.25) and dizygotic twins (A-TAC score of 2.80) the authors concluded that the results were unlikely to be attributable to confounding genetic and/or environmental factors. However it is of note that the intentions of this study related to the association of ASD traits and low birth weight and not specifically to confirmed diagnosis of autism and low-birth weight.

Rather than being a causal factor, perinatal complications such as breech presentation have been suggested to have a shared aetiology with autism (Bilder et al. 2009; 
Bolton et al. 1997). It is plausible that the characteristics of autism such as resistance to change and anxiety to new circumstances make negotiating the birth canal difficult resulting in increased risk of complications during birth. This is supported by a recent meta-analysis of 40 epidemiologic studies in which the strongest evidence for an association between perinatal and neonatal factors and risk of autism included abnormal foetal presentation, umbilical-cord complications, foetal distress and birth injury or trauma (Gardener, Spiegelman \& Buka 2011). However this review identified that the studies included in the analysis evidently show inconsistent and/or statistically inconsistent results (Gardener, Spiegelman \& Buka 2011). Exposure to medication in utero, such as valproic acid and thalidomide, have also been implicated in the cause of autism (Miles 2011; Rutter 2005). However, in the absence of evidence confirming this theory, it is likely that the impairments described in these studies are simply similar to the behavioural characteristics of autism.

Genetic heritability and twin studies to date provide the strongest evidence that genetics is the most likely causal factor of autism. A recent review of twin studies in autism-related research documented high heritability of autism in monozygotic twins (who share all of their genes) in comparison to dizygotic twins (who do not share all of their genes) (Ronald \& Hoekstra 2011). This review reported on original twin studies ( $\mathrm{n}=4$ ) of narrowly defined autism (Austistic Disorder), conducted between 1977 and 1995, of which the median values for monozygotic and dizygotic twins concordances were $76 \%$ and $0 \%$ respectively. More recent twin studies $(n=3)$ of autism spectrum disorders as a broader group (includes Autistic Disorder, Asperger's Disorder, and PDD-nos), conducted between 2008 and 2011, had median values for monozygotic and dizygotic twins concordances of $88 \%$ and $31 \%$ respectively (Ronald \& Hoekstra 2011). Therefore research has shown that a monozygotic twin is more likely than a dizygotic twin to also have autism if autism is present in the other twin indicating strong genetic influences. However these findings should be considered in light of limitations related to twin studies where wide ranges in measures used and sample sizes reduce reliable comparability. For example, from the seven studies included in the Ronald and Hoekstra (2011) review sample sizes ranged from 21 to 227 twin pairs and different diagnostic methods were utilised in each study. 
In addition to twin studies, results from sibling-based studies also support that genetics play a role in the aetiology for autism. For example, in a recent US study of 1,235 families ( $\mathrm{n}=2,920$ children) with at least one child with Autistic Disorder, Asperger's Disorder or PDD-nos, $10.9 \%$ of the families had siblings with DSM-IV defined Pervasive Developmental Disorder (Autistic Disorder, Asperger's Disorder or PDD-nos), and autistic qualities (i.e. language delay) was found in $20 \%$ of siblings who did not fit DSM-IV criteria for a Pervasive Developmental Disorder (Constantino et al. 2010). However it is of note that only $68 \%$ of the previously diagnosed children had undergone standardised assessments as part of receiving their diagnosis. The expression of personality, language, and socio-behavioural characteristics in the neurotypical siblings of individuals with autism that are qualitatively similar to the defining features of autism is known as the broader autism phenotype (Hurley et al. 2007; Losh et al. 2008). The incidence of the broader autism phenotype in the siblings of those with autism supports the notion of an underlying genetic propensity for autism (Hurley et al. 2007; Losh et al. 2008).

Despite an array of research no single gene or genes have been identified to cause autism (Happé \& Ronald 2008; Miles 2011; Verhoeven, Egger \& Feenstra 2011). However a range of genetic abnormalities potentially associated with autism have been identified using microscopic cytogenetic techniques and chromosomal genomic hybridization, as detailed in the table below. A number of genetic disorders have been associated with some of the features and behaviours that are present in autism providing further indication that autism has a genetic aetiology. These disorders include fragile-X syndrome, Rett's disorder, tuberous sclerosis, Timothy syndrome and 22q11 microdeletion syndrome (Miles 2011; Muhle, Trentacoste \& Rapin 2004; Verhoeven, Egger \& Feenstra 2011). It has been hypothesised that multiple susceptible genes when acting synergistically may predispose to the development of autism (Muhle, Trentacoste \& Rapin 2004; Rutter 2005). 
Table 1:

Gene abnormalities potentially associated with autism (Verhoeven, Egger \& Feenstra 2011, p. 220)

\begin{tabular}{|l|l|l|}
\hline Chromosome & Candidate Gene & Network/Function \\
\hline $2 p 16.3$ & NRXN1 & Synapse formation \\
2q12.3-q14.2 & DPP10 & Neurotransmission \\
$3 p 24-26$ & OXTr & Neurotransmission \\
$3 p 26-p 25$ & CNTN4 & Synapse formation \\
$4 p 14-q 21.1$ & GABRG/GABRA & GABA neurotransmission \\
$7 q 31.1$ & ST7 & Tumor suppression \\
$7 q 35-q 36$ & CNTNAP2 & Synapse formation \\
$8 p 23$ & DLGAP2 & NMDA neurotransmission \\
$15 q 11-q 14$ & GABRA/GABRB/GABRG & GABA neurotransmission \\
$15 q 13$ & APBA2 & Neurotransmission \\
$16 p 11.2$ & DOC2A & Neurotransmission \\
$22 q 11$ & PRODH & Neuromodulation \\
$22 q 13$ & SHANK3 & Synapse formation \\
Xp22.3 & NLGN4 & Synapse formation \\
Xp11.4 & TSPAN7 & Neuronal growth and development \\
Xp22.1-p21.3 & IL1RAPL1 & Interleukin receptor \\
\hline
\end{tabular}

In the search for the cause of autism many theories have been proposed, with a number of consequent therapies such as dietetic therapies, being utilised in the treatment of autism remaining today despite no empirical evidence supporting their effectiveness. To date research into the role of genetics in the cause of autism has been the most convincing. However, whilst many decades worth of research has been invested into the potential causes of autism, little evidence exists today supporting a specific aetiology, and as a result diagnostic criteria are still based on behavioural markers represented by the triad of impairment. The triad of impairment represents a pattern of behaviours consistently seen in individuals with autism. These behaviours, as identified previously, include impaired communication and social skills, and repetitive behaviours and narrow interests.

\subsection{Impaired communication}

The word communication is derived from the Latin word communicare, meaning to impart, make common or share (Rosengren 2000). Communication is commonly defined as "the process of using messages to generate meaning” (Pearson et al. 2011, 
p. 10). In communication spoken words, often combined with gestures and facial expressions, are used in the sending and receiving of messages between persons. As highlighted by Kanner (1943, p. 243) language is a "tool for receiving and imparting meaningful messages”. Common or shared meanings for words, phrases and nonverbal codes between the communicators are required for messages to generate meaning; that is for understanding to occur (Pearson et al. 2011). Communication will be hindered or even ineffective if a person has the inability to elicit a shared meaning of either, or both, verbal symbols or non-verbal codes. This inability may be characterised by an incapability to receive or send a message, misunderstanding of messages, and/or inability to negotiate a shared understanding of messages. These persons are considered to have impaired communication.

Communication impairment in autism is considered a core diagnostic feature. This impairment was first recognised by Kanner (1943) who described children whose language at an early age was characterised by echolalia, pronoun reversal, and unresponsiveness to questions despite being capable of clear articulation and phonation. Communication impairment in those with autism is complex as there is significant variability in the nature (both linguistic and cognitive) and extent of impairment in individuals. This is evident in Kanner's original cases where the communication impairment in his subjects ranged from muteness to the development of communicative language after the age of 5 years (Kanner, 1943). However we do now know that the communication impairment for those with autism is not limited to the range identified in Kanner's original cases. From evidence to date there is a known variability in language development in children with autism. Generally language impairment ranges from no significant delay (as shown in those who typically receive a diagnosis of Asperger's Disorder) to the presence of no functional speech (Hudry et al. 2010; Kjelgaard \& Tager-Flusberg 2001; Walenski, TagerFlusberg \& Ullman 2006). However, hyperlexia (superior word reading ability) is seen in a small percentage of children with autism (Newman et al. 2007).

The presence of early language delay is a differentiating diagnostic factor between Autistic Disorder and Asperger's Disorder. However research comparing outcomes in adulthood for those with autism without intellectual impairment supports that early language delay does not necessarily predict language outcome in adulthood. For 
example, a comparison of 34 adults with 'high-functioning autism' with 42 adults with adults with Asperger's Disorder, all with nonverbal IQs greater than 70, found both groups to have comparable language abilities, but language ability was below chronological age level (Howlin 2003). No significant differences in communication outcomes were identified and language comprehension and expression were comparable, despite those in the Asperger's group having been reported to not have had an early language delay (Howlin 2003).

It is estimated that around 20\% of those with autism never acquire speech (Lord, Risi, \& Pickles 2004). The proportion of those with autism who do not develop functional speech has reduced from around half of those with autism in the last thirty years (Paul 1987). This is considered to correlate with the increased access to intensive interventions for language and communication, and potentially a consequence of increased diagnoses of individuals with autism with average or above intellect based on IQ scores (Tager-Flusberg, Paul \& Lord 2005). Kjelgaard and Tager-Flusberg (2001) found a significant relationship, although not exclusive, between higher IQ and better overall language abilities in a sample of 89 children aged 4 to 14 years with DSM-IV diagnosed Autistic Disorder. However, as IQ tests are dependent on language, these results may reflect testability rather than a true reflection of IQ. Such tests are not designed to be sensitive to the impairments in complex language abilities that are found in those with autism (Siegel, Minshew \& Goldstein 1996). Language skill development for those with autism, including those with Asperger's Disorder beyond early development, is known to be protracted in comparison to neurotypical individuals (Eigsti \& Bennetto 2009; Howlin 2003). Most individuals with autism develop speech later, and at a slower rate, than neurotypical children (Tager-Flusberg, Paul \& Lord 2005).

Prior to verbal language development, children with autism have a narrower range of early communicative intent than neurotypical children (Tager-Flusberg, Paul \& Lord 2005). Preverbal communicative intentions expressed in children without autism include pointing to request (protoimperative pointing), and calling attention to/pointing to share attention to objects (protodeclarative pointing). Children with autism have protoimperative pointing ability but have impairment in protodeclarative pointing, as this requires the child to establish joint attention with the other person 
using mind-reading capacity i.e. make the other person attend to what they are thinking about (Baron-Cohen 1989; Baron-Cohen et al. 2000). Young children with autism also lack pretend play behaviour, as this too requires mind-reading ability by requiring the child to understand that the pretender is imagining something (BaronCohen et al. 2000). Echolalia and pronoun reversal, which are aspects of typical speech development, have also been suggested to be more common during the early stages of verbal language development in children with autism (Tager-Flusberg, Paul \& Lord 2005). Echolalia and pronoun reversal were described by Kanner in 1943 as aspects of abnormal language in children with autism (Kanner 1943).

For those with autism who develop language, non-verbal communicative behaviours are generally impaired such as their appropriate use of gestures, facial expressions and head nods (Dodd 2005), and paralinguistic features such as intonation and stress patterns may be unusual (Attwood 1998; Tager-Flusberg, Paul \& Lord 2005). However those with autism who develop verbal language have little or no impairment in grammatical and syntactical development as, although development is delayed, it is considered to be comparative to that of neurotypcial individuals of equal language development (Attwood 1998; Bishop 2003; Eigsti \& Bennetto 2009; Tager-Flusberg et al. 1990). This is because these aspects of language are rule governed and can consequently be learned through concrete processes by persons with autism. A further perspective is that speech is an accessible domain of language that can be targeted for intensive intervention in those with autism (Tager-Flusberg, Paul \& Lord 2005). Persons with autism have been found to score well on standardised vocabulary tests (Kjelgaard \& Tager-Flusberg 2001). However, their use of words that are not concrete descriptors, such as those that relate to cognitive states (i.e. remember, think), and metaphorical or slang words are underrepresented in their vocabularies (Dennis, Lazenby \& Lockyer 2001; Tager-Flusberg, Paul \& Lord 2005). It is these abstract words, or inferences, that are used to elaborate on and attribute meaning to verbal communication and therefore form the basis of successful communication (Dennis, Lazenby \& Lockyer 2001).

Abstraction ability is associated with strong central coherence; that is the ability to appreciate the whole context of a situation and therefore processing or interpreting information in context. The cognitive style of persons with autism is characterised by 
a weak central coherence and therefore information is processed piecemeal rather than within a contextual whole. As described by Dodd (2005, p. 10) "there is usually a preference for parts over wholes, a tendency to process information piece by piece rather than a gestalt approach of filtering information through general categories”. Therefore people with autism are unable to form a unified centrally coherent base of knowledge about the world through constructionist learning (Cashin 2005). The achievement of effective communication is hindered by this impaired ability to take in, process, store, retrieve and send information. Alternatively persons with autism store information chronologically as discrete chunks of visually coded information (Cashin 2005).

An advantage of pictures over words in access to semantics in those with autism was found in a Japanese study of 20 adolescents and adults with DSM-IV diagnosed Autistic Disorder with an IQ >65 compared with 20 matched controls (Kamio \& Toichi 2000). In this study the autism group performed significantly better on pictureword completion tasks than on word-word completion tasks supporting the notion that persons with autism process thoughts through a pictorial semantic system.

Examination of brain function using functional MRI provides further evidence that persons with autism support language comprehension through reliance on visualisation (Kana et al. 2006). Neurologist Oliver Sacks (1986) described the visual cognitive processing style of those with autism when he wrote about twins with autism who had a savant gift with numbers. As he observed, "if you ask them how they can hold so much in their minds- a three-hundred-figure digit, or the trillion events of four decades- they say, very simply, 'we see it.' And 'seeing' - 'visualising' - of extraordinary intensity, limitless range, and perfect fidelity, seems to be key to this” (Sacks 1986, p. 199).

A further feature of autism is speech that has a monotone quality (Cashin \& Barker 2009). The speech and prosody characteristics (stress, intonation patterns and rhythm) of adolescents and adults with autism and was compared to that of typical speakers by Shriberg and colleagues (2001) in the US. Diagnostic interview recordings and data from standardised assessments of 15 males with 'high-functioning autism' and 15 males with Asperger's Disorder aged between 10 and 40 years (mean ages 21.6 and 20.7 years respectively) was analysed in comparison to conversational speech data of 
53 typically developing male speakers in the same age range. It is of note that the authors specify that participants met DSM-IV criteria for 'autism' or Asperger's Disorder despite 'autism' not being listed as a diagnosis in the DSM. Participants in the 'high-functioning autism' group were deemed to have 'normal IQ'. However details relating to the assessment of IQ, including what constitutes as 'normal', were not provided by the authors. The study found those with 'high-functioning autism' and Asperger's Disorder had a high prevalence of speech-sound distortions (subphonemic changes in articulatory place and manner), and significant differences in the areas of phrasing (inappropriate or non-fluent phasing of utterances), stress (inappropriate placement of stress cues in utterances) and nasal resonance (utterances rated as nasal) in comparison to the control group (Shriberg et al. 2001). Interestingly, other than those with Asperger's Disorder being statistically more voluble, no differences were found between those with 'high-functioning autism' and those with Asperger's Disorder.

Prosody is both expressive and receptive as it is used to both portray (in expressive) and understand (in receptive) emotional and pragmatic aspects of speech and therefore affects social functioning (Peppé et al. 2007). In a study that explored receptive and expressive prosodic deficits autism Peppé and colleagues (2007) found reduced prosodic ability in 31 children with DSM-IV or ICD-10 diagnosed 'autism' (those with a diagnosis of Asperger's Disorder were excluded) who had a verbal mental age $>4$, more so in areas of receptive prosodic skills, when compared to 72 typically developing matched controls. This is in keeping with the findings from an earlier study by Shriberg and colleagues (2001), as discussed above, who found prosody deficits in those with DSM-IV diagnosed 'autism' and Asperger's Disorder were associated more with pragmatic processes rather than grammatical functions. The comprehensibility of a verbal exchange will be hampered if intonation cues are not used, or understood, to present an emotional tone (Tager-Flusberg, Paul \& Lord 2005).

Whilst the application and knowledge of language can be consumed by persons with autism in an eidetic way and learnt in a linear fashion due to being a rule-based domain of language, the application of language in meaningful communication requires gestalt processing where the person makes sense of what is being said in the 
context of judgements made about the speakers thoughts and feelings. The relative non-impairment to the application of language represented by vocabulary, pronunciation and syntax use may account for the less severely impaired expressive language abilities in comparison to receptive language abilities identified in research findings. For example, a recent UK study of 152 children who met the ADI-R and ADOS criteria for 'autism' aged between 24 and 59 months found greater impairment in receptive compared with expressive language skills using direct assessment and parent report measures (Hudry et al. 2010). Conversely an investigation of language functioning in a group of 89 children with DSM-IV diagnosed Autistic Disorder aged between 4 and 14 years suggested that verbal children with Autistic Disorder had expressive language skills comparable to their receptive language skill ability (Kjelgaard \& Tager-Flusberg 2001). From a series of standardised language tests no differences in receptive and expressive vocabulary knowledge or receptive-expressive differences in higher order knowledge of semantics and syntactic knowledge in participants was found (Kjelgaard \& Tager-Flusberg 2001). However, given the language-test nature of the study, it is acknowledged that findings may have been influenced by test related factors, such as understanding instructions and the pragmatic demands of the task.

Significant impairments in receptive language ability have been identified in both children and adults with autism. Paul (1987 p.77) described the difference in the development of expressive versus receptive language development in those with autism: "The autistic child who eventually masters the verbal system can, to some extent, be seen as developing syntactic and phonological systems that fail to 'hook up' with their semantic/pragmatic counterparts”. Persons with autism have been found to have difficulty with semantics; that is the domain of language that requires abstraction ability to recognise there may be several meanings to concepts and to process concepts in context. In a study examining language used by 40 individuals with 'autism' compared to 40 individuals without autism increased use of neologisms and idiosyncratic language, and use of words that had no semantic similarity to the intended word was found in those with autism (Volden \& Lord 1991). Such semantic errors may account for the over-literal language use characteristic of autism. However the diagnostic clarity of the study sample is poor as, whilst the authors claim participants to have met DSM-III and ICD-10 diagnostic criteria, detail relating to the 
criteria for each (i.e. Autistic Disorder, Asperger's Disorder, PDD-nos) has not been provided.

The appropriate use of language in context (pragmatics) is considered the most uniformly affected aspect of language in persons with autism (Manolitsi \& Botting 2011; Bishop 2003). Pragmatics and semantics relate to how language is used in a social context and are therefore essential for social communication. Impairment in social use of language is manifested in an inability to engage in reciprocal conversations (Cashin 2008). This inability has been associated with difficulties with conceptual perspective-taking, also refered to as 'theory of mind'. Theory of mind refers to the understanding of mental states, such as desires, beliefs, feelings and knowledge (Miller 2006). Hence, theory of mind enables the ability to understand and predict the thoughts and behaviours of others. There is an apparent association between theory of mind and language development as aspects of typical language development, such as engaging in joint attention and appreciation of intentionality within the context of communication and use of mental state words, are precursors of theory of mind (Miller 2006). These aspects of language development are known to be impaired in children with autism (Tager-Flusberg, Paul \& Lord 2005; Walenski, Tager-Flusberg \& Ullman 2006).

False belief tasks have been traditionally used to determine theory of mind ability as they require the individual to attribute a false belief in order to predict the behaviour of a misguided character (Lind \& Bowler 2009). Research has found children with autism require a higher verbal mental age to pass false belief tasks than typically developing children (Happé 1995). It is therefore postulated that semantic development, as discussed earlier, is developed at a later age through a learnt process by those with autism, may facilitate theory of mind understanding compared to aspects of typical language acquisition, such as joint attention and understanding intentionality, in children without autism (Colle, Baron-Cohen \& Hill 2007; Lind \& Bowler 2009). However, theory of mind deficits have been found in adults with autism using advanced theory of mind measures that require persons with autism to explain story characters' non-literal utterances and to infer mental states from the tone of a voice or from a picture of a person's eyes. For example, in a study by Beaumont and Newcombe (2006), when asked to make inferences about commercial characters' 
mental states, adults with DSM-IV diagnosed Asperger's Disorder and 'highfunctioning autism' ( $\mathrm{n}=20)$ answered correctly fewer questions than participants in the control group. Further, in a study using visual and auditory mental state attribution tasks, 24 adults with 'autism' (diagnosed with the Childhood Autism Rating Scale) who had IQ scores $>85$ performed statistically significantly ( $\mathrm{p}>.001)$ worse in comparison to 24 adults without autism (Kleinman, Marciano \& Ault 2001). This supports the notion that, although the development of theory of mind is correlated with language development, theory of mind remains impaired in adults with autism irrespective of whether they have enhanced language development. Theory of mind is therefore a core deficit of autism. As theory of mind facilitates social communication, in addition to pragmatic language skills, communication impairment is closely linked to impaired social functioning for persons with autism.

\subsection{Impaired social skills}

The impaired social skills of those with autism are closely linked to communication impairments as communicative interactions require comprehension of complex social themes. As identified previously, persons with autism have greater impairment of pragmatic language skills than expressive. This impairment from a social functioning perspective impacts on a person's ability to engage in conversational discourse. Effective social conversation not only involves expressive communication but requires an ability to comprehend, interpret and respond to both verbal and non-verbal behaviours of another person within a given context. Murray and colleagues (2009) examined parent and teacher perceptions of specific social behaviours using the Vanderbilt Treatment and Research Institute for Autism Spectrum Disorders (TRIAD) Social Skills Assessment in 45 children and adolescents with DSM-IV diagnosed Autistic Disorder, Asperger's Disorder or PDD-nos. Six of the participants had a diagnosis of PDD-nos and therefore had sub-threshold behaviours across the triad of impairment. A further limiting factor to this study was that data was collected from participants who were referred for social skills intervention; therefore all were known to have social impairment to the extent that warranted intervention. Despite these limitations this study highlighted social skill impairments in those with autism. Parents rated higher items pertaining to initiating interactions, whilst teachers rated higher items relating to responding and maintaining interactions. The authors 
consequently suggested that specific social behaviours may be context specific, i.e. at home children may be more comfortable to initiate interactions whilst at school the presence of peers may increase opportunity to expand on interactions (Murray et al. 2009). It is also plausible that the findings in this study are consistent with the premise that, within the school environment, teacher-initiated interactions are preferred over student-initiated interactions and there are high expectations for students to respond to teacher-initiated interaction. Interestingly both parents and teachers strongly agreed that the greatest deficit related to affective understanding and perspective taking; that is social interaction that requires theory of mind.

As identified previously, a deficit in theory of mind causes an inability to recognise both the emotions and intentions of others. Theory of mind is an essential component of social communication as "without the ability to comprehend the meaning behind what someone is saying, without the realisation that someone has different beliefs, or emotions, or feelings, or shares different backgrounds or experiences, almost every social interaction is likely to result in difficulties and misunderstandings” (Howlin 2004, p. 115). People with autism are therefore likely to have difficulties perceiving when a person is feeling sad, happy, upset or anxious for example, and are often described to lack empathy. Empathy requires an understanding of another person's feelings and an ability to predict or appreciate the emotional or social consequences of one's own actions on others (Howlin 2004). Inevitably, without such awareness the individual will lack the social skill of responding appropriately.

Adding further to social impairment caused by impaired theory of mind is weak central coherence: also characteristic of those with autism. The social impact of this cognitive processing style is failure to integrate information in context as enhanced attention to detail at a local level reduces attention to global information (O'Connor \& Kirk 2008). Difficulties processing social information will result in reduced ability or inability to interpret complex social situations (Happé 2003, O’Connor \& Kirk 2008). For example, interactions that require the individual to listen and respond appropriately to non-verbal cues and behaviour, and group-situated interactions, are likely to require the need to process complex social information. 
The correlation between theory of mind deficits and weak central coherence on aspects of social event knowledge in people with autism has been explored. Loth, Gómez and Happé (2008) used an even narratives task to explore event schemas of 21 individuals diagnosed with DSM-IV Autistic Disorder and Asperger’s Disorder. Event schemas have been described as an important cognitive tool for social understanding and entail the generalised knowledge of what happens at real-life events that commonly occur, such as dining at a restaurant (Loth, Gómez \& Happé 2008). Participants with autism who had failed theory of mind tests were profoundly impaired in describing common events in a generalised fashion, and whilst those who had passed theory of mind tests were able to describe familiar events their expectations of what happened was unusually concrete and rigid (Loth, Gómez \& Happé 2008). Weak central coherence was found to impact on the hierarchical organisation of event knowledge with weak central coherence significantly related to a tendency to represent actions and objects used in events with specific exemplars concrete in nature at the subordinate level rather than in terms of higher-order global actions (Loth, Gómez \& Happé 2008). These findings are supported by existing evidence that social event knowledge can be learnt by people with autism through targeted intervention. For example, in a systematic review of six controlled trials evaluating Social Stories ${ }^{\mathrm{TM}}$ (an intervention created by Gray (1994) that aims to provide social information relating to specific situations in terms of skills, social cues, perspectives and responses) statistically significant benefits to a range of social interaction indicators were found in five of the six trials with sample sizes ranging from six to forty-five participants (Karkhaneh et al. 2010). However, consistent with Loth, Gómez and Happé's (2008) findings, it is the variable aspects of social experiences that persons with autism will have most difficulty with. It is known that, unlike neurotypical children, children with autism have difficulty generalising newly learned behaviours to novel situations (Southall \& Gast 2011). Being rule-based learners, persons with autism can learn something in one context but have difficulty generalising and applying what they have learnt when in a different social context i.e. in a different environment, in a different place, with different people. Their lack of ability to transfer knowledge and experiences abstractly from one experience to another will impede this ability. 


\subsection{Repetitive behaviours and narrow interests}

A characteristic feature of autism is the presence of a restricted and repetitive range of interests and activities and at times stereotyped and ritualistic behaviours (APA 2000). It remains unclear if this behavioural inflexibility is a direct result of underlying cognitive and/or neurobiological deficits or an indirect functional coping mechanism as a consequence of other symptoms of autism (Cashin \& Waters 2006; Muskett et al. 2010)

In young children with autism these behaviours are predominantly represented by repetitive actions from stereotyped movements such as rocking and flapping hands to activities such as continuously lining up objects (Cashin \& Barker 2009). With age, particularly for those with higher intellectual ability these behaviours are replaced by more complex routines, rituals and repertoire of narrow interests and activities (Cashin \& Barker 2009; Howlin 2004). The restricted range of interests, often manifested in obsessions, are understood to act as a mechanism to mediate anxieties (Cashin \& Barker 2009). Interests obsessively pursued extend to collecting highly detailed information. For example information, including photos, pictures, license numbers, dates, and models, on every design model of aeroplanes or even toilets. Routines and rituals relate to day-to-day activities that are strictly adhered to and there is a subsequent dependence on these remaining the same to avoid anxiety (Dodd 2005; Royal College of Psychiatrists 2006). As suggested by Muskett et al. (2010, p. 2), "ritualistic behaviour offers a functional solution by imposing a level of predictability onto an otherwise unpredictable world".

Conversation analysis was used by Muskett and colleagues (2010) to examine the emergence of inflexibility during play in an eight-year old child with ASD. The authors suggested from their findings that the child behaved inflexibly because she found joint play unpredictable. From six 30-minute play sessions over a three week period it was found that, during early sessions, the child used particular types of turns idiosyncratically and repetitively, but in later sessions was able to engage flexibly in more imaginative and collaborative play. The authors therefore concluded that the manifestation of behavioural inflexibility represents an "active management of turnby-turn interactional concerns by a speaker with ASD and their co-conversant” 
(Muskett et al. 2010, p. 13). It should be noted that, other than using the term 'ASD', it is not documented what diagnosis the participant had, or if the participant had a coexisting intellectual disability. As the participant was recruited from a special school it is possible she had a co-existing intellectual disability, potentially affecting findings. However the findings from this study are supported by the observation that change is strongly resisted by those with autism and unpredictable or unexpected change may cause distress (Cashin \& Barker 2009; Frith 2008; Howlin 2004). This is suggestive that comfort is associated with behavioural inflexibility; therefore a person with autism who is in a situation where they are anxious becomes inflexible as a way to manage anxiety. It has been suggested that the desire for sameness by those with autism may relate to daily routines, times of activities, diet, and order of objects. Frith (2008) claimed that it is the extreme nature of obsessions and rituals that are typical of autism. However, whilst these behaviours act to reduce feelings of stress and anxiety, they have great influence over the actions and environment of a person with autism therefore further adding to social and communication impairments.

Further to the evidence of restrictive and repetitive behaviours in those with autism being a secondary deficit resulting from stress and anxiety, executive dysfunction has also been presented as a cognitive theory to explain behavioural inflexibility in those with autism (Hill 2004). Executive function relates to a range of frontal lobe cognitive functions necessary for flexible and adaptive behaviour that include planning, mental flexibility, working memory, impulse control, response inhibition and initiating and monitoring actions (Happé \& Frith 2006; Hill 2004; Lopez et al. 2005). The relationship between restricted and repetitive behaviours and multiple executive processes in those with autism has been explored. For example, in a study of 17 adults with Autistic Disorder, matched to 17 controls without autism, those with autism were found to have an executive profile of deficits in cognitive flexibility and planning, and relative strengths in working memory and response inhibition (Lopez et al. 2005). Restricted and repetitive behaviours in those with autism were found to be positively correlated with cognitive flexibility but not planning or verbal fluency (Lopez et al. 2005). However the authors recognise that valid alternate explanations for findings are possible given that correlational data was used. A positive relationship between restricted and repetitive behaviour symptoms and cognitive flexibility but not fluency was found in a recent US study of 89 children with DSM-IV diagnosed 'autism' 
( $n=34)$, Asperger's Disorder ( $n=32$ ) and PDD-nos ( $n=23$ ), with an IQ >75, through an examination of archival clinical data (Kenworthy et al. 2009). It is of note that, despite not being a diagnostic term, the authors specify participants met DSM-IV criteria for 'autism'. Therefore findings should be considered in light of poor diagnostic clarity of participants.

Research concerning this aspect of the triad of impairment remains unclear. Whilst restricted and repetitive patterns of behaviour are considered a core impairment, research has indicated this behaviour may be secondary to cognitive deficits in theory of mind and weak central coherence. It is also plausible that restricted and repetitive patterns of behaviour are a coping mechanism for managing social and communication impairments. What is known is that the presentation of restricted and repetitive behaviours, as with communication and social impairments, is greatly varied in clinical presentation and in how it is experienced by persons with autism. Factors such as co-existing intellectual disabilities further impact on the level of impairment experienced. Therefore the nature and extent of impairments are known to vary considerably between individuals with autism (Cashin 2005; Loth, Gómez \& Happé 2008). Variation also occurs in individual experience of impairments at any given time, dependent on external or contextual pressures (Cashin 2005; Cashin 2008).

\subsection{Autism and anxiety}

Anxiety in individuals with autism is known to be a common occurrence. A number of studies internationally have explored the prevalence of anxiety disorders in children and adults with autism. Prevalence rates of anxiety in these studies range from $13.6 \%$ to $42 \%$. However, wide variation in study samples and methods employed make comparison of these studies difficult. For example, in a Canadian study the prevalence of 'generalised anxiety' was found to be significantly greater ( $\mathrm{p}>0.001$ ) in children with autism than the general population (Kim et al. 2000). The parents of 40 children diagnosed with ‘autism' and 19 children diagnosed with 'Asperger syndrome' aged 9 to 14 years completed the Ontario Child Health Study Revised questionnaire. Diagnoses were made using ADI data and confirmed by meeting DSM-IV criteria for Pervasive Developmental Disorder and ICD-10 criteria 
for 'autism' or 'Asperger syndrome'. It is of note however that 'autism' is not a diagnostic entity listed in the ICD-10; therefore findings should be considered in light of poor diagnostic clarity of participants. Despite the inaccuracy of using IQ testing with individuals with autism due to the test's dependency on language, in this study participants with a diagnosis of 'autism' were required to have an IQ >70, aimed at ensuring the sample contained children who were 'non-retarded' only. The findings were compared to the findings from the authors' previous study in which the questionnaire had been standardised on a randomised sample of 1,751 children in the general population. Almost fourteen percent (13.6\%) of the sample scored at least two standard deviations above the normal population mean, reflecting a significant difference ( $\mathrm{p}>0.001)$. No difference was found between children with 'autism’ and children with 'Asperger syndrome'. This supports the idea that language development may not play a role in the prevalence of anxiety in children with autism as in this study the only difference between the groups was based on language acquisition. A Finnish study with a similar sample of 50 individuals aged 6 to 16 years with a DSMIV defined diagnosis of 'autism' or Asperger Disorder and an IQ score $>75$ found $42 \%$ of the sample had comorbid anxiety disorders based on parental interview (Mattila et al. 2010). It is of note that the authors specify participants met DSM-IV criteria for 'autism' despite this not being a diagnostic term listed in this diagnostic manual.

In Singapore a review of an autism clinic’s medical records of 71 children aged between 6 to 18 years, Ooi and colleagues (2011) found 33.8\% had 'anxiety problems' using 'DSM-orientated scales of clinical concerns'. However the diagnostic clarity of this study sample is poor as the authors claim that participants have a clinician made diagnosis of 'high functioning autism spectrum disorder' using ICD-9 and DSM-IV criteria despite neither diagnostic manual listing such as a diagnosis. A similar prevalence was found in a Norwegian study examining the prevalence of DSM-IV disorders in 71 children and adolescents aged 6 to 17 years registered at a special school for children with 'autism spectrum disorders' (Gjevik et al. 2011). This study found $31 \%(n=22)$ of the sample met the criteria for anxiety disorder based on parental interview. The authors suggest a higher rate of anxiety disorders, in particular Generalised Anxiety Disorder and Separation Anxiety, may have been found if the study sample was not predominantly of a low cognitive level (Gjevik et al. 2011). The 
results of this study are therefore limited by the inclusion of participants with a coexisting intellectual disability, and further by the inclusion of individuals $(n=12)$ with sub-threshold behaviours across the triad of impairment (i.e. those with a diagnosis of PPD-nos).

The levels of anxiety experienced by adults with autism have also been compared to a control group of individuals with intellectual disability without autism, matched by age, gender and intellectual ability. In the UK Gillott and Standen (2007) examined the levels of anxiety and sources of stress in 34 adults with autism and compared these to a control group of 20 individuals with intellectual disability without autism. Those in the autism group had significantly $(\mathrm{p}<0.001)$ higher overall anxiety when measured using the Children's Anxiety Scale-parent with modified language to suit adults. Sources of stress, measured using the Stress Survey Schedule, that significantly correlated with anxiety for those with autism were change $(\mathrm{p}<0.01)$, anticipation $(\mathrm{p}<0.05)$, unpleasant events $(\mathrm{p}<0.01)$, and sensory/personal contact $(\mathrm{p}<0.01)$. This positive correlation with precipitants of stress and anxiety support the notion that, the more anxious an individual with autism is, the less likely they will be able to cope with stress such as a change in their routine for example. Both the anxiety and stress questionnaires were completed by the participants' informant. Whilst the Stress Survey Schedule is a validated instrument for measuring stress in people with autism, the Children's Anxiety Scale-parent used in this study had been validated for use in children only. The findings of this study should also be considered in light of its small sample size.

The anxiety levels of individuals with autism are likely to fluctuate depending on their environment. It has been suggested that people with autism, who are known to be at increased risk of having a co-morbid anxiety disorder, are more likely to be hypersensitive to auditory, visual and tactile information and stimuli in their environment such as loud noises, visual complexity or unexpected touch (Liss et al. 2006; Green \& Ben-Sasson 2010). A US study exploring the relationship between dysfunction in sensory modulation and symptoms of affective disorders found a significant positive correlation $(\mathrm{p}=.000)$ between sensory hypersensitivity and anxiety in a sample of 50 children aged 6 to 17 years diagnosed with Asperger's Disorder (Pfeiffer et al. 2005). The findings of this study were based on parent-report measures 
and should be viewed in light of the sample being conveniently recruited mostly from private occupational therapy clinics where the incidence of adaptive behaviour impairment, specifically social skills deficit, is likely to be overrepresented.

It has been suggested that over-arousal associated with hypersensitivity may lead to repetitive and ritualistic behaviours in an individual with autism as he/she attempt to compensate by engaging in predictable and repetitive events (Liss et al. 2006). This was described in a qualitative study of six persons with autism aged 19 to 52 years on restricted interests (Mercier, Mottron \& Belleville 2000). In this study participants, who met the DSM-IV criteria for 'autism' (despite this not being a DSM-IV diagnostic term) or Asperger's Disorder, spoke of the positive aspects of their repetitive interests which included a calming, relaxing and restful effect as they engaged in, what was to them, something predictable (Mercier, Mottron \& Belleville 2000). It is therefore plausible that repetitive behaviours can enable relief of anxiety in environments that the person with autism may find overwhelming. Over-arousal of sensory stimuli has also been suggested to relate specifically to social anxiety in persons with autism as the social context is changeable and unpredictable in nature (Liss et al. 2006). Impairment in social skills and theory of mind ability are also likely to predispose individuals with autism to experience anxiety provoking social interactions that are unpredictable and overwhelming (Spiker et al. 2012). Other possible etiological associations between anxiety and individuals with autism include structural and neurochemical disturbances, and genetics as possible predisposing factors, although further research is required in this area (White et al. 2009).

\subsection{Autism and offending behaviour}

As discussed previously, people with autism have a number of cognitive and social impairments that result in misinterpretation of social cues, social naivety, circumscribed interests, difficulty with perspective-taking, and an innate lack of awareness relating to the consequences of one's actions. Literature has suggested that these characteristic features of autism may predispose an individual to engage in offending behaviour. This has largely been presented in case reports and small-scale case-control studies. 
A case-control study by Woodbury-Smith and colleagues (2010) investigated the circumscribed interests of 21 intellectually able offenders with 'autism' (ICD-10 diagnosed) compared with 23 non-offending individuals with autism. Through semistructured interviews and review of health care records, the authors determined the relationship between the participants' 'index offence' (the offence committed that led to the current incarceration) and his or her circumscribed interest. A level of relation (whether related to the content or the pursuit of the interest) between index offence and circumscribed interest was found for $29 \%(n=6)$ of participants. The content of interests were rated as violent (involving harm or the threat of harm to others) for four (19\%) of the 21 in the offender group, although only one of these participants' interests related to their index offence (fire-setting). No circumscribed interests in the non-offending group were rated as violent (Woodbury-Smith et al. 2010).

Violence-related offences were identified as the most common type of offending in a UK study of 16 individuals with Asperger's Disorder who had a history of engaging in offending behaviour (Allen et al. 2008). A review of case files identified documented records of "violent conduct" in 81\% ( $\mathrm{n}=13)$ of cases (Allen et al. 2008, p. 752). However the defining characteristics of what was considered to constitute 'violent' were not provided by the authors and this offence type was synonymously referred to as 'violence behaviour' in the text. Other arguably violence-related offences included "threatening behaviour" ( $n=12,75 \%)$, "sexual offending” ( $n=3$, 19\%) and "murder" ( $\mathrm{n}=1,6 \%)$ (Allen et al. 2008, p. 752). Whilst all participants had documented offending behaviours as the sample was purposely selected, it is of interest to note that only nine participants $(n=44 \%)$ had had their offending behaviour addressed via the criminal justice system. Five of these participants had received prison sentences, three had received “community orders” and one participant had received a "hospital disposal" (Allen et al. 2008, p. 752). Therefore four of the participants were diverted away from prison by being ordered to serve their sentence in the community (community order) or by being ordered to a psychiatric facility under a mental health act (hospital disposal).

A UK case-control exploratory study attempted to examine the association between the cognitive impairments of those with autism and their vulnerability to offending (Woodbury-Smith et al. 2005). Twenty-one adults with 'ASDs' (based on ICD-10 
diagnostic criteria) and a history of offending was compared to 23 adults with ASD who did not have a history of offending and 23 adults from the general population. Offences included manslaughter $(\mathrm{n}=1)$, attempted murder $(\mathrm{n}=1)$, arson $(\mathrm{n}=5)$, indecent assault ( $n=3)$, assault $(n=3)$, threats to kill $(n=5)$ and harassment $(n=1)$. Whilst it is stated that all in the ASD group met the criteria for an ASD according to the International Classification of Diseases (ICD-10), this diagnostic manual does not use the term ASD, nor are specific diagnoses of participants detailed by the authors. Using validated measures, although the findings need to be considered in light of the small size and limitations related to diagnoses, there was no significant difference found in theory of mind or executive function, contrary to authors' expectations. Those with ASD and offending behaviour were significantly more impaired in the recognition of facial expressions of fear in comparison to the non-offending ASD group and the general population group (Woodbury-Smith et al. 2005). In support of this, Schwartz-Watts (2005) presented a case of a 20 year old male with Asperger's Disorder who shot and murdered his girlfriend's father in what he perceived to be his defence after inappropriate recognition of the father's facial expression and nonverbal cues. Other murder-related cases $(n=2)$ of individuals with Asperger's Disorder presented by this author were claimed to be the consequence of tactile defensiveness relating to oversensitivity to touch, combined with a preoccupation with weapons (Schwartz-Watts 2005). None of the three cases had been diagnosed with Asperger's Disorder prior to the offence.

Barry-Walsh \& Mullen (2004) presented five cases of individuals whose offending behaviour was claimed to be attributable to their Asperger's Disorder. Two of the individuals had a preoccupation with lighting fires and, whilst arson was the offence of one of these, the other was charged with assault after hitting his father when he was confronted for lighting a fire in his garden. An individual in the third case also had a charge of arson, however he had ritualistic behaviour of listening to a particular radio station and burnt another radio station down when it began to interfere with the station he listened to. An individual in the fourth case had offending behaviour that related to the stalking and harassment of his healthcare professionals and was described as being obsessional towards certain people. The individual presented in the final case was described as having a preoccupation with sexual themes and after inappropriately advancing on young girls had received a number of sex-offence related convictions. A 
poor understanding of appropriate social boundaries was also highlighted as a contributing factor to offending behaviour in the latter two cases. All individuals were unable to perceive the legal consequences of their actions and, although all were subjected to the court system, all convictions were received without imprisonment (Barry-Walsh \& Mullen 2004). The findings from these case studies should be considered in light of diagnostic uncertainty. Only two individuals presenting in the five cases had received a formal diagnosis of Asperger's Disorder (one recently, and the other two years previously). The remaining individuals did not have a formal diagnosis but were described as having a history that was strongly suggestive of Asperger's Disorder (Barry-Walsh \& Mullen 2004).

Impairment in social awareness and reciprocal interaction has been suggested to lead to sexual related offences in those with autism. Kohn and colleagues (1998) described how a 16-year old male diagnosed with Asperger's Disorder in Israel had a history of sexual assault offences since aged 14 years that were the result of his impairment of social relatedness. In the case of this individual the assaults occurred when he attempted to express his fondness towards a girl by attempting to undress her or touch her genitalia. Social naivety combined with sexual frustration and preoccupation with sex and sexual-related fantasies were highlighted as contributing factors to sex-related offences in the cases of four males diagnosed with Asperger's Disorder (Murrie et al. 2002). Similarly Realmuto and Ruble (1999) presented the case of a young adult male, diagnosed with autism (method of diagnosis not provided by the authors), who had repeated offences of public masturbation and who also became sexually aroused by young children. Deficiencies in empathy were also described in the cases where the offenders were unaware of the harm their actions caused to the victims. However arguably this presentation may be related to errors in social judgement where the individuals were unable to perceive the social inappropriateness of their actions.

Offending behaviour in those with autism has also been considered unintentional when the offence may be an act of externalised misplaced blame (Murphy 2003) or be associated with dysfunctional coping strategies (Murphy 2010a). For example, Everall and LeCouter (1990) presented the case of a 17 year old male diagnosed with Asperger's Disorder who began fire setting in response to the uncertainty of his future placement as school ended. Murphy (2010b) also presented the case of a man with an 
'ASD' (details concerning diagnosis are not provided by the author) who murdered his work supervisor following a series of anxiety provoking events. Mawson, Grounds and Tantam (1985) presented that case of a 44 year old male with Asperger's Disorder who used violence to stop sounds he found distressing such as a baby crying and dog barking. The unusual behaviour and impulsivity of a person with autism may additionally be misconstrued as risky, threatening or potentially dangerous, with consequences that lead to a criminal conviction (Royal College of Psychiatrists 2006).

From a different perspective, autism has been described as a condition where the characteristic tendency of honesty and desire to abide by rules inclines such persons to be law abiding individuals (Howlin 2004). It has further been argued that offences committed by persons with autism are unlikely to be intentional, as to break the law requires deception and understanding of complex sequence of events, “deception involves understanding not only one's own actions but the impact of what is done or said on other people's behaviour" (Howlin 2004 p. 114). However there is no research to support or dispute these postulations.

Research to date exploring the association between autism and offending behaviour is limited to single case reports and case series, or small scale exploratory studies. These studies vary in diagnostic concepts used; a limiting factor that affects a review of any autism-related research. The findings from these studies suggesting that some behaviours characteristic to autism may pre-dispose an individual to participation in criminal acts. However, as these provide the accounts of just a few individuals, the findings are not representative of the population of individuals who have autism (Cashin \& Newman 2009). The findings of the studies are further implicated by the potential for other non-autism specific related factors mediating offending in individuals with autism. These factors include co-morbid mental disorder, substance misuse, poor educational achievement or social exclusion (Dein \& Woodbury-Smith 2010; Ghaziuddin 2005; Gómez de la Cuesta 2010; Långström et al. 2009; Newman \& Ghaziuddin 2008). For example, from a search of case reports related to Asperger's Disorder and violent crime, Newman and Ghaziuddin (2008) found that of the 35 cases presented in 17 publications, 11 cases (29.7\%) had a definite co-morbid psychiatric disorder and 20 (54\%) had probable co-morbid psychiatric disorder. In 
light of all these factors, the certainty of there being a positive correlation between the characteristics of autism and offending is currently unsupported by the literature.

\subsection{Prevalence of autism in offender populations}

A number of studies whose participants consisted of forensic psychiatric patients (offenders who have undergone legal processes, through which they have been deemed to have a mental disorder requiring treatment, with the majority having committed violent offences) have suggested a substantially higher prevalence rate of autism in comparison to the general population. Scragg and Shah (1994) examined the case notes of the entire patient population of a UK prison hospital $(n=392)$ and found six patients (1.5\%) met the diagnostic criteria for Asperger's Disorder and a further three patients $(0.8 \%)$ had evidence of autistic-like behaviours but did not meet all the diagnostic criteria for Asperger's Disorder. These cases combined equate to a prevalence rate of $2.3 \%$. A higher rate would most likely have been found if patients who had an intellectual disability had not been excluded from the study, given that it is known that autism may co-exist with intellectual disability (Cashin et al. 2012).

A less systematic study encompassing the patient population of three UK secure psychiatric hospitals (including Broadmoor Hospital studied by Scragg and Shah a few years previously) estimated a comparable prevalence rate. Hare and colleagues (1999) screened 1305 patients (96\% of the total patient population) for impairments in social and interpersonal functioning. Of the 240 patients who yielded a high score on the initial screening, 215 had their hospital records examined to determine if they had an 'autistic condition'. In total 31 definite cases of ‘autistic conditions' were identified, representing a prevalence of $2.4 \%$. Twenty-one of these met the criteria for Asperger's Disorder, the remaining ten were labelled by the authors as 'Autistic' and defined by IQ ( $\mathrm{n}=6$ had IQ below 50). A further 31 individuals were considered equivocal cases where there was insufficient information available for clear diagnosis or diagnostic criteria was partially met. These cases combined equate to a prevalence rate of $4.7 \%$. In consideration of this prevalence it must be noted that 57 individuals (4\%) were not included in the initial screening process (due to patient leave and those who were missed due to 'administration reasons') and a further 25 individuals (1.9\%) 
who were identified for further investigation from the screening process were excluded from the study (due to being unable to identify patient from questionnaire, patient discharge and patient death). Therefore the number of cases found with definite and possible autism may have been higher, and consequently the prevalence implicated by this study can be considered an estimate only.

In Sweden, a retrospective study reviewed the pre-sentence psychiatric assessment notes of 126 mentally disordered young offenders, aged between 15 and 22 years, who had been referred for pre-sentencing forensic psychiatric investigation after committing a serious offence (Siponmaa et al. 2001). Only four cases (3\%) were considered to have a definite diagnosis of Asperger's Disorder, and no cases had Autistic Disorder. Further cases were identified as having probable Asperger's Disorder. However, as a lack of available information in the case notes rendered a definite diagnosis impossible, these individuals were included in the $12 \%$ of the sample $(\mathrm{n}=15)$ considered to have PDD-nos.

It is of note that the findings from these studies are limited by their examination of the prevalence of autism in forensic psychiatric populations only. Therefore, although these findings suggest a raised prevalence rate in this population, the findings can not be generalised to reflect the prevalence of autism in all offender populations. The prevalence of autism in the general prison population (incarcerated individuals who are not forensic psychiatric patients) is unknown and autism related prevalence-based research in this population is yet to be conducted. The lack of research in this area is partly due to the difficulties associated with attempting to use existing diagnostic instruments for autism that are complex and lengthy in a population that is not only large, but subject to rapid turnover, as prisoners are released or moved to different prisons (Robinson et al. 2012). A recent attempt to design an autism screening tool for use by prison officers failed due to poor sensitivity and intra-rater reliability (Robinson et al. 2012).

Although not examining autism, the New South Wales (NSW) Prisoner Health Survey conducted in 2009 (Indig et al. 2010) found five of the 996 participants self-identified as having 'autism’ or Asperger's Disorder when asked if they had any mental health condition (D. Indig 2010, pers comm., 11 May). Based on this data it is reasonable to 
make a conservative estimate of a detained population of 50 individuals in the NSW prison system. This equates to a prevalence estimate of $0.5 \%$ of offenders imprisoned in NSW with autism, based on an estimate of just over ten-thousand individuals imprisoned in NSW (CSNSW 2011). It is reasonable to postulate that a higher prevalence of autism, closer to that found in the studies of forensic populations, would have been found if the Prisoner Health Survey had included the collection of data related to autism. As a result this prevalence estimate, as the only available data in NSW, is comparable to that of the general population in Australia. A higher than community prevalence rate is also likely when consideration is given to the knowledge that many health conditions are over represented in the prison population. For example in comparing the published Prisoner Health Survey data (Indig et al. 2010) to the National Health Survey data (ABS 2009) overrepresented conditions include asthma ( $29 \%$ vs. $10 \%$ ), hypertension (16\% vs. $9 \%$ ), epilepsy (5\% vs. $0.7 \%$ ), back problems (27\% vs. 14\%) and mental health or behavioural problems (49\% vs. $11 \%)$. Further a recent UK study found the prevalence of autism to be correlated with low IQ (Brugha et al. 2012). The authors tentatively suggested that the prevalence of autism in the general prison population may therefore be as high as $40 \%$ given that a previous study found the majority of UK prisoners had low or average IQ (Brugha et al. 2012).

The exact number of incarcerated individuals with autism is likely to be unattainable due to the probable high rate of undiagnosed, even more likely misdiagnosed, persons (Cashin \& Newman 2009; Gómez de la Cuesta 2010). Prisoners are known to be a population with characteristics that may predispose those with autism not to have received a formal diagnosis. For example, diagnosis of autism during childhood often requires a committed family to pursue a diagnosis, being in the same location long enough for a diagnosis to be made, and being in the same schools long enough for teachers to suspect the need for a diagnosis. Data revealed in the Prisoner Health Survey supporting a tendency for prisoners with autism to be a group subject to high rates of being undiagnosed/misdiagnosed include: $18 \%$ of prisoners had at least one parent imprisoned during their childhood, $13 \%$ of prisoners had been placed in more than two care placements before aged 16 years, 69\% of prisoners reported attending three or more schools and 51\% reported leaving school prior to completing year 10 (Indig et al. 2010). Available evidence, despite being limited, supports the notion that 
persons with autism are represented in the NSW custodial system. It is therefore reasonable to question how these persons experience incarceration and whether it differs to how prison is experienced by persons without autism.

\subsection{What is known about the experience of incarceration}

As early as the 1960s America began producing prison drama films that depict prisonbased experiences that as classics are well known in today’s society. In the 1967 film 'Cool Hand Luke' prison is portrayed as an environment dominated by a prisoner hierarchy based on power and respect, beatings from prison wardens and the use of solitary confinement as punishment (Cool Hand Luke 1967). A later film, The Shawshank Redemption is a 1994 American film that tells the story of one man's twodecade long experience of incarceration during the 1940s through to the 1960s. In this film the prison experience is characterised by gang violence, sexual assault and corrupt prison guards, where the acquisition of contraband, the use of solitary confinement for punishment and a working life within the prison walls featured predominantly (The Shawshank Redemption 1994). Although the story is told over a 20-year period the prison culture that encompassed these features did not change and the story ended with an extravagant escape plot.

In the Australian film 'Chopper', released in 2000, prison experiences in a Melbourne based maximum security prison are characterised by gang violence and prisoner power struggles, where committing murder and violent assaults on other prisoners are means to gain status within the prisoner hierarchy (Chopper 2000). Unlike the fictional American prison dramas described previously this film was based on the semi-autobiographical books by Mark Read (also known as 'Chopper'), and are claimed to be based on his experiences during a 16 year prison sentence commencing in the 1960 s.

The dramatisation of Australian prison life has also been created in the form of the television soap opera 'prisoner' that originally aired in Australia between 1979 and 1986 (Prisoner 1979-1986). The story lines of this hugely successful series centred on a female maximum security prison wing and portrayed prison life around volatile prisoner relationships, violence and corrupt prison officers. Bullying, sexual 
harassment, racism, power-related conflicts and friendships amongst prisoners were featured throughout the series, whilst violent storylines involved beatings, murder, suicides, use of improvised weapons and riots. Other aspects of prison experiences such as institutionalisation, access to contraband, drug use, and body searches were also featured. Whilst this portrayal of the incarceration experience is very similar to those provided in films, what is known about the prison experience through research is limited.

Conducting prison based research is often not desirable for researchers due to the extensive time requirements in comparison to non-prison based research, and the range of challenges associated with such research. For example, logistical challenges include accessing participants who are confined and restricted by security measures, and enabling the use of audio-recording equipment (Quina et al. 2007). Further prison based researchers are faced with specific ethical considerations including the increased vulnerabilities of the prisoner population, especially vulnerability to coercion, the restriction on use of research incentives, and prison specific confidentiality and disclosure related issues (Brewer-Smyth 2008; Paternelj-Taylor 2005; Quina et al. 2007). Despite the challenges associated with conducting research with prisoners there are a number of studies internationally that have examined the effects of incarceration, and aspects of the incarceration experience.

\subsubsection{Prison and the general experience of incarceration}

Donald Clemmer (1958), a clinical psychologist, was one of the first to study the experiences of prisoners in the 1930s. At the US based penitentiary at which he worked as a clinical psychologist, Clemmer engaged in a three-year study of 2,300 prisoners publishing his findings in the first edition of his book 'The Prison Community' in 1940. Clemmer combined his experiences obtained from his working role with observations and findings from prisoner interviews, to explore the social processes of prison life. He introduced the notion of the presence of a prisoner subculture characterised by a hierarchical-based social order consisting of three classes of prisoners: the élite class (the intelligent, dignified and sophisticated offenders), the middle class (neither outstanding in character nor as a criminal), and the “hoosier” class (the sex offenders, the 'dull' and 'feeble-minded' and those who 
lacked physical courage) (Clemmer 1958, pp. 107-108). Clemmer theorised the prisoner subculture to be underpinned by a distinct set of values (the 'prisoner code') that fundamentally represented "the value of loyalty among prisoners", that was not only characterised in their dealings with each other, but also with officials by not informing on another prisoner (Clemmer 1958, p. 152). Clemmer coined the term 'prisonization' to refer to how prisoners become assimilated to prison life by adopting the prisoner subculture: "the term prisonization to indicate the taking on in greater or lesser degree the folkways, mores, customs and general culture of the penitentiary" (Clemmer 1958, p. 299).

Clemmer's work was expanded on by Sykes (1958), a sociologist, who used a variety of data collection methods, including observations and interviews with prisoners and prison guards, to examine the prisoner social system of a maximum security prison in the US. It was from this study that Sykes introduced the concept of 'the pains of imprisonment' to reflect the meaning of imprisonment for the study participants (Sykes 1958, p. 63). The pains of imprisonment related to the deprivations (of liberty, of goods and services, of heterosexual relationships, of autonomy, of security of safeness) and frustrations (of sexual desire) associated with prison life. Sykes’ later work is well known for theorising the deprivation model where, in order to cope with the negative social and physical experiences of incarceration, prisoners engage in an adaptive process accounting for the formation of the prisoner subculture (Sykes \& Messinger 1960).

The prisoner subculture, characterised by hierarchies of domination and codes of conduct, described throughout prison sociology has also been explained using theories of masculinities (Newton 1994). Although the prisoner subculture in female prisons has not been subject to the level of research that male prison subculture has received, the female prisoner subculture is known to be characterised by a social structure centred on the existence of fictive families (Foster 1975; Jiang \& Winfree 2006; Watterson 1996), as opposed to dominance and power characterising the male prisoner culture. Theories of masculunities suggest that the male prisoners' masculinity is centred in the deprivations of imprisonment as "loss of autonomy and independence, enforced submission to authority, lack of access to material goods, all of which are central to his status as a 'man'” (Newton 1994, p. 197). Therefore, in 
order to achieve superordinate status and counteract the disrespect felt from the prison system, prisoners resort to hypermasculity, in the form of wanton violence and aggression, homophobia, rape, and victimisation (Kupers 2005; Newton 1994). In an US study of 239 male prisoners examining the predictors of prisonization a strong positive relationship between holding an approving attitude toward violence and a prisoner's tendency to adopt the prisoner code was found (Paterline \& Petersen 1999).

The impact of the prisoner subculture was highlighted in an ethnographic study conducted in an English adult prison that explored prisoners' perceptions of adapting to the social environment of prison (de Viggiani 2006). This study employed participant observation and one-to-one interview methods to explore experiences of imprisonment. The atmosphere of the social environment was described as being tense in nature. High levels of suspicion and paranoia amongst prisoners was worsened by the transient nature of the prison population and stress experienced associated with living in close proximity to other prisoners. Prisoner to prisoner relationships were described as superficial with prisoners employing tactics such as projecting a false façade to appear confident and macho, and engaging in 'prison talk' characterised by offensive humour, sexist and homophobic banter, and masculine topics, for becoming socially accepted (de Viggiani 2006). Therefore prisoners aligned themselves the social values of the prison, as described by Sykes and Messinger (1960), as a way of coping with social demands. Prisoners in this study also perceived that failure to appear macho and aggressive signalled weakness to other prisoners rendering them vulnerable to abuse, and gaining respect of other prisoners meant avoiding becoming a target for bullies. Vulnerable prisoners experienced verbal and physical abuse, and exploitation (de Viggiani 2006).

Literature suggests violence in prisons is widespread. Violence, in addition to predation and exploitation, has been suggested to be associated with limited resources where the gaol is attainment of material goods such as food or cigarettes (Ireland 2000). Underlying these practices and behaviours is a prisoner subculture that is hierarchical in nature. As highlighted in de Viggiani’s (2006) ethnographic study, traits such as dominance and aggression are valued and those who are fearful or vulnerable are considered inferior (Ireland 2000). The hierarchy is also influenced by a prisoner value system where sex and/or child abuse related offenders are considered 
inferior to offenders who committed crimes such as murder (Love \& Morrison 2002). In a case study of a US maximum security penitentiary, prisoner status was found to be largely dependent the individuals' adherence to the prisoner code of conduct, type of offence, pre-prison status and gang affiliation (Faulkner \& Faulkner 1997). This ranking system, in addition to the presence of a prisoner social system where those who are gang members or have influential peers are ranked highly, has been argued to be inevitably conducive of an environment where bullying and victimisation is endemic (Ireland 2000; South \& Wood 2006). This is supported by a study that found bullying was positively related to the perceived importance of social status ( $\mathrm{p}<$ 0.001) in a study of 132 adult male prisoners across six UK prisons (South \& Wood 2006).

The experience of bullying and victimisation by prisoners has been well documented in the literature. Aspects within these experiences vary widely from indirect ostracizing, gossiping or theft, to verbal, physical and sexual abuse (Banbury 2004; Connell \& Farrington 1996; Edgar 2005; Ireland 2000; Ireland \& Archer 1996; Nagi, Browne \& Blake 2006; O’Donnell \& Edgar 1998; Power, Dyson \& Wozniak 1997; de Viggiani 2006; Wolff \& Shi 2009). Research concerning the prevalence of bullying and victimisation in prisons has found varying results. For example, Nagi, Browne and Blake (2006) carried out a descriptive analysis of questionnaires completed by 51 adult male prisoners in the UK that aimed to explore the nature and extent of bullying. Results indicated that $51 \%$ of participants reported having experienced victimisation and $76 \%$ reported witnessing bullying in prison. In a larger study involving 707 young offenders in Scotland, 29\% of participants reported having experienced bullying whilst in prison (Power, Dyson \& Wozniak 1997). Of 138 male and female adult offenders in the UK, $46 \%$ reported witnessing bullying in prison but only $4 \%$ admitted to being victims of bullying (Ireland \& Archer 1996). A high rate of bullying was found in a Canadian study of young offenders, aged 16-18 years, with a quarter of participants indicating they were a victim of bullying (Connell \& Farrington 1996). However these findings are based on a small sample size $(n=20)$ and the average length of incarceration was less three months. Whilst this research is predominantly UK based, an Australian study examining the experiences of 16 young offenders also found bullying to be a major theme where victimisation of the vulnerable was commonly reported (Ashkar \& Kenny 2008). 
Less extreme forms of violence were reported in a study exploring the nature of routine victimisation experienced by 1182 participants incarcerated in two male prisons and two male young offender institutions in the UK (O’Donnell \& Edgar 1998). For young offenders ( $n=588)$ most commonly reported forms of routine victimisation was verbal abuse and threats of violence (reported by $56 \%$ and $44 \%$ of young offenders respectively), whilst for adults $(n=594)$ it was cell theft (reported by $34 \%$ of adults). Other forms of victimisation reported by both adults and young offenders were assault, robbery and exclusion. The reported victimisation rates, were much higher in general for young offenders than adults (O’Donnell \& Edgar 1998). In qualitative interviews with 92 participants the motivations for victimisation were reported as: to manage conflict, to gain status, for retaliation, to relieve boredom, for material gain or in response to the nature of the victim's offence (O'Donnell \& Edgar 1998). Similarly, in a US study of 111 incarcerated young offenders aged 17 to 25 years, the most frequent form of victimisation experienced in prison was verbal harassment/name calling followed by stolen property as reported by $58.6 \%$ and $48.6 \%$ of participants respectively (Maitland \& Sluder 1998). Definitional differences or the absence of definitions of bullying and victimisation in these studies make comparison difficult. Furthermore, as highlighted by Ireland (2000) such studies may underrepresent bullying and victimisation due to the potential that participants underreported incidences as a consequence of terms such as ‘bullying’ holding negative connotations.

The experience of victimisation by female prisoners has also been explored. In a comparative study of 6,964 male prisoners and 564 female prisoners in the US, female prisoners reported higher incidences of physical victimisation (actual or threat of physical assault and theft) than their male counterparts with 52\% versus 33\% respectively reporting having experienced physical victimisation from another prisoner in the previous six months (Wolff \& Shi 2009). Male prisoners were more likely to report having been victimised by a staff member $(37 \% n=2,572)$ than by another prisoner, whilst female prisoners reported statistically significantly less incidents of victimisation from staff $(13 \%, n=74)$. Similarly in a smaller UK study of male $(n=90)$ and female $(n=48)$ prisoners, significantly higher $(\mathrm{p}<0.001)$ rates of bullying was reported by women compared to men (Ireland \& Archer 1996). The 
higher rates of reported incidents of victimisation by female prisoners compared to male may be associated with male prisoners being less likely to report incidents of victimisation by fellow prisoners due to a prisoner subculture centred on status as being a victim is associated with weakness.

The experience of sexual-related violence in prisons has also been reported. Banbury (2004) employed a multi-method approach to analyse the experiences of coercive sexual behaviour experienced by participants whilst they were incarcerated in UK prisons. A total of 408 ex-prisoners ( $n=333$ male, $n=75$ female) participated completing surveys and/or qualitative interviews. Two-hundred and eleven participants (51.7\%) reported having been victims of coercive sexual behaviour (rape and sexual assaults, forced drug search not conducted in line with prison rules, nonconsensual sexual activity, and sexual exploitation including blackmail and sex in exchange for goods) during their incarceration (Banbury 2004). However high incidents of experiencing sexual coercion in this sample can be expected given that just under half of the sample $(n=200)$ were participating as self-referred victims (i.e. motivated by being a victim of sexual coercion they choose to participate in the study). Only eleven (5\%) participants who had no prior knowledge of the research, and therefore arguably more representative of the general prison population, had been sexually coerced. Whether incidents of coercive sexual behaviour were reported more frequently by males versus female participants was not reported on by the authors. It has been suggested that sexual-related violence in prisons is motivated by power and masculinity, as an intended form of domination and exploitation of the weak and vulnerable (Newton 1994).

In addition to the social experiences of incarceration associated with a prisoner culture conducive of violence and aggression, are experiences associated with the physical environment of prison. From his experience as a researcher of Australian prisoners Korn (1994, p. 112) described this environment: "Prisoners live in a world of locks. The drab walls, squeaky clean linoleum floors and solid metal doors are cold, stark and instantly unwelcoming”. The physical environment of prison is dominated by architecture designed to confine, seclude, segregate and enable total surveillance of those inside its secure perimeters (Doyle 2003). Limited privacy resulting from these factors has been highlighted by prisoners describing their experiences (Ashkar \& 
Kenny 2008). Constant surveillance by officers was perceived by the prisoners in de Viggiani’s (2007) ethnographic study to reduce personal autonomy, privacy and dignity. Living conditions for prisoners has long been recognised to have negative implications on the prison experience. The pains of imprisonment detailed by Sykes (1958), for example, focus on the deprivations suffered by prisoners as the result of forced confinement. In a UK study that aimed to compare the experiences of imprisonment for first-time $(n=102)$ and recurrent prisoners $(n=165)$ from two medium-security prisons, being away from family and loss of freedom/confinement/no privacy/crowded were perceived as the worst things about being in prison by $36 \%(n=96)$ and $28 \%(n=75)$ of participants respectively (Souza \& Dhami 2010).

Using the deprivation and overcrowding theories, Huey and Mcnulty (2005) examined the effects of prison characteristics on incidence of suicide using National Prison Census data. Deprivation related to medium and maximum security facilities (i.e. reduced autonomy, social isolation) was associated with higher incidents of suicide in comparison to low security facilities where prisoners are less affected by deprivation. However, overcrowded low security facilities had equivocal suicide rates compared to medium and maximum security facilities (Huey \& Mcnulty 2005). Earlier studies examining the effects of overcrowding in US prisons have also found a positive correlation between overcrowding and increased incidents of violence (Gaes \& McGuire 1985). However, other potential causes for violence were not factored for in this study.

Restrictions associated with the regimentation and regulations imposed by prison life have been described by prisoners to induce a sense of loss through reduced autonomy. For example, in a qualitative longitudinal study of three males aged 18 to 20 years detained in juvenile detention centres in Germany, one participant described how he had succumbed to pressure in prison caused by restrictions and limitations to his autonomy (Bereswell 2004). This study employed psychodynamic approaches to obtain the biographical accounts of participants' lives before and after incarceration, and also their experiences during incarceration, which were then subjected to hermeneutical interpretation. For one of the other participants in this study the incarceration experience was about knowing the rules of the prisoner subculture and 
acting accordingly to avoid violence and drugs, whilst for the remaining participant the experience was focused on his engagement in work-based activities to distract from drug use (Bereswell 2004).

The effects of the prison regime have also been argued to hinder the formation of close friendships, as there are limited hours for quality social contact, in addition to increasing anxiety when there is unfamiliarity with the prison regime (Biggam \& Power 1997). A study examining prisoner poetry as an untapped source of ethnographic information on prison life described daily prison routines to be 'mindless' and 'mundane', yet 'brutalising' in reference to the normality of strip searches (Johnson \& Chernoff 2002). Similarly, the daily prison routine was perceived as monotonous and boring by prisoners in de Viggiani’s (2007) ethnographic study conducted in an English prison. Prisoners spent long period of time locked in their cells and underemployment was associated with apathy and poor motivation (de Viggiani 2007). The enforcement of prison rules and routines as a source of conflict with prison staff has also been described by prisoners to be a significant aspect of the prison experience (Ashkar \& Kenny 2008; Johnson \& Chernoff 2002). The authoritarian management style of officers as they imposed prison rules was perceived by the prisoners in de Viggiani's (2007) ethnographic study as a source of conflict in officer-prisoner relations, as prisoners were forced into either subservience or rebellion. In this study, prisoners described officer-prisoner relations to be damaged by experiences of officers exerting power and control and being patronising, insulting, demoralising and dehumanising towards prisoners (de Viggiani 2007). The prison environment has been suggested to intensify hypermasculinity in prisoners as a response to confrontations with officers who exercise control (Kupers 2005).

The experiences of incarceration portrayed in the international literature are reflected in the only two Australian studies examining the experiences of incarcerated individuals. In 2003 a phenomenological study was undertaken of 16 young offenders aged 16 to 19 years detained in a maximum-security facility in NSW, Australia, to determine their experiences of incarceration (Ashkar \& Kenny 2008). From content analysis of the textual data obtained from transcribed participant interviews, the experience of incarceration was delineated into three themes: Prison culture, service 
delivery and loss. The prison culture of entrenched hierarchy amongst prisoners, substance misuse and authoritarian management styles of officers were perceived to be associated with being bullied and prisoner-officer antagonism. The theme of service delivery related to participant dissatisfaction with service provision, and loss concerned with reduced autonomy and limited privacy experienced by participants in addition to the loss associated with missing their family (Ashkar \& Kenny 2008). Whilst the participants of this study were detained in a juvenile-detention facility their experiences of incarceration are comparable to that of individuals detained in adult facilities.

The second study provided a detailed account of prison life for prisoners incarcerated in NSW, Australia, and was published in the form of a book titled, 'Life Behind Bars: Conversations with Australian male prisoners’ (Korn 2004). Korn (2004), a social researcher, interviewed seven prisoners on four occasions each over a two and a half year period with the aim to portray their life experiences, including their experiences of incarceration, through the presentation of their narratives. Participants described cramped cell conditions that they were forced to share, along with the cell's toilet facilities, most often with a stranger. In addition to their loss of privacy participants described the loss of their liberty where they were not only confined to their cell for upward of 14 hours each day but were also continuously surrounded by locks, gates, and surveillance cameras (Korn 2004). Constant disruption was described by participants with regular cell searches and movements to another facility without warning. The prisoner subculture also featured highly in the participants' narratives with similarities to that which was presented in de Viggiani’s (2006) ethnographic study conducted in an English prison discussed earlier. Participants spoke of navigating prison life through their knowledge of rules, similar to the prisoner code of conduct, to avoid confrontation with other prisoners. The author highlighted the participants' attempts to avoid predation and victimisation by being acquainted to well-respected prisoners and by adopting a "confident façade of overt and oldfashioned masculinity” (Korn 1994, p. 134). The participants’ experiences of witnessing violence in prison were related to conflict resolution, retribution, and debt collection and as a means for the aggressor to impose superiority. This study offers detailed insights into the incarceration experiences in Australia. However, whilst the researcher used a quasi-quantitative approach in an attempt to cover the various 
permutations of the prison population, it should be noted that the ultimate decision of which prisoners would participate was made by prison officials. As a result the portrayed experience of incarceration, although it most likely reflects the general experience of incarceration, is not transferrable to all imprisoned individuals in Australia. This is reflected in the denial by prison officials to allow a transgender prisoner to be interviewed for the research, due to the controversial nature of the individual's experience.

The experience of incarceration has for many decades interested sociologists, researchers and the public alike. Early research in the field, such the studies by Clemmer (1958) and Sykes (1958), provide invaluable insights into the experiences of incarcerated individuals in studies that enabled large participant numbers. These researchers were fortunate to have had access to the imprisoned for ethnographic and observational-type research. However, as highlighted by Simon (2000), since the years when researchers were given access to both prisoners and prison staff for sociological research, changes have occurred in both prison administration and prisoner society and as a consequence valuable ethnographic prison-based research is now rarely conducted. As a result the vast majority of recent research is focused on specific aspects of the incarceration experience such as the rates and types of victimisation experienced, or the effects of specific deprivations or environmental factors, such as loss of autonomy, overcrowding, on the imprisoned, rather than the experience in its entirety, with the exception of a few studies with limited participant numbers as discussed above. Collectively however, these studies portray commonalities in what appears to be the general experience of incarceration.

\subsubsection{The experience of incarceration for those with autism}

How incarceration is experienced may differ for those with autism as social naivety may render them vulnerable to exploitation and bullying (Dein \& Woodbury-Smith 2010; Royal College of Psychiatrists 2006). They are, for example, vulnerable to the consequences of retribution for breaking the 'prisoner code' such a reporting a fellow prisoner to a prison officer as rule enforcer for not following a rule. This is typical of those with autism who adhere strictly to rules as seen in school children with autism who inform senior persons that fellow students have broken a rule (Howlin 2004). 
Survival in prison has been linked to abiding by the 'prisoner code' which, a set of social rules, is not likely to be understood and subsequently followed by a prisoner who has autism. Prison routines and regimes may become a source of stress and anxiety, or such structure may be of comfort to a person with autism (Royal College of Psychiatrists 2006). However, given that it is known that the prevalence of anxiety in persons with autism is high, it is plausible that attempting to navigate the prison environment with a social and communication impairment is a distressing experience. In addition to this, the routines and rules governing the prison environment are unpredictable and subject to change as prisoners are moved around the system. The effect of this on prisoners with autism is unknown.

Literature concerning the general experiences of incarceration has highlighted that movements to different correctional centres during incarceration is a common occurrence. Each year in NSW there are on average 150,000 prisoner movements, with almost a third of which are from prison to prison (NSW Department of Attorney General and Justice 2011). Prisoner movements in total cover approximately three and a half million kilometres each year (Woodham 2004). Prisons in Australia are also currently operating at $105.9 \%$ capacity (International Centre for Prison Studies 2011). Being in excess of $100 \%$ capacity requires the need for prisoners to be frequently moved between prisons (Levy 2005). Therefore prisoners in NSW experience long journeys, often overnight, to different prisons across the state with little notice in order to reduce the risk of escape (i.e. where prisoner has time to inform family to organise a hijacking situation on the road during transfer). In the cases of non-high risk transfer, it is not a requirement to give the prisoner notice of transfer. Alternatively it is "desirable that prisoners be given 24 hours notice whenever practicable” (CSNSW 2012, p. 11). In addition to anxiety caused by the instability and unpredictability associated with prisoner movements, an incarcerated individual with autism is likely to have difficulty applying what they have learnt about a routine to another centre due to an inability to generalise learning's from one context to another i.e. from one correctional centre to a visually different correctional centre. The inability of a person with autism to articulate their frustrations appropriately is likely to compound the risks to themselves and others (Dein \& Woodbury-Smith 2010). An understanding of the experience and research in this area is required to inform the development of appropriate services to support those with autism in 
custody. Despite this, to date the experience of incarceration for those with autism has not been extensively explored.

Only two internationally published studies were identified that explored specifically how individuals with autism experience incarceration. Most influential of these studies was that by Paterson (2008) who presented two case examples of individuals with Asperger's Disorder imprisoned in the UK. Semi-structured interviews were conducted with the participants to obtain their perceptions of prison life. The participants were also observed by the researcher and a range of prison staff interviewed with the aim of identifying problems encountered by the participants in prison that were attributable to their developmental differences. Three main themes relating to participant behaviour in prison: adherence to prison regimes, relationships and empathy were identified from the collective findings. The first participant was described to be rigorous and rigid in his adherence to prison routines, and had been repeatedly involved in minor misdemeanours. Whilst the participant claimed to interact well with other prisoners observations did not reflect this. The participant was observed to have a constant agitated and aggressive demeanour towards others which resulted in him experiencing bullying and isolation, or developing superficial relationships only. The second participant was housed in healthcare due to his vulnerability to being bullied. He did not comply with prison regimes and spent the majority of his time in isolation. His social interactions with others were affected by his inability to comprehend abstract language and consequent lack of understanding of subtleties in interactions. This often led to aggressive outbursts and altercations towards others.

The second study by Allen and colleagues (2008) aimed to identify the experiences of 16 individuals with Asperger's Disorder who had a history of offending behaviour within the criminal justice system in South Wales, UK. Data were gathered through questionnaires completed by key informants from services used by the participants (such as mental health and learning disability practitioners and probation officers). Six of the participants also consented to being interviewed using a semi-structured approach, four of whom had experienced incarceration. The four participants who had experienced incarceration all described difficulties in the general aspects of prison life. These difficulties included missing family, being bored, finding it difficult to 
make friends, and being locked in cells with strangers. However, in the absence of other data to refute accounts provided by the participants, no difficulties were identified that were perceived by the researchers as being directly attributed to their Asperger's Disorder. The information obtained from informants did not focus on incarceration experiences but did highlight that the individuals were likely to be verbally aggressive, socially naïve, and had previously experienced social rejection and bullying.

These studies provide insight into how the cognitive and behavioural characteristics of autism, such as inability to empathise, inability to read social situations and poor social skills can impact on how an individual copes with incarceration and the increased vulnerabilities to which they may be exposed. However, methodological limitations, that include small sample size and participant self-disclosure methods do not permit generalisation of findings. A lack of comparable studies available in either the Australian or international literature further limits findings. It is also of note that whilst Paterson's (2008) findings were partly based on the participant perspectives, the methodologies in both studies did not permit the telling of what it means to experience incarceration for those with autism. Further research is required in order to determine the lived experience of incarceration for those with autism. Awareness of how such individuals experience incarceration will potentially guide appropriate service delivery and design.

Those with autism who have an intellectual disability may receive some level of support from prison disability services. However, how tailored such a service is to the specific needs of those with autism will be discretionary to the knowledge and skills of health professionals providing the service. There is ambiguity regarding the level of support, if any, available for persons with autism who do not qualify for support from prison-based disability services due to them not having a significant intellectual impairment. It also may be the case that the structure of prison life enables the individual with autism to function whilst in prison without support (Royal College of Psychiatrists 2006). The identification of such individuals may enable the provision of support in preparation for their return to a less predictable life in the community when released from prison. 


\section{Methodology}

A research methodology that is focused on examining human experiences as they are lived is phenomenology. The etymological meaning of the word phenomenology is the study of phenomena (Crotty 1996). It is the study of "objects as they present themselves” (Blattner 2006, p. 28). The methodology used in this study is that of hermeneutic phenomenology. Hermeneutic phenomenology aims to bring to light, or let manifest, the phenomenon, "that which shows itself in itself, the manifest" (Heidegger 1927/1962, p. 28), through interpretation: “Our investigation itself will show that the meaning of phenomenological description as a method lies in interpretation” (Heidegger 1927/1962, p. 37). It is a methodology that provides a way of exploring the experience from the inside (Osborne 1994), and as such can offer nurses a deep understanding of the unique experiences as they are lived by their patients, enabling the opportunity for nursing practice to reflect the patients' contextual realities (Benner 1994).

The phenomenological movement was founded by Edmund Husserl (1859-1938) who was concerned with the study of phenomena as they appear through human consciousness (Koch 1995). Husserl in his early work was influenced by French Philosopher René Descartes (1596-1650), and was traditional in his view of the person that he perceived as a knowing subject, that stands in relation to a world as an object of which it is conscious (Leonard 1989). From this view, Husserl brought meaning to the concept of 'intentionality', which referred to the idea that "the individual mind is directed towards objects by virtue of some mental content that represents them” (Dreyfus 1991, p. 2). Intentionality was a concept introduced by Franz Brentano (1838-1917), Husserl’s mentor, who in his field of psychology used the term Intentional Inexistence as a defining characteristic of inner mental phenomena (Morrison 1970). Mental phenomena, for Brentano, were distinguishable from physical phenomena by directedness toward an object (Kockelmans 1967). It is this relation to an object by consciousness that Husserl saw as intentionality, where consciousness is conscious of something: "The multiplicity of the intentionality belonging to any cogito - to any that relates to the world, by the very fact that such a cogito not only intends something wordly but is itself intended in the consciousness of 
internal time - is a theme not exhausted with the consideration of cogitations as actual subjective processes” (Husserl 1929/1950, p. 44). Crotty (1996, p. 38) captured intentionality as that which evokes "the idea of the human mind reaching out and into the objects of which it is conscious". The intentionality of consciousness was significant for Husserl in establishing phenomenology as a rigorous science. It was the study of this intentional content of consciousness, that directs the mind toward an object, that enabled the critique of knowledge in its original sources in immediate experience (Morrison 1970).

In his desire for phenomenology to be an objective science of consciousness, Husserl proclaimed a process of reduction in which the intentional content of consciousness can be reached through the achievement of transcendental subjectivity (Moran 2000; Wojnar \& Swanson 2007). This process required judgements about the external world to be suspended and assumptions regarding the phenomena put on hold, or bracketed, in order to remove the subjective nature of the investigator (Paley 1997). Husserl aimed for this to be a process of purification, or eidetic reduction, of consciousness where one suspended one's "belief in the actual existence of the objects of experience” through a process of laying aside, or 'bracketing' in order to understand the object as it presents to consciousness (Crotty 1996, p. 59). Once this process of reduction is complete, the investigator is in the realm of transcendental subjectivity. In this realm the transcendental source of intentional acts is accessible and the primordial phenomena, or as Husserl termed the 'things themselves', is able to be described. The ‘things themselves’ exist in consciousness prior to human judgements (Paley 1997). Primordial phenomena has been described by Crotty:

The experience referred to (which) has not been subjected to self-conscious rational processes. It is not our experience after we have developed or applied ways of understanding and explaining it. It is experience as it is before we have thought about it. It is 'prereflective' (Crotty 1996, p. 53).

There was disagreement among philosophers that the search for objective knowing should be the gaol of phenomenology, as such a gaol would deny human actions of their context (Benner 1994). One such philosopher who advanced a conception of phenomenology free from the traditional notions of objectivity was Heidegger. 
Martin Heidegger (1889-1976), was mentored by Husserl as his colleague at the University of Freiberg during 1919 to 1923, and became his successor in 1928 (Feinstein 2010). In 1923 Heidegger joined the National Socialist Party and became Rector of the University of Freiburg soon after, whilst Husserl, being Jewish born, was expelled from his professorship by Heidegger (Bender 1999). Unlike Husserl whose focus was on consciousness, Heidegger's life-long exploration was related to the meaning of Being, publishing his phenomenological study of the meaning of Being in Being and Time (Blattner 2006; Crotty 1996). Heidegger shifted phenomenology away from the epistemological focus of how humans know what they know, to the ontological focus of understanding the situated meaning of a human in the world (Annells 1996; Dreyfus 1991). For Heidegger phenomenology was 'making manifest that which manifests itself ... (by letting) that which shows itself be seen from itself in the very way in which it shows itself from itself' (Crotty 1996, p. 79). Like Husserl, Heidegger too was concerned with primordial knowing as 'the things themselves': “the term 'phenomenology' expresses a maxim which can be formulated as “To the things themselves!'” (Heidegger 1927/1962, p. 27).

Heidegger was influenced by the work of Wilhelm Dilthey (1833-1911) who, from his view of experience existing before subject and object, created the ontological dimensions of hermeneutic philosophy (Geanellos 1998). Dilthey was concerned with the study of 'lived experience', emphasising the essentially historical character of human existence where human experience is embedded within a historical and social context (Crotty 1998). Hermeneutics was originally a method for the study of sacred and biblical texts: And like Dilthey, Heidegger generalised hermeneutics to a way of studying human activities (Dreyfus 1991). The word 'hermeneutics' is of Greek origin, derived from the Greek God 'Hermes’ who was responsible for making clear, or interpreting, messages between the Gods, and roughly translated means 'to interpret' (Crotty 1996; Lopez \& Willis 2004). The aim of interpretation is to bring to light, or to make clear, that which is hidden or fragmented (Geanellos 1998). Hermeneutic phenomenology involves bringing to light the lived experience through the interpretation of meaning acquired in text created from the narratives of those being studied (Annells 1996). 
The concept of intentionality for Heidegger becomes ontological as human beings are intentionally related to their world, rather than expressed in purely epistemological terms, where intentionality is attributed to consciousness (Crotty 1996; Dreyfus 1991). Heidegger proclaimed that the self, or being, is both constituted by and constitutive of the world. From the phenomenological viewpoint, world is the set of shared practices, relationships and language that we have by virtue of being born into a culture on which we depend for meaning and intelligibility (Benner 1994). This means that experience is translated through a cultural lens, where a person uses their situated context, of which culture is a part, to impose meaning on an experience; as one's situated context, including culture, is the source of thought and behaviour. Crotty (1998 p. 54) captured this system of intelligibility: "when we first see the world in meaningful fashion, we are inevitably viewing it through lenses bestowed upon us by our culture. Our culture brings things into view for us and endows them with meaning”. Heidegger used the term thrownness (Heidegger 1927/1962, p. 135) to express that a person is situated in the world without an element of choice, as one is born into a given culture, language and values. The person is therefore understood as being-in-the-world (Heidegger 1927/1962, p. 53), meaning that interpretation and understanding of an experience can occur only within a given situational and historical context of participant and interpreter of experience. Heidegger consequently refuted Husserl's notion that the investigator of phenomena can abstract their self from the world in order to view the phenomenon free from human subjectivity.

Hans-Georg Gadamer (1900-2002) further developed Heidegger’s ideas around historicity and hermeneutic understanding. Gadamer (1989) claimed that, in order to understand that which is to be understood, in its true dimensions, an appropriate historical horizon is to be acquired. The horizon is "the range of vision that includes everything that can be seen from a particular vantage point” (Gadamer 1989, p. 301). Husserl too used the term horizon, and wrote of "an intentional horizon of reference to potentialities of consciousness", where horizons are "predelineated potentialities of conscious life at a particular time" that are to be uncovered or explicated (Husserl 1929/1950, p. 44-45). The historical horizon for Gadamer, is the historical context of both inquirer and of that towards which the inquirer is directed, including the culture they are shaped by, (i.e. the experience of the participant). For Gadamer to be 
understood can only be understood historically, and he therefore introduced the notion of 'historically effected consciousness' to reflect that understanding is only possible due to the historical continuum shared by interpreter and the phenomenon being studied (Muller-Vollmer 1988). This means that the present horizon of understanding cannot be formed without the past and, according to Gadamer, understanding is the fusion-of-horizons; that is the fusion of the historical with the present horizon (Gadamer 1989). The historical horizon refers to the experience and the meaning of the experience made intelligible by culture and tradition of society. The present horizon refers to the understanding held by the researcher (Gadamer 1989). An inquirer can only acquire a horizon by looking "beyond what is close at hand ... to see it better, within a larger whole and in truer proportion” (Gadamer 1989, p. 304). This means that, in order for the researcher to understand an experience in its true dimensions, he/she must 'transpose' him/herself into the historical situation. This is achieved through consideration of their own past and the past toward which historical consciousness is directed.

Context as a central concern was emphasised by Heidegger in the concept of Dasein, which translated means the human way of being in the world, "Dasein exists. Dasein is an entity which in each case I myself am... Dasein's Being takes on a definitive character ... understood a priori as grounded upon that state of Being which we have called 'Being-in-the-world'”' (Heidegger 1927/1962, p. 50). The meaning constructed about an experience by individuals can only be within the context in which they are situated in the world for "meaning is found as we are constructed by the world while at the same time we are constructing this world from our own background and experiences” (Laverty 2003, p. 8). This means for a participant of research, as Beingin-the-world, experience is not a detached entity as it is not separate from their world. An experience, to which the researcher is directed, is not presented to them as a decontextualised entity to be understood as an isolated object (Johnson 2000). Therefore the meaning of participants' experience cannot be detached from their other experiences and can only be understood with consideration of the contextual whole, and it is the role of the researcher to bring to light the things themselves - that is to reveal and make explicit the meaning of the experience under investigation. To understand the experiences of others, and the meanings given to the experiences is to understand their lifeworld. According to Crotty (1996), Husserl too, in the last decade 
of his life, incorporated the concept of lifeworld into his work titled 'The Crisis of European Sciences and Transcendental Phenomenology', in which greater attention was paid to embodiment and historicity, and exploration of the everyday world, than his earlier work that reflected transcendental idealism. For Heidegger historicality of understanding and interpretation are vital notions in achieving understanding of one's lifeworld.

Heidegger described the process of interpretation to be circular, where understanding is sought through a dynamic movement between the part and the whole of texts, and from the text to the historical context and back again (Benner 1994; Crotty 1998). Gadamer too captured the circular nature of hermeneutic understanding: "the movement of understanding is constantly from the whole to the part and back to the whole. Our task is to expand the unity of the understood meaning centrifugally. The harmony of all the details with the whole is the criterion of correct understanding. The failure to achieve this harmony means that understanding has failed” (Gadamer 1989, p. 291). The investigator enters the circle through identification of preunderstandings, or as Heidegger termed fore-structure of understanding (Annells 1996). Within the fore-structure of understanding, according to Heidegger, interpretation is founded upon fore-having, fore-sight, and fore conception: "interpretation will be founded essentially upon fore-having, fore-sight, and foreconception. An interpretation is never a presuppositionless apprehending of something presented to us” (Heidegger 1927/1962, p. 191). This means that researchers are required to identify from their own world their prior knowledge, including past experiences, that make interpretation possible (fore-having), and their socio-cultural background that both carries with it the view point from which an interpretation is made (fore-sight) and also the expectation of what might be found in an investigation (fore-conception) (Wojnar \& Swanson 2007). It is also the historically situated thinking (“fore-having”; Heidegger 1927/1962, p. 191) that leads a researcher to their study.

Gadamer's work on historicity of hermeneutic understanding emphasised the importance of prejudice: a notion he used to represent fore-understanding. He made comprehensible that, without prejudice, understanding would not be possible as the researcher and the phenomenon he studies share a historical horizon (Gadamer 1988; 
Gadamer 1989). In Cartesian influenced phenomenological methods, such as Husserlian phenomenology, judgements are to be excluded (bracketed) completely as they are "the source of all error in the use of reason (therefore having) no foundation in the things themselves” (Gadamer 1989, p. 279). However, in hermeneutic understanding, Gadamer stipulated that not all prejudice is negative, but prejudice can be of positive value that is "legitimate prejudices" that bring about genuine understanding (Gadamer 1989, p. 278). Bracketing would preclude these understandings. These legitimate prejudices are the inherited notions derived from one’s culture (Crotty 1998). Gadamer, like Heidegger, proclaimed a historical mode of being, therefore a participant can only relay his experience to the researcher as situated in their historical consciousness. The relay of the experience in turn can only be genuinely understood by the researcher historically through legitimate prejudice.

Further to this, the primordial experience can only be understood through the hermeneutic circle. Heidegger described the hermeneutic circle:

In the circle is hidden a positive possibility of the most primordial kind of knowing. To be sure, we genuinely take hold of this possibility only when, in our interpretation, we have understood that our first, last, and constant task is never to allow our fore-having, fore-sight, and fore-conception to be presented to us by fancies and popular conceptions, but rather to make the scientific theme secure by working out these fore-structures in terms of the things themselves (Heidegger 1927/1962, p. 153).

This reflective process, as the beginning of understanding, involves "a willingness to engage in a progressive letting go of what we currently know and understand” (Holroyd 2007, p. 5) in order to contain the influence of pre-understandings and foreconceptions on new understanding. Wolff (1984) captured this also in his notion of 'surrender and catch', where the researcher is required to surrender to the phenomenon in order to catch new meaning. To 'surrender' the researcher engages in a letting go of current awareness in order to be open to allow new meaning to emerge; that is so that new meaning to be 'caught' by the researcher (Wolff 1984).

Gadamer, in his book titled 'Truth and Method', additionally reinforced the epistemological assumption in hermeneutic phenomenology that language is integral to understanding: "Language is the universal medium in which understanding occurs. 
Understanding occurs in interpreting” (Gadamer 1989, p. 389). According to

Gadamer, and also Heidegger, language is not a mere instrument for communication; instead persons are born into language by nature of birth and are therefore already biased in their thinking (Holroyd 2007). In the hermeneutic circle "language opens access to meaning, and is the condition on which the human world is disclosed" (Holroyd 2007, p. 5). As Heidegger observed, language is a medium for which things manifest as "the way in which discourse gets expressed is language" (Heidegger 1927/1962, p. 204). It is therefore through language that people primarily develop meanings of their experiences, as their world is interpreted through language.

Language however, reflects Dasein's self-interpreting being-in-the-world (Dreyfus 1991). Therefore in order to reach the primordial phenomena, the things themselves, one has to drill down beyond individual interpretation in order to get to the primordial interpretation, or telling, which is more complete, in-depth and unified (Dreyfus 1991). Individual interpretation is when a being, through thematic assertions, uses words/speech to point things out in a shared situation. This form of interpretative language is used within a context to point out characteristics of an entity, or experience, within a shared world to another being. At the stage of pointing out, language becomes impoverished where, as observed by Heidegger (1959/1971, p. 123) "words in our language (are) mostly (used) in a disparaging sense”. Dreyfus (1991) further elaborated on this concept by highlighting that words lose their original meanings and the beings' intentional states reflect conscious subjects relating to objects through disclosure of their beliefs, desires and perceptions. This stage therefore does not enable primordial understanding as "we do not so much understand the entities which are talked about; we already are listening only to what is said-inthe-talk as such. What is said-in-the-talk gets understood; but what the talk is about is understood only approximately and superficially” (Heidegger 1927/1962, p. 212). This stage however "presupposes a more fundamental way of being-in-the-world that cannot be understood in subject/object terms” (Dreyfus 1991, p. 5). It is the pointing out of the pointable and the saying of the sayable that enables primordial telling to become concrete as linguistic telling (Dreyfus 1991).

Hermeneutic phenomenology therefore is a methodology informed by a number of key philosophers. Whilst for Husserl the aim of phenomenology was to objectively 
study phenomena under the rigour of eidetic reduction, his successor Heidegger, who was influenced by hermeneutics, shifted phenomenology toward the ontological focus of understanding the situated meaning of a human in the world. A person, as being-inthe-world, is born into a given culture and language. As experience is not a detached entity separate from one's world, a participant of research can only give meaning to their experience within the context of their culture. Their experience is then selfinterpreted through language that is most often impoverished and not a reflection of the things themselves. The horizon of the participant's experience, including the meaning of the experience made intelligible by culture and language, is fused with the horizon of the researcher's understanding in order for the researcher to be able to understand the experience under investigation in its true dimensions. The aim of this methodology is to bring to light the things themselves, that is the experience under investigation through a process of interpretation. This process entails researcher engagement in a circular process of movement between the part and the whole of the text commencing with the identification of pre-understandings. These preunderstandings, or prejudices using Gadamer's terminology, enable the primordial experience to be genuinely understood. 


\section{Method}

Informing the method of this study is, as stated previously, the methodology of hermeneutic phenomenology. The methodological approach employed therefore aimed to bring to light, through interpretation, the experience of incarceration for study participants as the phenomenon under study. Hermeneutic phenomenology moves beyond the stance of subjective interpretation to the study of phenomena examined through the hermeneutic circle (Holroyd 2007). The focus of phenomenology is on the "objectivity to be found in the subjective", and is about getting behind the mundane, everyday experience of subjective accounts to the primordial experience (Crotty 1996, p. 55). The method of data collection, and analysis, therefore reflected this aim of phenomenology and had to be in congruence with the philosophical underpinnings of hermeneutic phenomenology. How this was achieved is described throughout this chapter.

\subsection{Study participants}

Individuals incarcerated in the NSW adult prison system who had autism were invited to participate in the study. Participants were sought from all thirty-three metropolitanand rural-based adult correctional centres in NSW. Purposive sampling was the method used to identify participants. This method of participant identification is in alignment with the phenomenological concept of intentionality, where it is the understanding of a given structure (the experience of incarceration for those with autism) that is intentionally sought by the researcher who is driven by their forestructure of understanding (i.e. that which has lead them to the research). This method of identifying participants therefore enabled the study sample to consist of identified individuals who are able to provide the desired information (Schofield 2004), i.e. those with autism who were able to talk about their experience of incarceration.

The sample size was not predetermined as experience can never be fully understood. Understanding of experience is situated historically, as highlighted by Gadamer (1989), and therefore each additional participant has potential for new meaning to be included in that which is understood. Rather, recruitment of participants took place 
within a given timeframe over a two and a half year period, based on concurrency with the period in which data interpretation took place and by which point the researcher was satisfied that the themes identified had resonated throughout interviews. In total eight participants were interviewed. Selection criteria was based on the phenomenological concept of intentionality, in that the directedness of the researcher toward the given structure placed limiting criteria on that which was to be explored. This meant that the participants were not beyond that to which the researcher was intentionally directed. Participants who were unable to provide consent, who did not speak English, who had an absence of an adequately documented diagnosis of autism in their medical notes or who were located in remotebased correctional centres (to which travel-related funding was not available) were excluded from the study. Those with PDD-nos, although considered an Autism Spectrum Disorder, were also excluded from the study, as this is a diagnosis used for sub threshold behaviours across the triad of impairment. Therefore included participants were limited to having a diagnosis of Autistic Disorder or Asperger's Disorder that was documented in their medical record by a Forensic Psychiatrist, a Child and Adolescent Psychiatrist, a Paediatrician, a Clinical Psychologist or a Nurse Practitioner.

\subsection{Procedures}

\subsubsection{Recruitment}

Participant recruitment took place between October 2009 and March 2012.

Incarcerated individuals with Autistic Disorder or Asperger's Disorder were identified from a search of Justice Health \& Forensic Mental Health Network (JH\&FMHN) electronic databases: Mental Health Outcomes and Assessment Tool (MHOAT), and Patient Administration System (PAS), using the search terms autism, Asperger's Disorder, Autistic Disorder, and autistic spectrum. Incarcerated persons with autism registered with the CSNSW Disability Service were also identified as potential participants via liaison with the Correctional Services New South Wales (CSNSW) disability officer. Information regarding the study was also distributed to health staff in all correctional centres via email, electronic notice boards and/or in-person by the researcher. This information contained contact details and process for staff to highlight potential participants to the researcher. 
In total eighteen potential participants were identified. Four potential participants were released from prison prior to meeting with the researcher. The remaining fourteen potential participants were approached and provided with a participant information sheet. The information sheet was read to the participant and an explanation of the project, including aims and what was involved, in plain language was given. Consent to participate in the study was also sought at this time. All identified individuals who provided consent to participate had their medical notes screened for an adequately documented diagnosis of Autistic Disorder or Asperger's Disorder before inclusion in the study sample. Six individuals who provided consent were excluded from the study due to an inadequate documented diagnosis of autism in their medical record.

\subsubsection{Data collection}

Consenting participants who met the inclusion criteria were interviewed. The interviews were conducted within the prison environment in a location that facilitated as much privacy as possible, whilst keeping within the security constraints of their individual classification.

Conversational style interviewing techniques were employed in an attempt for interviews to resemble an engaged conversation regarding the participants' experience of being incarcerated. This method of interviewing aimed to allow participants to describe their experience as it was meaningful to them, whilst eliciting a narrative that was complete with context surrounding their experience (Johnson 2000). To elicit context-laden narrative was essential for the researcher to in turn achieve a historically-situated hermeneutic understanding as described by Gadamer (1989). Conversation indicators were driven by the researcher's fore-structure of understanding, using Heidegger’s (1927/1962) terminology, in that preunderstandings enabled meaningful direction of conversation. In consideration of the phenomenological concept of horizon, conversational style interviewing aimed to limit narrowness of the researcher's vision. Narrowness may be caused by asking leading questions; therefore limiting the boundaries of what is going to be talked about. Conversational style interviewing also promoted seeing beyond that which was 
given through the opening up of new horizons, as the researcher remained open to what was being said; therefore opening up possibilities of meaning.

The interviewing style of the researcher was also modified with sensitivity to the information processing style of those with autism using techniques asserted by Newman, Cashin and Waters (2010) for using a hermeneutic phenomenological approach with study participants who have autism. Individuals with autism have a unique cognitive processing style that is potentially at odds with the epistemological assumptions underpinning hermeneutic phenomenology. These assumptions are: that language is integral to understanding, and that people develop meanings of their experience through language. This use of language is reflective of the ability to abstract information; ability held by neurotypical individuals ('neurotypical is a term coined by Gray and Attwood (1999) to depict persons without autism). For neurotypical individuals information is stored using a linguistic code in a manner that creates a unified base of knowledge about the world (Cashin 2005). Such individuals are then able to construct meaning of their experiences by retrieving and expanding on previously stored knowledge. Individuals with autism, however, as a result of a non-neurotypical cognitive processing style, process information visually, as opposed to linguistically. Thoughts about the world, or experiences, are stored chronologically as discrete chunks of visually coded information, as opposed to linguistically coded and stored in context with similar concepts of experiences (Cashin 2005). Individuals with autism therefore not only have concrete thinking, but are not likely to be able to recall memories linguistically or find externalising their thoughts, feelings and experiences through spoken words a natural process (Newman, Cashin \& Waters 2010). Consequently, specific methodological consideration was given to how the researcher could engage with participants who were unable or had difficulty verbalising their experiences to make meaning of their lived experiences in order to be congruent with the underpinnings of hermeneutic phenomenology.

Hermeneutic phenomenology requires jointly focused attention between researcher and participant, or “willing” using Heidegger’s term (Heidegger 1971/1975, p. 67). Therefore language used was intended to be sensitive to those with autism in order to promote clarity about the process. This was achieved through excluding the use of superfluous words and jargon. The achievement of a shared 'willing', using the 
modifications detailed by Newman, Cashin and Waters (2010), was to be aided by the use of a visual aid to turn the abstract concept of 'the past' into something concrete that an individual with autism could talk about. Here, the visual aid used was a specifically designed comic representation, based on the principles of Gray's (1994) Comic Strip Conversations that aid the teaching of conversation skills to individuals with autism. Its intention was to direct the participant's attention through a simple drawing of someone outside of a prison cell looking in on a figure with the thought bubble "I have autism" while the figure on the outside has the thought bubble "I wonder what it is like to have autism and be in prison” (see appendix I).

Further methodological modification required was in relation to eliciting the linguistic expression of experience from the participant with autism. In hermeneutic phenomenology, a researcher would usually be required to drill down beyond individual interpretation provided in a telling of a participant during a conversationalstyle interview. This will be laden with impoverished language and subsequently be far from the primordial telling that one is attempting to reach (Heidegger 1959/1971). In this study, as a technique detailed by Newman, Cashin and Waters (2010), the researcher sought to obtain concrete examples of the experience that, once stimulated, are free from individual interpretation. These concrete examples manifest in chunk form and require little or no abstraction ability from the participant; hence suit the cognitive-processing style of those with autism. The stimulation of concrete descriptors, or chunk recall, will result in less requirement of the researcher to 'drill down' past the self interpretation laden version of verbal expression that pertains to neurotypical accounts, as usually required in hermeneutic phenomenology. This concrete telling of experience by those with autism has been likened to the interpretation-free recall of memories characterised as ‘eidetic memory’ (Newman, Cashin, \& Waters 2010). The researcher aimed to aid, when required (i.e. when the participant is unable to or has difficulties with verbalising their experiences), the linguistic expression of concrete examples of the experience through the use of visual cues, for example, by asking the participant to draw sections of their day with the aim to cue or trigger the participant to articulate an experience. Such tactics aimed to tap into the eidetic memory of participants and, where coupled with the use of guidance from the researcher, were aimed at enabling a concrete visual representation of their experience as a cue for the participant to verbally express that experience. Guidance 
was offered through the use of grounding questions where required that focus on externalising the experience to give it a concrete entity.

Interviews were audio-recorded and recordings transcribed to create a text for analysis. Participants were allocated a code and all data were identified by this code. The code was kept on a master list and stored separately to the data. Written documents contain de-identified data only. All data were stored separately and securely in locked filling cabinets or password protected file access at the researcher's workplace, a JH\&FMHN office.

\subsubsection{Data Analysis}

Interpretative understanding, according to Gadamer, is achieved through a circular process moving between the part and the whole: "the movement of understanding is constantly from the whole to the part and back to the whole” (Gadamer 1989, p.291). Consistent with hermeneutic phenomenology the process of data analysis was not undertaken in isolation from data collection as a discrete phase, but was a process commencing during the first participant interview, as listening to an experience may provoke thoughts relating to the meaning of what is being said (Cohen, Kahn \& Steeves 2000). The researcher entered the hermeneutic circle through identification of pre-understandings; that is fore-having (prior knowledge, including past experiences, that make interpretation possible), fore-sight (socio-cultural background that both carries with it the view point from which an interpretation is made), and foreconception (expectation of what might be found).

The researcher then became immersed in the data through transcribing the interviews verbatim and then reading and re-reading the transcriptions. Thoughts about the text, relating to parts of the whole transcript, were intently followed by movement to the contextual whole embedded within the text in its entirety. It is only by moving between parts and the whole of the text can understanding of the text deepen and meanings become visible (Johnson 2000). The text aimed to be understood with consideration of the context in which it was produced and the social and cultural context of the participant (Annells 1996). The text was organised for emergent themes and text not relevant to topic eliminated. The researcher engaged in a reflective process of writing and re-writing as interpretation is open to re-interpretation as fore- 
conceptions (pre-judgements) required revision with the movement of understanding and interpretation. Gadamer described this as 'working out the fore-projections' where fore-conceptions that originate as anticipations are, through the constant task of understanding, confirmed by the things themselves (Gadamer 1989, p. 270).

Throughout interpretation the researcher retained an open-stance and fore-grounded prejudices in order for that which was hidden to be uncovered. As meaning and new meanings emerged the researcher continued engagement in the circular process by, as described by Gadamer (1989, p. 271), "situating the other meaning in relation to the whole of our own meanings or ourselves in relation to it”. Through this process a fusion of the historical horizon of both researcher and of that towards which the researcher is directed with the present horizon of understanding was achieved (Gadamer 1989). Analysis was finally dialogued with existing literature to understand whether incarceration is uniquely experienced by those with a diagnosis of autism.

\subsection{Ethical considerations}

This study received ethical approval from the JH\&FMHN (formally known as Justice Health) Ethics Committee, the CSNSW (formally known as Department of Corrective Services) Ethics Committee and the University of Technology Sydney Ethics Committee (see appendix II). There were a number of ethical implications of consideration related to undertaking this study. These related to vulnerability of the participants and issues of voluntary participation, ethical disclosure, potential for harm to the participants, ensuring anonymity and confidentiality of information, maintaining researcher safety in the prison environment and maintaining integrity of the participants' narrative.

Prisoners are considered a vulnerable population. Persons with mental health problems, learning difficulties, substance misuse problems, and persons who are Aboriginal or from a cultural minority are overrepresented in the Australian prison population (Indig et al. 2010; Levy 2005), and are subsequently typically subject to discrimination, stigmatisation and marginalisation (Paternelj-Taylor 2005). The potentially high vulnerability status of prisoners coupled with high incidents in the 
prison population of history of abusive relationships, and being subject to abuse and exploitation can influence voluntary participation in research (Brewer-Smyth 2008).

Prisoners are also considered vulnerable to being coerced into participating in research as "a direct consequence of their dependency status within the correctional system” (Paternelj-Taylor 2005, p. 348). A US study that assessed the susceptibility to coercion in 30 mentally ill prisoners found the main reasons for research participation included alleviating boredom, meeting someone new and to appear cooperative to prison officials (Moser et al. 2004). Whilst these factors may influence a prisoner's decision to participate, they are not forced or emotionally coerced into participation. Emotional coercion in this population may potentiate in the form of perceived penalisation from prison or health staff if they declined to participate (Moser et al. 2004). In this study it was therefore made clear to the participants during the process of obtaining consent that their choice not to participate would not affect their access to health- or correctional-based services.

The right for voluntary participation in the study was respected, including the right to withdraw from the study at any time. This was made clear to participants as detailed in the participant information sheet (see appendix III) and participant consent form (see appendix IV). Due to the variable nature of the degree of impairments that characterise autism and the possibility of a co-existing intellectual disability, some individuals with autism may be unable to understand the purpose of a research study and to offer insights into their experiences (Barnbaum 2008). In the absence of a coexisting intellectual disability and with consideration of the cognitive processing style of those with autism, there is no reason why individuals with autism cannot make the informed choice to consent to participate in a research study, to articulate their experiences, and to share their perspective on the topic being studied (Newman, Cashin \& Waters 2010). This has been demonstrated in the few qualitative studies conducted with individuals with autism (see for example: Hurlbutt \& Chalmers 2002: Müller, Schuler \& Yates 2008). Consent was sought from all participants with sensitivity given to the unique cognitive processing style of those with autism. This involved taking into consideration their ability to understand and conceptualise information, for example not providing more than one idea or notion at time, and no use of jargon or superfluous words. It was also recognised that some of the 
participants may have a co-existing intellectual disability. Therefore the participant information sheet and consent form was written at an easy readability level (as identified using the Flesch-Kincaid Readability Statistics in Microsoft Word) and additionally read to those participants with an intellectual disability or to those unable to read. If the participants were under guardianship, and they consented to participate, the guardian was also approached to seek consent for participation in the project.

A further potential source of coercion in the prisoner population is the offer of incentives for research participation. In prison the value of what would, in non-prison environments, be considered a reasonable incentive for research participation (i.e. a small financial compensation) is likely to be perceived as greater value than nonparticipation. In an environment where the smallest financial compensation or nonfinancial item such as a bottle of shampoo or writing materials, are valuable the risk of participation without an understanding of what is entailed is high (Brewer-Smyth 2008; Waldram 2007). The potential high value of incentives also raises ethical concerns as the receiving of an incentive for research participation may increase the likelihood of the prisoner being a victim of bullying and exploitation. Because of these ethical concerns no incentive was offered for participation in this study.

A further ethical dilemma related to conducting research in prison is the potential for the research participant to disclose information related to their crime or to a criminal act undertaken whilst in prison. For example they may disclose plans to escape or intent to harm another person, or in talking of their experience they may disclose an incident in prison where they had been sexually abused. There is also the potential for a research participant to disclose information on criminal activity conducted before they came to prison. It is the responsibility of the researcher to report such disclosure of information, as bound by ethical agreement with CSNSW. Therefore during the consent process and prior to interviewing, the researcher discussed with the participant that she was duty-bound to report anything of this nature that was disclosed. Also participant disclosure of traumatic events (i.e. incidents of sexual or other abuse whilst in custody) may cause secondary psychological trauma to the researcher (Brewer-Smyth 2008). Therefore the researcher was mindful of the potential for such an effect, and ensured adequate provision of de-briefing 
opportunities with research supervisors was available, and consideration to the promotion of emotional self care was given.

Participation in the study involved participants' talking about their experiences of being in prison. As a result there was the potential for psychological stress to be induced if reflection on upsetting or disturbing experiences was involved. If this occurred a plan was in place to discontinue the interview and to refer the participant to Justice Health nursing staff for assessment and support, in addition to an Aboriginal Health Worker if the participant identified as Aboriginal.

Participants' were assured anonymity and confidentiality of information prior to consent being obtained. Participant anonymity was ensured by the documentation of de-identified data only. Given the nature of the hermeneutic phenomenological interview, a participant may provide detailed information identifiable to the participant. Therefore identifiable recorded content was replaced by de-identified written data during transcription and the recording destroyed. Confidentiality was also maintained through the coding of data, where participants were allocated a code and all data identified by this code only.

Consideration was also given to confidentiality issues specifically applicable in prison research. Firstly, in conducting research with prisoners there is the potential for the participant to disclose their participation in incriminatory acts or harmful intent (Schlosser 2008). Participants were therefore informed prior to interview that the interviewer is obligated to disclose intent to harm self or others, informing proper authorities as appropriate. Secondly, ensuring privacy to conduct interviews in the prison environment has also been discussed as an ethical concern due to the potential implications relating to confidentiality (Quina et al. 2007). Due to the restrictive and security valued nature of a prison environment, privacy during interviewing may be hindered by a lack of 'safe' private rooms, common interruptions by custodial and/or health staff, and the requirement for the presence of a correctional officer. In the prison environment it is challenging to find a suitable room for conducting research interviews that provide complete confidentiality (Paternelj-Taylor 2005). Even closed rooms with no prisoner or staff presence are usually glass fronted so that correctional staff have visual access to the participant and researcher to ensure safety, restricting 
the ability to protect the identity of research participants. In this study attempts were made to ensure privacy by pre-organisation of a private room free from interruptions, without the presence of others where possible. Where the interview was required to take place under observation of a correctional officer for security purposes (i.e. in the case where as a visitor to the centre the researcher required to be escorted at all times or in the absence of a personal duress alarm for the researcher), attempts were made to ensure this person was not within hearing distance of the interview. If the instance arose, as a requirement of the participant's security status (i.e. if they were considered a risk to staff), that a correctional officer had to be present in the interview room, the participant was to be notified of this instance and confirmation of their wish to continue with the interview sought. From an ethical perspective, the presence of an officer had an implication on not only privacy and confidentiality, but also integrity of data. This is because the participant may choose not to disclose, or to be untruthful about, aspects of their experiences in fear of retribution knowing that an officer will be able to hear what is being said.

Ensuring researcher safety in the prison environment is also an ethical concern in prison-based research due to the risk of violence towards the researcher. Participants may potentially have a history of committing violence-related offences, including murder, sexual assault and hostage taking. For this study the risk to the researcher had the potential to be increased during interview where the conversation was distressing in nature. The researcher was prepared for such incident, and de-escalation techniques were to be employed. Environmental safety precautions were also taken. The precautions included wearing a duress alarm, ensuring prison staff were aware of where an interview was taking place and with whom, and ensuring appropriate researcher positioning during interviews that enabled a direct means of escape if required. In the instance of a participant being known to be of high risk of being violent towards staff, including a researcher, there was a requirement for a correctional officer to be present during the interview.

In the prison environment recording devices such as a digital voice recorder required for recording participant interviews, are considered to be contraband items. It was therefore a requirement endorsed by the CSNSW Ethical Committee that written 
approval from each Manager of Security or General Manager from each correctional centre was to be obtained prior to participant interview.

Finally, ethical consideration was given to maintaining the integrity of the participants' narratives. The methods for data collection and analysis aimed to ensure that the participants' voice is heard and their experiences are accurately captured as they are lived and perceived by the participants. 


\section{Findings}

A total of eight prisoners were interviewed at seven correctional centres. However these prisoners spent time during their incarceration at a total of fourteen New South Wales correctional centres with a combined incarceration experience of more than 22 years. All participants were male and were aged between 20 and 43 years. The mean age was 27 years.

The lived experience of incarceration for those with autism, as highlighted by the themes discussed in this chapter, was about experiencing the normalities of prison life, but having to navigate such through a way of being that was dominated by ongoing anxiety and distress. The first theme discussed (deprivation of attempts to regain control) related to incarceration meaning that participants were constantly forced to negotiate an environment that deprived them of their ability to regain control of their world. The second theme discussed (being constantly present in an unpredictable environment) is about the prison environment for participants being one characterised by routines and rules imposed by correctional officers that impeded or removed completely their ability to regulate their own experiences. This was expressed by participant two, "(prison is) an environment with a list of rules ... you can't pick where you want to go it's like you're ordered to do this or you're ordered to do that ... I hate being told what to do”. Despite the imposed rules and routines, prison was not a structured predictable environment for participants. Prison rules and routines were unpredictable and ever changing as they were imposed at different correctional centres and by different correctional officers, "each officer has their own little version of how things should run ... people accept the discretionary nature of each officer having his own system, and I can’t quite grasp that” (participant five). In addition to the unpredictability of prison routines, these routines, when enforced, were on occasion unfamiliar and strange concepts that participants found difficult to understand. This is discussed in the third theme: Strangeness and associated incomprehension of prison routines and rules. The consequent effect of being unable to regain control in the unpredictable and unstructured prison environment where participants were often unable to make logical sense of imposed routines and rules was distress and anxiety. The fourth theme (negotiating the social world of prison) 
related to the unique social demands faced by participants associated with incarceration. The final theme (coping with the social-related demands through selfisolation and avoidance) identifies how participants sought to cope with the social demands they faced.

\subsection{Deprivation of attempts to regain control}

Many of the participants talked about the imposed prison routine of attending muster. Muster in prison is when prisoners are required to come together at a certain place and time a number of times a day when directed for a roll call to be undertaken to account for all prisoners. Muster is vital to ensure security is maintained and is therefore taken very seriously by correctional staff. Failure to attend muster can result in charges and consequent punishment being laid. Participant seven described the purpose of this regime: “they just do it to sort of check who’s here and check who's not here and make sure the people who are here are meant to be here and if they're not they try and find out where they are and if they're nowhere to be found then we get locked down because they could have escaped or something”. For participants this imposed routine was associated with negative experiences. Participant one attempted to take some control during muster, as a prison routine that he had no control over, by not standing in the same line as others but one step back, "a muster line, a cow line, is where you stand you have people either side of you... they understand that if I am not in the same line, if I am one step back”. By standing one step back participant one was abiding by the prison routine but was doing so on his own terms which for him alleviated anxiety. Participant one was located, and had been for almost two years, in a small rural correctional centre where the employment of correctional officers was regular and long-term in nature. Correctional officers therefore had the opportunity to 'get to know' prisoners. This differs to the larger, usually metropolitan-based, correctional centres where correctional officers are generally rotated around centres and/or units of a correctional centre regularly. Participant one had therefore managed to create this routine at the correctional centre he was currently incarcerated as the correctional officers in this centre knew that this is what he needed to do to manage his anxiety, "everyone is quite familiar that the little autistic one is there ... they respect that I am unique, a bit different”. 
For participant five muster was a humiliating enforcement that he recognised that he had no control of. He spoke of engendering some control by controlling his thoughts in relation to it and reducing its significance by creating his own routine around it, "it just becomes so routine that you don’t put any attention to the thought of it, just like eventually you don't see the bars or you don't see the fences. You just don't see it. You know, you accept it as micro world ... you build a routine around it ... you create your life around it so that it becomes insignificant. I find it very humiliating, that whole idea”. Being late for muster for participant five meant receiving warnings from the officers or even being punished as a consequence. He spoke of one incident where he got formally charged by the officers for not attending muster. Being charged for behaviour misconduct in prison is a formal internal process based on the principals of adjudication where accusations made by correctional officers may result in the accused prisoner receiving a form of punishment. On this occasion new medication that he had been given left him feeling too sedated to physically get out of bed and attend, “once I was charged for it (not attending muster), and that was only because I couldn’t wake up because I had Seroquel and I just couldn't wake up and I got charged”. For participant six muster also engendered a negative interaction with officers as they exerted control through giving orders, "some of them (officers) are just absolutely hopeless, just really arrogant and that ... (because of) the way they yell at you to all be quiet and that sort of thing in muster”.

There are times in prison where it is compulsory for all prisoners to be locked in their cells (known as lock-downs or lock-ins). This prison regime may be expected or unexpected by prisoners. Expected lock-ins take place at certain times each day on each individual unit or wing to comply with the prison regime specific to the unit or wing. For example prisoners will be unlocked from their cells at 7.30am then locked back into their cells at 3.30pm until the following day. Expected lock-downs that apply to the entire correctional centre may also occur on a particular day each month for correctional officer training to take place for example. Unexpected lock-downs occur more frequently and may occur as the result of a security risk or staff shortage. The data indicated that the times and periods of lock-downs or lock-ins varied across correctional centres, and sometimes even within units of the same correctional centre, and consequently some participants were subject to lengthy periods of time locked in their cell, while others were subject to very little. Participant eight, although only 
incarcerated for three months, had experienced the two extremes whilst incarcerated at one correctional centre, from being locked in his cell for 16 hours a day on one unit to not having his cell door locked at all on another unit. The first few weeks of incarceration that he spent in the main location of the correctional centre was for him senseless as he spent nearly all day locked in his cell, "in the main ... they only let us out to walk up and down the yard and then lock us back in the landing at 12, which is a bit ridiculous”. He was then moved to a minimum security unit within the same correctional centre where the security was lessened to the extent that it made him feel almost like he was on holiday, "It's actually way different. When you first go up there you think it's a motel ...(here) we've got more freedom than what the main does 'cause they only lock you in the unit of a night time ... if they're going to lock you down they just lock you into the unit and leave you in there which is a bit freaky 'cause you're not locked in a small cell, you're actually locked in the whole unit and you're free to walk around”.

The experience of being locked in their cells for participants had varying effects, as for some the isolation provided relief, but for others the imposed routine and loss of control engendered anxiety. For participant two, imposed lock-ins and the lack of distractions on offer provoked anxiety, "when I get locked in, I will think to myself now hang on this person touched me, this and that ... then the anxiety comes up. But um, yeah it suffers me a lot when my mind's not occupied”. Some participants experienced lengthy individual lock-ins due to being housed on special units for prisoners under protection from security or safety concerns. Prisoners classified as 'protection' prisoners are housed in segregation units when they require protection from the general prison population. This is often due to vulnerability to abuse from other prisoners either because of their offences committed (i.e. sex offences), or because they were considered to have a mental or developmental disorder and at risk of harming themselves or others. Characteristically in prison segregation units prisoners are housed in a single cell often under observation by correctional officers through CCTV, and are locked in their cell up to 23-hours a day with time out of cell often for showering and exercising purposes only. Participant six described how being housed in a segregation unit meant spending the majority of the day in his cell, "we spend 18 hours in our room”. 
Once such segregation unit for participant four was the 'detox cells' (a unit attached to the prison health centre designed for prisoners going through detoxification from drugs or alcohol in a safe environment where treatment is available) where, because he had very little to occupy his time as he was locked in the cell all day, "it was pretty boring ... I was stuck in the detox cells for five weeks, only had half an hour exercise a day”. He described how he was segregated from the main prison location for his own safety, “I was scared for my safety ... I didn’t want to be on the wing, too much hassle, too many people bashing people. I didn’t want to get myself bashed so I stayed there”. Participant four was frustrated at having no control over being locked in his cell day in and day out, “I don’t want to come back to gaol ever again, I hate gaol ... (the) worse thing (is) being locked up in your cell for hours ... its just annoying”. Throughout his prison sentence this participant, as he was considered to be too vulnerable to be housed in the main location of correctional centres, had been housed in segregation units, mental health units (units within prisons for prisoners requiring mental health treatment or assessment), or the 'DD unit' (a unit for prisoners with intellectual disability known colloquially by correctional and health staff, and as was documented in the patient's medical record, as the Developmentally Delayed Unit). Participant four expressed his vulnerability, "I get bashed every gaol I go to”.

Participant two also spoke about his experiences of being locked in a cell as a protection prisoner but, unlike participant four, he was locked in a cell with another protection prisoner who was being housed on the 'protection' unit because he was a 'sex offender'. Being locked in, with the correctional officer controlling when the cell door was opened, deprived him of the ability to choose to remove himself from a situation in which he felt uncomfortable. In this situation his cell mate did what were to him inconceivable acts, "I had this old man one day you know and he’s going up to me, I was asleep and he was trying to touch me! I don't know what he was doing. He was always playing with my back and mucking around, and exposing himself. This was an old man! ... I was shocked you know”. In this instance participant two told the officer and was moved to a different cell, but the incident left him wary of new cell mates who he didn't know, “you're locked in there (a cell) with someone you don’t even trust”. 
The undertaking of routine searches in prison was a cause of distress to participant two as he was deprived of control over the enforced situation. Correctional officers are required to undertake searches with the aim of seizing contraband items. Contraband in prison are items that are prohibited because they pose a security or safety risk. Contraband items include mobile phones, drugs, and weapons. The consequence of being in possession of a contraband item for the prisoner varies dependant on the item found. Standard and regular searches include searches of the prisoners' cells and searches of the person after a visit for example. For participant two being searched was an anxiety provoking event that was about not being able to obey all the directions from the officers as his need to be in control was greater than the control being dictated and worthy of the punishment he would receive for not following orders. One of these directions was a routine order by the searching correctional officer for him to run his own fingers through his mouth in order to eliminate the possibility of concealment of a contraband item in the mouth, "I suffer a lot of anxiety. They tell me to put my fingers in my mouth! ... I don't do it, and then I get myself in trouble you know”. The not following of the directions resulted in the officers laying formal charges and punishment in the form of not being allowed visits or phone calls. Similarly participant two perceived that cell searches caused problems with officers because they would have to remove some of his items that he had stored up in an act of gaining control over his anxiety that manifested in his need to use brand new products only, "sometimes they would remove some of my items. They say you can only have one of this and one of that and one if this and one of that. But I always stocked up with extras because I like them brand new”. He described the stress that the imposed cell searches and the mandatory removal of items from his cell caused him and the aggressive response he had to this stress, "I had a big argument with one of the officers ... I started to get angry and start firing up you know I start to stress out”.

For the majority of participants' meal times were imposed by the prison routine, a routine that was unique to each correctional centre. Participant two attempted to assert control at mealtimes by controlling both how he got his food and how his food was provided to him, "I need to get my own meals and see it in its own package because if any of the package is tampered with I will not eat it”. Participant two described a distressing incident when he was deprived of this control, “I didn’t want to eat the 
food they were giving to me ... So I didn't take the food and they said get to your cell and I didn’t go to my cell and three of them come and dragged me to my cell ... if you don’t obey their directions, it’s not good”. Participant two attempted to further control mealtimes by choosing to eat in his cell to avoid an accidental mix-up of his food items and cutlery with that of another prisoner’s, “I go up to my cell to eat there you know because, for example, if I had one $300 \mathrm{ml}$ milk here [pointing to a place on the desk in front of him] and then a 300ml milk here [pointing to a place on the desk close to first point] and a spoon in the same thing in that and that one, I put that down for a second, uh oh, that's a bit of trouble because I think to myself which one is mine? I'm a one hundred percent sure that that is mine but there's still doubt that that's mine. So there's a lot of conflict”. It is of note that, whilst the prison routine imposed the time that the participants ate, participants were able to control the place that they ate by choosing to eat in their cells and not at communal tables with other prisoners.

Working in prison is a compulsory endeavour with only a few prisoners exempt from working, such as those who are medically unable to work, those in segregation units, those engaged in full-time education in prison, or prisoners on remand who are yet to be sentenced in court. The type of work varies across correctional centres often dependent on the industries associated with that centre. For example the industries at the participants' correctional centres included textiles (manufacturing clothing and items for health or hospitality services), commercial printing, cable assembly, furniture refurbishment, commercial laundry, and appliance repair. Other work available to prisoners deemed responsible enough to hold such position is grounds maintenance work and unit or wing 'sweeper' responsible for general cleaning and other duties on their unit or wing. Nearly all participants had worked during their incarceration as a sweeper. A wing sweeper is, as described by participant seven “that's just your cleaning, handing your meals out, do this, do that”. Being a sweeper provided a form of positive routine for participant seven "sweeping the wing, it's alright because for the whole day you're busy, other than what you do for your routine; you're always cleaning, you're always sending things out, doing things. So you're busy, you're preoccupied”.

A sweeper position is considered a privileged position because the individual is given more freedom to move around the unit or wing to carry out their duties, and with such 
carries a level of trust from the correctional officers and envy from fellow prisoners as they are often let out of their cell to carry out their duties when the other prisoners on the unit or wing are locked in. Participant two was given this job because he was good at it as anxiety for him manifested in excessive cleaning habits, "I spend most of my time in prison being a sweeper for someone because they all know. They know I'm a good cleaner”. Participant two spoke of being taken advantage of by staff where his deprivation of control over his prison working life rendered him vulnerable to being made to work within the realms of a sweeper position as the manifestation of his anxieties were considered valuable qualities to staff, "hire this pussy cat and you get it done properly”. He described incidents of such by health staff, "the nurses ... they said look stay out of your cell til eight thirty at night, they give me big pods, three pods to clean, I do it every day for them. I did it for six months straight”, and by correctional staff although he perceived that correctional staff only had his best interests at the foremost of their intentions, "let's just say they accepted that I had a mental illness... they all knew that I had some kind of mental illness because they could see me struggling in my cell but what they do is move me to a cell, I clean it all top to bottom, next day they tell me to move again so then I got to do it again and again and again. I spend all the time washing these new cells”.

Participant five's experience of working in the correctional centres he had been to, with the exception of his current placement, was that it was an enforced activity that he perceived to be a waste of his time; it was something that he had to do that wasn't on his terms, "this gaol has that option where you don't have to (work). All the other ones that I've been to beforehand have made it compulsory ... (working was) mindnumbingly boring, frustrating because, again, you know, you could be doing more productive things with your time”. In centres where working was enforced participant five attempted to regain control by arguing against the rules imposed in relation to work in prison in an attempt to choose his own work. For him, this work was a continuation of his work as a lawyer before his incarceration experience. His continuation of legal work (working on his own legal case) in prison enabled him a means of controlling his prison work life, "I had a pretend job ... the pretend job was being a library sweeper, not paying me anything, and just let me in the morning and let me out at night, and I would pretend to have a job and they would pretend too, and that way they covered their rules and there's a reason for me to be in the computer 
room all day”. Whilst work for some participants, including participant five, was compulsory, participant four spoke of how he currently is able to exercise control over his day in regards to working or not. Participant four, who was housed in a special unit for prisoners who had intellectual disabilities where going to work was not compulsory, spoke of being given the choice by correctional staff to attend work on a daily basis. This choice enabled him to control being locked in his cell as he was able to choose to go to work, on his own terms, as the alternative was to be locked in, "they asked me at 6.30 if I wanted to work. I said no but then, at 8, I said yes ... they locked everyone in their cell till 1 o'clock if they didn't work, so that's why I went to work".

The effect of being constantly present in an environment dominated by imposed rules and routines over which they had no control was anxiety provoking for participants. Participant four spoke of the stresses of being in prison in general as opposed to being on 'the outside'. He regained control of his anxieties associated with this by smoking or by deliberating hurting himself, "if I think about stuff on the outside, like my family and that, I get really upset and depressed and then I hurt myself. But ... I try not to be stressed out by having heaps of cigarettes and I've made sure (that) I had smokes”. Smoking for participant four was a significant coping mechanism for coping with the deprivation of control that he experienced, "I never used to smoke but I come to gaol and I started smoking ... because I was getting stressed out and I found that having a smoke helped me not stress out”. Participant two attempted to regain control over his anxieties by wearing disposable gloves when touching things that other prisoners have touched, "I am going through a box of one hundred gloves, disposable ... because what I am doing, if I touch something now I prefer to use gloves so I don't have to wash the hands". And by doing things on his own terms by having his own towel for example, "I’ve had that towel for four months, I wash it myself in the laundry ... and my name’s on it, I know it’s mine!”, even if this breaks prison rules by having items that he was not allowed to have, “The officers don't allow you to have a mop, bucket or mop in your cell. I need to use my own one you know, brand new. So I used to get into trouble for taking the mop to my cell and keeping it there”.

Participant five also spoke about prison rules that are enforced by officers. He perceived the actions taken by officers when he breached prison routine as a means 
for officers themselves to deprive him of control as they are encouraged to do so by the prison system, "the mainstream thought of the gaol system is to disempower you so that you do not cause trouble, and that's the way they assert control”. He recalled battling the rules governing specific aspects of prison life and feeling helpless as he lost these battles, "it's that fighting for access (to a computer), fighting for simple things like mail and faxes or, you know, that sort of thing ... because you're not allowed to, there's an extreme sense of helplessness”. He attempted to regain control by doing all that he could to spend time on a computer, "if they can put me on a computer I would sit there from morning til night; I would never leave”.

\subsection{Being constantly present in an unpredictable environment}

The prison environment for participants was unpredictable with constant changes in cells, cell mates, officers and imposed routines and rules. Their placement within prison was also unstable as they were regularly moved to other correctional centres or units where the routines and rules were once again different to their last placement. Participant seven provided an example of how the lock-in times and mealtimes were different in different centres and the internal disruption this caused to him, “coming from a gaol when you're out eleven hours of the day, coming to a gaol where you're out four hours a day and then getting dinner at 2.30, two o'clock, it's a lot of difference and it's changing my whole routine. 'Cause when I was at (centre name) we'd get out at seven and you're in at quarter to six, six o'clock in the afternoon or at night and you're locked-in, but with (centre name), you're in and out of the wing access all day, cell access all day. Here they lock the cells I think at 9.30(am) 'til 2(pm), 'til just before muster”.

Participants sought the comfort of sameness in an environment that was unpredictable and ever-changing. For participant three sameness was achieved by imposing his own routine at meal times where he chose to eat in his cell because that was what he has always done, "I’ve always gone into my cell to eat lunch, I have never been outside to eat lunch”. Six participants sought sameness through creating a self-structured routine as a way to cope with the lack of structure provided for in their day. As participant six said, “there's not a lot to do here”. Participant five attempted to self-structure his routine by engaging in formal legal work which meant his time was spent accessing a 
computer or the library to read, write or use the phone, "in the mornings I get a coffee and then get on the phone, try to get into the library ... every day is the same ... too many files to read, to many things to write”. His ‘legal work' provided a focused and predictable structure to his environment. For participant six his self-structured routine was to spend his time going through the process of accessing the phone and making phone calls up to eleven times a day, “(I) just spend the whole day trying to get on the phone so I can make phone calls to my family... I speak to them anywhere from 11 times a day to about four times a day”. Participant six described the structure of his day, "during the day time I usually ring my family at home ... when the phones go off at 11 o'clock ... I go in my room and have breakfast and do a few things and then I'm around waiting for the phone again”. This self-structured routine motivated him to get out of bed, "I get up so I can jump on the phone”, to leave his cell, "I come out (of the cell) so I can jump on the phone”, and to work in order to earn money to make phone calls, "I’d prefer to be working to earn money ...I can afford to ring up to 10 times a day”. And the experience of enforced all day lock-downs were only problematic to him as they impeded on his ability to follow this self-imposed routine, “(being locked in) doesn't really make a difference to me, except if I try to make a phone call”. The self-imposed routine for participant one was being in his cell writing books ensuring that his time was occupied, "my time is absorbed within four white walls a window and a door ... (I) wake up 7.30(am), have breakfast and clean, my room is clean by 8(am), I work from 8.30(am) to 9(am), from 9.30(am) I then have a shower. I then write all day, all night, I'm up to book two”.

Participant eight coped with the lack of structure provided for in the prison routine by engaging in a self-structured cell cleaning routine, "I clean (my cell) every day ... and then I'll change it all around (and) clean it all out”. Similarly participant two coped by not having much to do by creating an intense routine of cleaning, “there isn’t much activities for us to do in here ... a normal day for me, everyday in here for me is, for me I have a pretty bad routine of cleaning and I'm obsessed with cleaning”. The unpredictability associated with different routines being applied at different centres caused disruption to participant two as he was forced to change his routine, "coming from a gaol when you're out eleven hours of the day, coming to a gaol where you're out four hours ... it's a lot of difference and it’s changing my whole routine”. 
Participant seven also engaged in his own self-imposed routine. For participant seven the unpredictable environment associated with having the many other prisoners going about doing different things brought chaos to his world, "Being in such a clustered environment ... in such a big environment where there's always people around, there's always things going on, there’s always distractions”. Engaging in his routine brought some order to this chaos. For him this routine involved numerous things of which he did depending on what day of the week it was or whether he was locked in his cell, “(I) play cards, train, read books, pray ... I’ve got my set days or my set routine ... (and) I’ve made another routine for if I get locked-in”. Anxiety was provoked for participant seven when he was forced to change his self-imposed routines due to unexpected changes in prison-imposed routines (i.e. unplanned changes to the day when prisoners on his wing are forced to be on the oval, or unplanned lock-ins), "those one off things that come out of the blue that upsets my whole, my whole day or my whole week and then I have to change things around”. This disruption to his routine had a spiralling affect to his anxiety where his frustration with such causes him to get 'the shits' with everyone, and to start talking with 'a bit of attitude' in his voice to an officer which, in the incident he described, then resulted in the officer locking him in his cell 'stuffing up' his daily routine even more. Similarly the sudden and unexpected lock-ins for participant seven were a source of frustration as they brought change and disorganisation to his self-imposed routines for which he was unprepared: "out of the blue, like one day it could be a full day, the next day we'll be organising things then we'll wake up in the morning to different officers saying ‘look you're going to be locked in’. Or you might be allowed to get out for the next half day, we don't know; it just catches you off guard ... I had a routine to stick to and when I don't stick to the routine it sort of mucks everything up and then I just, I get really frustrated”. And whilst an unexpected lock-down may last no more than one day, for participant seven the effects of such lasted a week, "when we have a disorganised day like that, when they just wake us up in the morning and say 'look, you're going to be locked-in' it just, it mucks my whole week up. If I have one offset day the whole week's gone and I just, I have to start again and it really annoys me”.

Being frequently transferred between prisons was a common theme discussed by participants and was associated with fear, upset, distress and confusion. Being 
transferred to another correctional centre for participant seven was an unsettling experience as being informed only the morning or the day before a transfer occurred he had little time to prepare and being transferred meant disruption to his selfimposed routine that provided him with sameness, "like if I'm settling in and I've got to move it upsets me a lot and really annoys me because I've just settled in, and getting settled, you know, and getting into my routine”. Participant two was also distressed by the disruption to his routine caused by being transferred. Unlike participant seven who had been given a number of hours notice of his transfer participant two was not given any notice, “they said ‘(participant's name) pack your stuff, you're going to (another prison)'”. The anxiety of being transferred unexpectedly and the disruption this caused to his routine of which he had become familiar was so distressing he started to hear voices, "No (I did not know I was being transferred). I was very shocked... I was hearing voices because they changed my routine". As a result of this reaction participant two was placed in a 'safe-cell' for his own protection where environmental conditions of the cell are designed to reduce the risk of self-harming behaviour, “they said look we can’t throw you in the yard because what about if something happens you know, it wasn't possible. So by me saying that I was stuck in a place with a nightie. No underwear, no shoes, no nothing, just a camera in the back. I wasn't able to do nothing. Not even a TV or a book”. The results of this imposed routine of being placed in safe-cell conditions further worsened participant two's anxiety which manifested in an intense need to repeatedly wash his hands in a back and forth manner with the repetitiveness of this action providing comfort, "I spent most of my time backward and forward from the tap like washing my hands because of it, it kept me busy”. Participant six too had a similar experience of enduring an unexpected transfer that caused him distress. He was attending court following being formally charged with assault on a prisoner. As he was charged for this offence as an adult due to its violent nature he was transferred from court to the adult correctional system rather than returning to the juvenile correctional centre as he had expected. He described this experience, "When I first come in from juvie to here I got bail refused for an adult charge ... and that was a shock because I was expecting to go to gaol at (juvenile correctional centre) on (date) and I went straight to (adult correctional centre holding cells) and then I never expected to go from (holding cells) and I went straight to (Adult correctional centre)”. Like participant two the implication of his fearful and distressed reaction to the 
unpredicted transfer and imposed unfamiliarity was to be placed in an observation cell for his own safety, "I was scared. I was kept in a observation cell in case I tried to commit self-harm. I had nothing in there. I had a pair of undies on; that's it, and nothing in the cell. And, yeah, I was scared and stressed out”.

The changes in prison routines and lack of uniformity as they are imposed by different correctional officers also left participants unable to predict what they were meant to be doing. The discretionary nature of prison routines as they were imposed by correctional officers related to all aspects of prison life from basic rules to complex routines, “you either have these sort of rights or you don't have rights. It's up to whether the individual officer is in the mood on the particular day ... everything (changes), from how many pillows you have to toilet paper to when your visit finishes to access - a complete gamut of things, pretty fundamental things” (participant five). Participant five provided an example of this happening to him where he got into trouble with one officer for keeping back-up disks of his work. He was told to do so by another officer after an incident where he was told that Correctional Services could not take responsibility if his work went missing after it got deleted from a computer by another prisoner. He described this this encounter, "they (the officers) said 'no, we don't take responsibility (of your work). You keep back-up disks. It's your problem. You keep them. You hide them, your problem if they go missing. Anything that gets left on the computer if it gets deleted we're not taking any responsibility'. Okay, fine. So I do it and I keep back-up disks in my cell. The new manager of security comes in; they find the disks 'You're not authorised to have the discs', 'Well, you're predecessor told me I had' - bang - 'don't want to hear it. Guilty'”. The punishment he received for this incident was exclusion from being able to purchase buy-ups (groceries available for prisoners to buy on a weekly basis through the prison 'buyup’ system) for 28 days. Participant six also spoke of the unpredictability associated with different officers imposing different rules in regards to the visitation routine, “because we're getting hour visits, we were supposed to all go in together, because we'd get changed and then get our key strapped onto our back, and then ... they timed it from when the first person went in, and that's when they started to time it and most of us only got about 40 minutes. The visits start at quarter past one and we'd get there at $1.30(\mathrm{pm})$ and we'd miss out in 15 minutes”. The unpredictability associated with this routine cause him distress, “(I feel) just angry and just sad”. The concept of an 
hour long visit only lasting for 40 minutes was just one example of an incomprehensible routine for participant six.

\subsection{Strangeness and associated incomprehension of prison routines and rules}

Prison routines and rules were on occasion unfamiliar and strange concepts to participants. For example, participant seven found the unfamiliar concept of muster difficult to grasp, "when I first come here I had to take a while to get used to it and there was a few times I was late ...even though it's every day but it was different, it was something weird that we had to get used to and had to sort of stick to every day”. The reasoning behind prison routines and rules were at times incompatible with the logic that they held. Participant seven, for example, was unable to grasp the reasoning behind why he was being routinely transferred to another prison when he had not been classified to that prison, "they either tell you that morning or the day before, so I'm prepared to go but it's still more or less not the point, you know, I'll be classoed to that gaol so why do I got to go?”. Participant seven perceived that he had been classified by correctional authorities to a particular rural-based correctional centre due to the proximity of this centre to his family to enable him to receive familial visits. A prisoner receives classification to a correctional centre based on their security-risk status (i.e. low or high risk), based on the seriousness of their offence, or gang affiliation and escape-risk status. Once a prisoner has been issued a security classification, they may receive a further classification to a particular correctional centre. This acts as a centre preference for the incarcerated individual but the individual may still be subject to routine prison transfer for security purposes.

Participant five also spoke of a prison routine that for him was not logical. He expressed an inability to comprehend the transfer-related routine when talking about his experience of being transferred from prison to court. When a prisoner is transferred from prison to attend court or from one prison to another, they have to contend with lengthy periods of time in temporary holding cells. Participant four described these holding cells, “you just wait there for hours and hours to be moved somewhere”. Prisoners being transferred are also subject to strict security protocols, including being handcuffed and transported in purpose built security vehicles with armed correctional officers as escorts. Participant five was located in a correctional 
centre that was within the grounds of a correctional centre complex. Within this complex there are numerous correctional centres with varying purposes (i.e. for women prisoners only, for remand prisoners only, for minimum security prisoners only), and also has facilities for prisoners to appear in court via video-link. Participant five spoke of an incident where he had to go through the entire transfer-related routine from the correctional centre in which he was located to another centre within the same correctional centre complex to attend court via video-link. For him it was not logical to have to go through the lengthy routine when his destination was in such close proximity, "I finished the court case; it was exactly 12.10 ... they take you from one cell and they put you in another cell, and I was there until 4 o'clock. I mean it's across the road. It's literally 10 minutes ... and all you do is just sit in a cage for four hours for no reason at all, you know, and then there's a truck that picks you up and drives five metres, going through a whole lot of security checks - you know, guns and things and all that - handcuffs - the whole experience - and it's a 10 minute - you know, that just sums up the whole - the way it works. It's just unnecessary”.

Participants also at times had difficulty following imposed routines which was related to not understanding that which was required of them or why certain actions were taken by correctional officers. Participant five was repeatedly in trouble with correctional staff for not following the prison routine as no clear directions outlining this routine was provided: “they’ve come up with all these things called 'not following routine', you know, and anything could be a routine. It's never documented. You don't know what the routine is”. One such incident was when he was working in a prison maintenance role. During a routine search by an officer participant five was found to be carrying on his possession a screw that he had taken from a broken frying pan that he aimed to find a matching screw in order to fix the item. As a consequence he was charged with having contraband on his possession. For participant five the consequence of having a screw in his pocket was to be formally charged by correctional officers with possession of contraband and as punishment he lost his privilege of a single cell and maintenance job. Another incident for participant five of not understanding actions of correctional officers related to the use of the in-cell emergency intercom system, where his view of an instance which required the use of the intercom differed to that of the officers, “you'd press the buzzer, 'oh well you shouldn't have pressed the buzzer unless it's an emergency, what's the emergency?', 
'well I need to get my pills', 'oh, no, no, no, you should have waited till we came and locked up' so therefore you'd get charged .You know, so ridiculous”.

Not understanding the actions taken by correctional staff following an incident that related to a breach of security was expressed by participant three. In this incident the prisoners on his unit, including himself, were locked into their cells by correctional officers as a fight had broken out between some prisoners. Distress was experienced by participant three as he was unable to comprehend why he had been locked into his cell during a time when the cell doors were meant to be open, "someone was having a go at someone else and I got locked in with everyone else in the (unit) ... (it was) uncomfortable (because I was) just thinking of why we were locked in ... to begin with no (I didn’t understand why), but by the end I figured it out”. Similarly participant seven was unable to comprehend the actions taken by correctional staff following an incident that involved, from the officers' perspective, participant seven displaying self-harming behaviour. In this incident participant seven was transferred to a 'crisis centre' (a unit within the correctional centre for prisoners with mental health problems) to be housed in safe cell conditions after hitting a wall. He felt confused because he didn't understand why this action was taken, “I’ve gone over to hit him and I've missed and I've hit the door... to this day I still don't know why they thought I was hurting myself but they dragged me out of there and put me in the pound which is a dry cell for bad people when they do stupid stuff ... and then they sent me to (another prison) to the crisis centre for one week. Then I'm sitting there, even the nurses have gone 'well why are you here?' 'because I've gone to hit him and I accidentally hit him (and the officers) pulled me and I've missed (him) and I've hit the door".

\subsection{Negotiating the social world of prison}

Incarceration for participants came with social demands. They had been imprisoned in a societal arena characterised by over-crowdedness and a unique social code. Time, if not spent locked in a small cell with another prisoner, was spent locked in a crowded prison yard, prison wing or workshop where situations requiring social mindedness were difficult to avoid. For participant three being unable to avoid the constant presence of other prisoners in one unit he had been in was a difficult task, “(centre 
name) I didn’t like one bit ... (I felt) uncomfortable, just made me feel uneasy around certain people”. Participant two experienced fear when forced into the social situation associated with being locked out into the prison yard, "I remember when I was chucked in (centre name), oh my gosh I was freaking out, that (was) very scary ... what was scary is your chucked in the yard all day with a hundred prisoners”. For participant seven the prison yard was manageable when there were a smaller number of other prisoners, "if there's not too many people, not too many idiots", otherwise the frustration he felt of being forced into this social situation resulted in aggression towards other prisoners, "I'll just get the shits and if I get the shits with one person I get the shits with everyone”. Whilst for participant four not being able to escape the social act of conversation irritated him, "they're (other prisoners) just annoying ... they get on your nerves, talk too much”. Participant five justified being unable to interact with other prisoners by his inability to relate to them, "there's the way that they talk; there's they way that they think; there's the way that they behave that I just find repulsive, so I don’t (socialise)”. From the data it was clear however that the social demands experienced by participants varied depending on both the correctional centre and the unit within the correctional centre within which they were placed. Participant seven summed this up when talking about how easy he found it to make friends in prison, "it depends on the gaol I'm going to, it depends on the people that are in the wing. If I go to a hard-core gaol, not really; if I go to a soft gaol like this one (a centre for prisoners undertaking special programs) it doesn't take long (to make friends)”.

Some participants were aware that they had a different way of being to other prisoners. Participant eight was clear about this awareness, "everyone (in prison) is different than what you are ... I'm different to everyone else”. This way of being often rendered their behaviour different and for participant five this meant he was in a vulnerable position and a target for abuse, “I don’t do that (socially mix) ... that makes you aloof and consequently a victim of abuse and target for, you know, everything else ... by being an oddity”. Participant two perceived that he too was a target for abuse, “cause I have a mental illness they (other prisoners) would deliberately do something to me". When asked what it was the other prisoners did to him, his misinterpretation of the social situation was clear with his perception of being targeted related directly to the manifestation of his anxieties, "just touching me, they 
would shake my hand, this and that, touch things”. He regained control in this situation by choosing to not use certain items in his cell that may have been touched by another prisoner, “if my razor's been moved I won’t use it”. Participant two also misperceived a social situation that involved a correctional officer when he was being escorted during a community hospital admission. In this instance the correctional officer allowed him to watch movies on the officer's personal laptop and participant two perceived this to be an act of kindness towards him rather than a means for the officer to alleviate his boredom, "we were at the hospital, they had no TV, and you know what he done, he brought his little laptop yeah we were there watching games and watching movies ... they treat me very right”. Participant two naively failed however, to understand that watching the officer play games was a not aimed as entertainment for him, but as entertainment for the officer. The participant himself was not allowed to play games, just observe the officer doing so.

Participant two provided another example of a negative social interaction in which he misperceived an act of kindness but this incident involved another prisoner whom he thought wanted to cause him harm. In this instance the other prisoner made his bed for him after he had had hand surgery, “a lot of them (other prisoners) didn’t accept my mental illness. People (another prisoner) trying to make my bed cause I only got one arm”. For him this perception that other prisoners did not accept him for being different resulted in the experience of stress and altercations with other prisoners, “there was a lot of conflict ... just with arguments with other people, people not accepting that I have a mental illness”. Participant three also spoke of an incident in which the intentions of another prisoner during an interaction were misperceived. However, oblivious to the intentions and motivations of the other prisoner, the interaction was not a negative one unlike that for participant two. In this interaction participant three misperceived that another prisoner was helping him by giving him advice, but when questioned it turned out the other prisoner was telling him what to do for his own benefit rather than for the benefit of participant three, “I’ve had people ('other prisoners') helping me out so that the officers don't go off at me ... they would give me advice ... cleaning advice”. But when asked what this advice was, he responded by saying the other prisoner said to him "keep yourself clean otherwise we will all get locked-in”. 
For participant four the incarceration experience was dominated by abuse from other prisoners, "(prison is) real hard (because of) prisoners standing over me and bashing me up all the time”. Being 'stood-over' in prison is a form of bullying where the bully acts to obtain something from his victim such as tobacco, food items, prescribed medication or even sexual favours. Participant four 's being stood over experience centred around his smoking and this meant that he lost his cigarettes to other prisoners, “every time I pull out smokes they ask for some and by the time they've finished asking I've got none left”. He spoke of having a cell mate who repeatedly stood over him and was subject to threats and actual physical abuse if he didn't submit to demands made, "every time he (cell mate) wanted me to hand something over (he'd say) just give him them or 'I'm going to bash you' and I said, 'no, I need them'. He just bashed me”. Participant two also spoke of being stood over by other prisoners but unlike participant four he acted against it, "they tell me to get them drugs. Try to force me to bring drugs in for them and I won't do that”. As a result of this participant two was fearful of the repercussion of not surrendering to their demands and told the officers, breaking an imposed prisoner code of not telling on other prisoners, “I was pretty shocked and scared you know, because if I didn’t get it they were gonna do something to me you know ... I had to tell the officers and that landed me in a lot more trouble because the people, it eventually catches up”.

Participant eight, like participant two, also acted against attempts by other prisoners to stand over him but by standing his ground with the prisoners rather than telling officers, “(they) wanted to stand over me for my buy-ups and for smokes and things, which I wasn't going to put up with ... I stood back up to them, told them to fuck off, told them that I wasn't going to do it”. The attempts by other prisoners to stand over him whilst he was located in the main location of the correctional centre were what defined his prison experience as a negative one, “(prison is) a bit difficult. It's not what I expected and it's a lot harder than people think. Yeah, it's just a bit shit ... (because) people like to stand over other people and if you ain't got a backbone they will stand over you”. Participant eight was unique from all the other participants in that his Aboriginal status in a correctional centre where being Aboriginal was not belonging to a cultural minority and being a family member to other prisoners gave him automatic gang affiliation and support in the form of help from his family and peers when he was fighting against being stood over, “if you don't have anyone that's 
going to help you then you're basically screwed ... the people that I knew, they were all old fellas, which didn't have to fight anymore, they had the respect from the young fellas”. The other participants did not automatically receive such support like participant eight, and they lacked the social ability to be able to affiliate themselves with others to be the recipients of such support. Participant eight was relieved when he was moved to a minimum security unit and his need to continuously defend himself was left behind, 'that's how it is in here, you're either going to fight or you're going to get stood over. So I was glad to get out of there 'cause I was sick of fighting”.

Being in prison was also a difficult experience for participant seven due to a constant worry of being abused by other prisoners, “(prison has) been pretty hard. It’s very confronting ...I've always got to worry about looking over my shoulder or is something getting stolen or am I going to get hit. I've always got those worries where I'm looking over my shoulder”. Participant six also spoke about other prisoners standing over him, calling him names and giving him a hard time whilst he was housed in the main location of a correctional centre. He however perceived the reason for this to be because it was his first time in custody, and because of the nature of the offense that he had been convicted of, "if you're in for a serious charge like murder or rape or something like that, they used to try and make your life hard, because my charge was high profile around the area and, yeah, they used to try and make my life as difficult as possible”.

A number of other participants, like participant six, spoke of experiencing name calling. However unlike participant six they often could not comprehend why. Participant three for example, spoke of an incident where another prisoner called him an 'idiot' and was unable to explain a reason for why this happened. Participant seven also spoke of an incident where another prisoner "barked" at him and called him a "gonk" without understanding why this happened. And participant four spoke of how other prisoners irritated him because they call him names, "people annoy me ... (by) name calling”. Participants dealt with the stress associated with name calling by reacting in aggressive ways. For example, the reaction of both participant three and participant seven to experiencing name calling was to react back by raising their voice and wanting or attempting to physically fight back. Participant four attempted to 
ignore the other prisoners when they called him names but stated that when he couldn’t he fought them, “(I) try to ignore them, but if I can’t I fight them”. Participant three described his uncontrollable reaction to being called an idiot, 'I can go off my nut really quickly ... I went off on another prisoner because he was going off his head and I just snapped and went off at him ... he was just calling me an idiot”. In talking about his aggressive reactions in situations requiring social mindedness, participant three similarly spoke of an incident with a correctional officer when the officer did not explain his tobacco situation properly to him, "I asked one of the officers if I could get a bit of tobacco and they said 'what tobacco, there's no tobacco here' and I just lost it really quickly”.

Participant seven too spoke of wanting to react to being irritated by other prisoners with physical violence. He described how a social interaction with another prisoner centred on televised sport could escalate to such a reaction where he would get really annoyed because he had to argue his version of events: "I’m a really big fan of sports, I love my sport... Every time the cricket, football ,car racing, everything's on, tennis, whatever, I'll watch it and if someone tries to talk to me about something I really like, like cricket, car racing, football, and there's a team or something I know about, a certain team, and they try to go 'oh no, this happened, this, this, this...' it just, it really ticks my engine, it just makes me really aggro and I just get really angry with and I start getting shitty and then I just start getting fired up”. The certainty associated with knowing the sport-related facts for participant seven was reassuring and the questioning of this certainty was anxiety provoking resulting in a stressed reaction of aggression towards the other prisoner responsible for invoking the uncertainty. He described how he becomes uncontrollably aggressive with others, "I'm the type of person I don't care what the size you are, what the size of the person is, if I'm ticked off I black out, I don't know what I'm doing, I don't know who I'm doing it to, if I'm hitting someone or dumping on someone or whatever”. But participant seven had to tame his aggression in prison in fear of being punished for altercations with other prisoners, “when I was younger I used to just fight ... whoever was pissing me off, I'd just smack 'em in the mouth but now I can't do that because I'm in here and there's worse consequences to that in here than outside ... here there's lock-ins, there's no phones, no visits, no nothing ... so now I have to sort of keep myself under control”. 
Some participants also found themselves in social situations with other prisoners where they were unable to successfully maintain a balance of power in their relationships. Participant six for example disliked sharing his cell as he had experienced cell mates who exerted control, "like a lot of them are dominant with the TV”. Similarly participant seven had cell mates who told him what he could and couldn't do in the cell, "I've had a few people (cell mates) put verbals on me ... just sort of laid down rules and said, 'you've got to do this, you've got to do that' ... like, 'I want to watch what I want to watch’ or you can’t go to the toilet after lock-in, 'can’t do this. Don’t drag the chair. Don't do that.' Just some of that sort of stuff that's real small but, yeah, they do it themselves”. His subdued reaction was to avoid confrontation and to let the cell mate have control, "I just did what I had to and just got it over and done with”. Control, for participant six, was also exerted by other prisoners outside of his cell also and like participant seven he reacted submissively. He spoke of one incident where, when it became his turn after waiting in line to use the phone, another prisoner took claim on the phone usage, "I jumped on the phone and then he said 'oh, rah rah's next, this guy’s next', and I thought, well he was just on the phone and, I don't know, I was going to have an argument and then I thought no, stuff it, just let it go”.

Participant five also spoke of experiencing altercations with other prisoners. In one such instance he was assaulted by another prisoner following an altercation over something of his that had been stolen. Like participant two, who told on prisoners who were attempting to stand over him to correctional officers, participant five was also unable to justify and abide by the imposed prisoner code of not telling on another prisoner, “a young guy who punched me in the eye and I thought, 'oh stuff this', and just reported it ... and everyone turned nasty because that's something you don't do. And I said, ‘well, where did I sign up for these rules?' you know oh, you don’t dob, I said, 'sorry, I didn’t sign up for it, you know, these rules may help you but they don't help me and I didn’t sign up for them. I don't agree with them and I don’t accept them, so bad luck”. In a similar experience participant seven expressed an understanding of the prisoner code of not dobbing in, but in an incident where another prisoner threw tomato sauce on his head he went to tell the officers knowing that he shouldn't dob them in but the officers were too busy to talk to him at that time, "I went up to the office... I said 'these fuckwits down here in my wing put tomato sauce 
on me... they said 'what happened?' I said... 'I'm not dobbing them in', and then they're like 'well come back in five minutes' cause I wanted to tell them, I wanted them to sort it out and tell them look, you can't do this”.

\subsection{Coping with social-related demands through self-isolation and avoidance}

Participants chose to isolate themselves from other prisoners as a means to cope with the social difficulties such interactions posed. Participant five summed this up, "I have difficulties with other prisoners in particular, so I can’t fit, won’t fit in”. Participant five perceived his social difficulties with other prisoners to be directly related to being unable to relate to them. He was therefore selective in who he interacted with as a way of managing his social-related anxieties and this enabled him to engage in social interaction on his terms only, “there’s no common ground with most people.

Occasionally you get some white-collar people who have something a little more intellectual to say ... but that's few and far between”. To avoid interacting with other prisoners participant five was isolative and lived within his own world, "it's isolating because things that I just don't think about, because I'm always - you know, I'm pacing and I'm wondering about something, and I'm just simply not aware of things that other people find important ... people call it aloof, but it's not aloof. It's you're in your head and you're thinking about something and you're not wondering about which path you've cut across or what - you know, you're just not focused”. Similarly participant one also avoided social attachment to other prisoners, but he saw the benefit of this being that he was uninvolved in any trouble, “I don’t get into any groups that would warrant attention (from correctional officers). My lonely little being gets by without any attention so I am fortunate. I am the one that they see but don't hear".

All participants at some point during their day sought to be alone in order to avoid social demands. Six participants spoke of choosing to eat in their cell alone. Participant three ate alone because he was afraid of other prisoners, "I've always gone into my cell to eat lunch... because when I first came into gaol I was classed as a RIT (a prisoner deemed at risk of self-harm) and I was locked in my cell 24/7 ... (it) turned me into a person who was afraid of everyone because I couldn't associate with people”. For participant five his cell offered him a place to escape from enforced 
social interaction with other prisoners at mealtimes. Participant five had one other prisoner whom he felt comfortable enough with to sit and eat dinner with on his own terms, otherwise he chose to avoid the social situations centred around mealtimes by eating alone in his cell, "I've got a recent guy here, an accountant, who I can relate to. You know, we do our own thing and we'll go and sit at the table and have a civilised sort of dinner, but otherwise you just hide in your cell ... because I didn't have the relationships where you could, you know, have more civilised discussions”. For participant eight his cell became his refuge to eat when he felt overwhelmed by the number of prisoners eating in the communal area, “if I don't feel like sitting in the lounge room, whatever, I just go in my room and sit in there (to eat) ... the lounge room 'cause it gets crowded over, 'cause everyone takes over”.

In talking about his anxiety relating to being surrounded by and in close proximity to other prisoners participant one also dealt with this anxiety by choosing to be alone, "I like to be alone ... to be surrounded by people it increases my anxiety... they can just walk into your room and say hello and try to talk to you yet you don't want to be any near them. So isolation, the only way you can stop that is by closing your door”. For participant one his cell, that he was fortunate to not have to share with another prisoner, was his haven, a haven that belonged to him in a world where beings are possession-less, "I am fortunate that I have always been in a 1-out, in my little confined space ... my little room is my space”. Cell sharing in prison is a necessity to house the vast number of prisoners. Some prisoners are fortunate to be sharing their cell with only one other prisoner (known as a 2-out cell), whereas, as experienced by participant two and participant seven, some prisoners maybe sharing their cell with two (3-out cell) or even three (4-out cell) other prisoners. A limited number of cells also exist within the correctional system to house prisoners on their own (1-out cell). However these cells being limited in number are generally reserved for prisoners who have a medical requirement for such, or for violent prisoners known to be at risk of harming a cell mate if they were to share. Despite the limited number of 1-out cells seven of the eight participants spoke of having been given such at some point during their incarceration.

Participant four preferred to not share a cell as he had previous bad experiences with cell mates who physically abused him and called him names. For him, his own cell 
enabled a way to avoid others and a consequent means of staying safe, "people just annoy me and I annoy them back and then they bash me ... (they annoy me by) name calling ... nothing happened to me at (centre name) because I was in a cell by myself”. Both participant five and participant seven too sought solitude in not sharing their cell with another prisoner. For participant five cell mates were a cause of frustration as he perceived the situation as an imposed need to socially connect with another prisoner, “you're stuck to talk with someone that you just don’t have anything in common with to talk about ... people talk complete rubbish because they feel like they have to do something - so that is a little more stressful”. When enforced to share a cell he copes by ignoring the other prisoner and blocking out any attempts of small talk made, “I just shut off ... eventually if you don’t respond long enough they stop”. This participant was able to lay claim on his own cell by using his 'legal work' as an argument for such, “because of all the legal work. You've got papers lying around everywhere that are confidential and you don't have enough room”. For participant seven his own cell provided him a place to remove himself from other people who simply provided unwanted distractions that prevented him from doing what he chose to do, “being in such a, I don’t know, clustered environment it's hard for me to be free. The only good thing about this gaol is I'm 1-out. What I mean by 1-out, I can do what I need to do without any distractions, and being in such a big environment where there's always people around, there's always things going on, there's always distractions".

Both participant two and participant eight spoke of being fortunate to have spent time during their incarceration sharing a cell with a family member. This enabled them to avoid the enforced social contact associated with cell sharing that wasn't on their terms. Knowing their family member provide comfort and ease from a social perspective. For participant two this meant having a cell mate who understood him for being different, "he understands my mental illness. Other people if they share a cell with me they think far out this man's crazy". And for participant eight sharing a cell with his uncle meant staying safe for the lengthy time periods he was locked in his cell, "if you're in with the wrong celly (cell-mate) they could bash you, stand over you all night; they can do anything being in the cell because you're in there all night, 16 hours a day. Basically you're screwed for 16 hours if you get in the wrong celly. And I'm glad that I didn't. I'm glad that I got put in with my uncle”. Having multiple 
generations of the same family incarcerated at the same centre and time is not unusual especially at rurally based correctional centres.

Although on occasions participants had no control over the social demands associated with cell sharing, other social situations in prison that demanded them to be social were avoided by participants when possible. For participant two the anxiety associated with his communication and social difficulties manifested as a phobia of physical contact with other prisoners and staff, "I have difficulties communicating with people, getting close to people, shaking hands with people and interaction with others". To manage this anxiety he chooses to isolate himself from others, "I can't pick and choose these people so I would rather stay away from them all”. This even included staying away from, or avoiding, working in prison so that he would not be put in a situation where he would have to shake hands with the boss. Being searched for participant two was also a negative experience as it entailed physical contact. Participant two described the act of being physically searched by correctional staff, "sometimes I have bad experiences with the officers. Because they try and search me you know they like to touch and uh do this and that”. This imposed physical contact induced anxiety, manifested by compulsive hand cleaning, for participant two, as he stated when asked what happened when he was searched, "I get very ah, anxious and a lot of anxiety. Yeah like I will scrub myself that many times (referring to an earlier statement he made that he washes his hands 40 to 50 times a day)”. Participant two further spoke of his experience in a maximum security correctional centre where his fear of interactions of other prisoners meant he avoided contact despite not experiencing anything more than small talk from other prisoners, "what was scary is your chucked in the yard all day with a hundred prisoners, no officers and every one of them is a violent offender ... some of them tried (to talk to him) ... just make general conversation like hello how are you and I thought oh what's going on here you know, something's going on ... I try and avoid them ... I tried to do my own thing and got along with myself”. Participant two continued to liken this experience to his current experiences of being housed in a prison mental health unit where when prisoners make conversation with him he has to ask them to keep their distance; therefore the social contact is on his terms, "even in the mental health pod now people come and talk to me there has to be distance between us. I say look stand back a bit”. Participant two also attempted to regain control of his anxieties in social situations 
with other prisoners by undertaking a ritual in order to choose who to interact with or who to isolate himself from, "I would talk about, pretty much how long they have been in the system for, where they come from on the outside, what they like doing, and if I see a good match, like someone that's actually in my category”.

Social situations with other prisoners for participant six were dominated by other prisoners making his life difficult because he had been charged with a violent offence, "just workers and that sort of thing like giving you a hard time and that because of your charge - my charge". He therefore chose to avoid these situations by making a request to correctional staff to be by himself. A consequence of this request however was for him to be housed in a segregation unit where the majority of the time he would spend was locked in his cell alone with little or no privileges, "I was in my room for six weeks just in my undies, nothing else. I was getting out an hour a day and, for another three months after that, I was in a room by myself. I had clothes and a bed but that's it. I never had phone calls or anything, and that was because I spoke to the governor and I wanted time out by myself because I had problems with other prisoners ... I wanted time out because I had problems with other prisoners giving me a hard time”. Whilst this provided him a means of social isolation for him being housed in segregation was punishment, “(I) wanted to be by myself ... and they ended up just throwing me in solitary confinement by myself for nothing when I hadn't done anything wrong”.

Participants generally spoke of being socially acquainted with other prisoners, however most often referring to these other prisoner as associates or acquaintances rather than being friends. Participant four stated that he did have some friends in prison but when it was explored further the contact he had with these so called friends was not interaction based, "(I have) a couple (of friends) but not that many ... I saw my mate twice in one day walking past my wing”. Participant six identified having social relations in prison but had difficultly identifying these persons as friends, "(I) sort of have a few people I guess you'd call mates ... "they're not really friends; they're just people I associate with and talk to, you know, like two or three people, that's it”. Participant seven and eight similarly referred others as just people they could talk to or hang out with rather than friends, "You can talk to people but they wasn’t your friend” (participant eight) and “I wouldn’t really say friends but people I 
can sort of hang out with” (participant seven). Participant three, in talking about having friends claimed to have them, like them, and spend time with them, "(I) sort of (have friends) ... (they’re) really nice ... (I spend) as much time as I can (with them)”. Yet he chose to part take in activities alone rather than with his friends. When questioned further about his relation with his friends he identified having only other prisoner he spoke to whom he had known outside of prison and other prisoners were just people he knew of, they were acquaintances, but not friends because he hadn't known them long enough. His attempts to make friends with these prisoners were dampened by his social impairments and his advances were rejected, "no (I don’t have other friends) just associates ... people I know but don't really want to be friends with ... because I haven't known them long enough ... I try to (get to know them) but sometimes they don't want to get to know me ... because they think I'm a retard ... because certain things have to be explained out in simple form, people have to dumb things down so that I can understand it better”. He copes with this social rejection by isolating himself from the other prisoners. He spoke repeatedly of wanting to be alone, "I like to keep to myself” and "I like to have my privacy”, and spending lengthy periods of time in cell on his own, “(in the afternoons I go) back into my cell and try to get some more sleep ... (for) four to five hours”. When questioned further on how he spends his time he spoke of activities, the majority of which he did alone, whether that was playing cards by himself, “I usually play solitaire”, or even playing squash by himself, "some people would offer me a game of squash and sometimes I turn them down; I would rather play with me self”. Choosing to partake in activities alone was too described by participant four and participant six. Participant four's daily activities were "drawing and reading" and "hanging around the yard" all of which he did alone to avoid the irritation cause by the company of others "they're (other prisoners) just annoying... like they get on your nerves, talk too much or something”. And participant six's activities involved jogging laps around the prison sports oval by himself and studying for his HSC most of which was done alone in his cell, "most of the work I'm doing in the cell”.

Being able to work free from social demands was also favoured by participant one. Being a sweeper for participant one meant he was able to work in solitude and he sought to work only in solitary positions within the prisons, "I painted all the cells here ... and then another sweeper job where I was by myself. The positions I've been 
in are fortunate enough that I have just been able to do by myself it was just the stipulation with the employment. I told them that I was Asperger's, my needs for working alone, these need to be met”. Although not completely free from working with others like participant one, participant eight liked his job sanding and painting pallets because work offered him a sense of escape from the social demands as no talking was allowed in the workshop, "Its good when you actually get into the shed and work. There's, well no talking, just work and you've got a radio to listen to music”. These participants took comfort in the removal, for short periods of time, of social demands. 


\section{Discussion}

The current study aimed to examine the lived experience of incarceration for those with autism currently imprisoned in the New South Wales correctional system. The lived experience of incarceration for the participants of this study was about being in an unpredictable environment characterised by ever-changing routines, incomprehensible rules and actions by the controllers, and complex social situations. Experiencing anxiety was a prominent theme throughout participant interviews. For participants, anxiety stemmed from being deprived of their ability to create predictability in their environment, and the confusion and distress experienced by being forced to comply with actions that were in conflict with their logic. The environment further allowed participants to isolate themselves and avoid social interactions as a form of maladaptive coping with the social-related demands of incarceration. The discussion that follows aims to examine these experiences in light of what is known about autism and to situate these experiences within the neurotypical experience of incarceration portrayed in existing literature in order to identify that which is unique to those with autism.

\subsection{Participant experience and what is known about autism}

The findings presented in this study are consistent with the findings detailed in the one published study examining the incarceration experience of those with autism by Paterson (2008) that explored the problems encountered by two individuals with Asperger's Disorder who were incarcerated in a UK prison. Like the majority of participants in the current study the first person presented in the case example by Paterson (2008, p. 55) was described to have "customised his own routine within that of the prison”. This routine involved engaging in rigid adherence to his self-imposed routine of cell cleaning, very similar to participant two and participant eight in the current study who also engaged in a self-imposed routine of cleaning their cells. Other self-imposed routines of the participants in the current study included writing, undertaking 'legal work', and repeatedly using the phone. Another participant had two set self-imposed routines; one standard and another that he undertook during periods of lock-ins. Engagement in idiosyncratic routines, such as those of the 
participants in the current study, for persons with autism has been suggested to act as a coping mechanism for anxiety and distress by enabling predictability and a subsequent sense of organisation (Mercier, Mottron \& Belleville 2000; Muskett et al. 2010; Spiker et al. 2012). This appeared to be the case for participants in the current study whose self-imposed routines provided them with predictability in an environment characterised by chaotic routines and social situations. When participants were unable to undertake their idiosyncratic routines the consequence was increased experience of distress and anxiety. For participant two and participant six, for example, the distress they experienced as a consequence of disruption to their selfimposed routines when they were transferred to a different correctional centre was so great that correctional staff perceived them to be at risk of self-harm and they were consequently placed under constant supervision for their own safety.

In the current study the participants' engagement in self-imposed routines also provided a way for them to occupy their time, as not only did the prison environment offer little structure in their day, but the participants often spent long periods of time locked in their cells. Self-imposed routines enabled participants to focus their attention on structured activities, for example, specifically defined reading or writing, motivations to access the phone or on cleaning-based rituals which relieved anxiety and provided comfort through sameness and predictability. On occasions unexpected changes to prison routines inhibited their ability to undertake such routines which in turn caused anxiety. Similar experiences were presented in a Canadian psychosocial study on the restricted interests of six individuals aged 19 to 52 years with DSM-IV diagnosed Autistic Disorder or Asperger's Disorder (Mercier, Mottron \& Belleville 2000). From participant interviews restricted interests were described by participants as a source of calming pleasure, with one participant describing it as, "a measure of predictability and a security in the sense that you know that you have something interesting to do, that you are looking forward ... no surprises” (Mercier et al. 2000, p. 415). It is of note that the restricted interests of the participants interviewed by Mercier and her colleagues included collecting items such as dolls and postcards, listening to music in a repetitive way, and seeking to obtain knowledge relating to a precise area such as on insects or watches. However the prison restrictions related to contraband meant that participants in the current study were not allowed to pursue any similar pleasurable interests hence they resorted to what they could, such as cell 
cleaning and making phone calls. Arguably these activities are more about curbing anxiety rather than being enjoyable, as experienced by the participants in the study by Mercier and colleagues (2000).

The cognitive theory of executive dysfunction in autism may also be used to explain the restricted patterns of behaviour of some participants in the current study. Executive functions are, "higher-order cognitive abilities necessary for flexible and adaptive behaviour in the service of novel gaols” (Happe \& Frith 2006, p. 17). Whilst in children with autism deficits in executive functioning include planning, flexibility and inhibition, greatest deficits in adults with autism are seen in cognitive flexibility (Hill 2004). Cognitive flexibility is required for dealing with novelty and unpredictability. This may explain why the participants in the current study engaged in self-imposed routines and had difficulties with the unpredictable aspects of the prison environment as they were unable to adapt their behaviour to different situations. This is supported by a study examining how the cognitive abilities of 17 adults with Autistic Disorder related to the behavioural symptoms of autism (Lopez et al. 2005). By determining the bivariate correlations between restricted and repetitive behaviours of participants (measured using the ADOS-General, ADI-Revised, Gilliam Autism Rating Scales and Aberrant Behaviour Checklist-Community) and measures of executive functions (measured using the Delis-Kaplin Executive Function Scale) deficits in cognitive flexibility were found to be significantly correlated with restricted and repetitive behaviours $(\mathrm{p}=.007)$. Whilst the executive functions of working memory and planning were also found to be positively correlated with restricted and repetitive behaviours ( $\mathrm{p}=.02$ and $\mathrm{p}=.02$ respectively), no significant correlations were found between restricted and repetitive behaviours and planning or fluency ( $\mathrm{p}=.74$ and $\mathrm{p}=.07$ respectively). From standard multiple regressions, cognitive flexibility was found to be the only impaired executive process to predict a uniquely significant portion of variance in restricted and repetitive behaviours. However this finding was not supported by further exploratory analysis (Lopez et al. 2005).

Participants in the current study also had difficulties with the comprehension of prison routines and rules. On occasions this related to a conflict with the imposed routine or rule and individual logic: for example, not understanding the logic behind routines 
relating to prison transfer and classification procedures, and visitation procedures. This at times rendered the imposed routines or rules strange and incomprehensible to the participants. Difficulties with the comprehension of rules for the participants in the current study may also have been related to communication difficulties where pragmatic language impairment rendered them unable to follow complex instructions given by correctional staff. Difficulties with decoding complex instructions are associated with comprehension difficulties in persons with autism (Howlin 2004). Failure of incarcerated persons with autism to respond appropriately to instructions given is likely to be misinterpreted as being uncooperative by correctional staff and may result in a penalty such as being formally charged and punished for not following routine. The difficulties comprehending routines and rules meant participants in the current study were at times unable to predict what they were meant to be doing, resulting in confusion and distress. Frequent prison transfers added to difficulties experienced by participants relating to being unable to comprehend and correctly follow prison routines.

For incarcerated persons with autism, having weak central coherence would hinder their ability to apply what they have experienced from one correctional centre to another. For example, being able to apply the routines of one correctional centre to another when transferred from one correctional centre to another. Kanner, in his original work, recognised this process in his subjects: “A situation, a performance, a sentence is not regarded as complete if it is not made up of exactly the same elements that were present at the time the child was first confronted with it. If the slightest ingredient is altered or removed, the total situation is no longer the same and therefore it is not accepted as such” (Kanner 1943, p. 246). Therefore although the fundamental routines, such as muster and lock-ins, may be a common factor amongst different correctional centres, persons with autism are likely to have difficulties accepting such commonalities. This is because, for them, it would be a whole new routine to learn and adjust to as detail at the local level is different, for example the physical environment, the people, and the timing of the fundamental routines. This may partly explain the heightened distress, anxiety and confusion experienced by some participants in the current study when they were transferred to another correctional centre. This is supported by a study that examined the role of weak central coherence in event schemas (generalised knowledge of what happens at common social 
scenarios) in 21 individuals aged 8 to 28 years with Autistic Disorder or Asperger's Disorder (Loth, Gómez \& Happé 2008). The participants in this study showed local processing preference where there was a tendency for actions to be represented at the individual exemplar specific level rather than global level, supporting the notion that weak central coherence impacts on ability to transfer knowledge of a specific event to the same event in a different context (Loth, Gómez \& Happé 2008). It is of note however that, from a review of 50 empirical studies of coherence in autism, Happé and Frith (2006) concluded recent evidence to suggest that persons with autism can process global information but their cognitive style has a processing bias toward local processing, rather than an inability or deficit in global processing. It is therefore arguable that incarcerated persons with autism may be able to transfer some knowledge and/or experiences of prison routines from one centre to another, but this ability will vary dependent on individuals’ skill to focus on the wider picture. However being able to do such is likely to be dampened when the individual is experiencing distress and anxiety.

The impact of social impairment on the participants' ability to negotiate the social world of prison was a prominent theme in the current study. Consistent with the findings in the current study, social related anxiety in persons with autism is common. For example, one study of 41 adolescents aged 12 to 18 years diagnosed with Autistic Disorder ( $n=19)$, Asperger's Disorder $(n=16)$ or PDD-nos $(n=6)$ found that $49 \%$ of the sample scored high social anxiety levels using the self-report measure Social Anxiety Scale (Bellini 2004). However it is of note that 11 adolescents included in the sample had a previous diagnosis of anxiety, and 16 of the participants were taking medication for anxiety symptoms. This is suggestive that the sample may have been skewed toward individuals with anxiety. Another more recent study of 52 individuals aged 8 to 15 years with 'high-functioning autism' and Asperger's Disorder in Finland similarly found $57.1 \%$ of the sample exceeded the clinical cut-off for social anxiety on two self-report measures used (the Social Phobia and Anxiety Inventory, and the Social Anxiety Scale for children-revised) (Kuusikko et al. 2008). However the diagnostic clarity of the study sample is poor as whilst diagnostic confirmation was based on the ADI-revised, ADOS and ICD-10 diagnostic criteria, 'high-functioning autism' is not a diagnostic entity asserted in the ICD-10 as claimed by the authors. 
It has been hypothesised that the unpredictability and uncertainty of social situations is a cause of social anxiety in persons with autism (Tantam 2003). Difficulties with the comprehension of non-verbal communication, difficulty understanding the perspective of others and inability to predict patterns in social behaviour render social situations unpredictable, overwhelming and anxiety provoking for persons with autism (Spiker et al. 2012; Tantam 2003). In the current study, participants were constantly subjected to complex social situations characterised by hierarchies. In prisoner to correctional officer social relations, prisoners subordinate to authoritarian correctional staff. In addition to this, prisoner to prisoner social relations were centred on rules, regulations, power and abuse. Successful navigation of these situations required knowledge and understanding of the prisoner code, as well as effective communication and social skills, to avoid being vulnerable to abuse and exploitation. Central coherence is required here for interpreting complex social situations, and theory of mind skills for appropriate prediction of and response to social situations. Weak central coherence, where there is an inability to integrate local information with global information, inhibits an individual's appreciation of social context and will therefore hinder ability to adjust social behaviour appropriate for context (Schultz, Chawarska \& Volkmar 2006). Deficits in theory of mind skills have also been related to impaired social skills, as the inability to appreciate and predict the state of mind of another person inhibits social understanding (Miller 2006). Misinterpretations of social situations and incidents of ineffective navigation of social situations can be explained for these participants by these theories as discussed below. The impact of communication impairments on the participants' ability to effectively navigate social situations demonstrates the interconnectedness of the communication and social aspect of the triad of impairment.

Impaired theory of mind ability has been used to explain inhibited social understanding by persons with autism. Theory of mind is the ability to infer mental states and is required to explain and predict the behaviour of another person (Levy 2007). Theory of mind enables a person to understand the beliefs and intentions of another, to elaborate meaning and to intuitively understand social situations required for understanding and responding to social situations (Loth, Gómez \& Happé 2008). Inhibited social understanding leads to social misunderstandings, as experienced by the participants in the current study. Participant two, for example, misinterpreted the 
actions of other prisoners, such as when they wanted to socially greet him by shaking his hand or to make his bed when he had injured his hand, as acts aimed to purposively cause him distress (as he did not like physical contact or his belongings being touched by others). In these incidents the participant was unable to infer the motivations behind the actions of the other prisoners: that they wanted to be polite, make friends or assist him when they believed he needed help. A further example is that of participant three who misperceived that another prisoner was helping him by giving advice but in actual fact the other prisoner was telling him to do something so that his actions would not have negative implications for himself. In this incident the participant was unable to empathise with the other prisoner and see his perspective; if the participant did not clean his room that the other prisoner would be punished. Being unable to predict the behaviour of others based on conceptual perspective taking, and being unable to predict or appreciate the emotional states of others, such as not recognising when another prisoner is angry or sad, will result in the individual with autism lacking the skill to respond appropriately and increase the likelihood of altercations with others.

Communication skills are also essential for social understanding to take place. Impairment in pragmatic language ability for those with autism renders social conversations difficult, as non-verbal language and utterances inherent and dependant on social context are often not noticed or are misunderstood (Levy 2007; Walenski, Tager-Flusberg \& Ullman 2006). An inability to process pragmatic use of language in conversation and non-verbal behaviour correctly, such as non threatening behaviour being misinterpreted as threatening, may lead to misunderstandings and other prisoners taking offence. This may render prisoners with autism vulnerable to altercations and abuse. In the second case presented by Paterson (2008, p. 56) the person experienced problems as a result of his social impairment. This individual was observed to have difficulties in "the comprehension of abstract language and understanding subtleties in social situations”. It is plausible that the participants in the current study had similar experiences, but such interactions were misperceived as being positive social interactions. This is supported by the majority of participants speaking of having positive social interactions but when explored deeper the interactions discussed were rarely of a positive nature. For example, the friends that participant three spoke of in fact called him names and did not want to get to know 
him. Similarly in the first case example presented by Paterson (2008) the person when interviewed claimed to have friends in prison. However this was a misperception of the individual as participant observation and interviews with prison staff revealed his interactions with other prisoners to be superficial only. The result of his communication and social impairments was altercations with other prisoners as he misperceived social situations (Paterson 2008). Research exploring the nature of friendships for school children with autism has found a lack of reciprocity in friendships to be common. For example, in a study of 398 children, 17 of which had a confirmed clinical diagnosis of 'autism' or Asperger's Disorder and an IQ within 'normal range' (obtained via documents provided by parents), children with autism received significantly fewer $(\mathrm{p}<.05)$ reciprocally nominated top three peers than the matched peer group (Chamberlain, Kasari \& Rotheram-Fuller 2007). Another study of school children found significantly poorer friendship quality in companionship ( $>>$.05) and helpfulness ( $>>$.05) for seven adolescents with autism compared to 13 peers without autism using the Friendship Qualities Scale (Locke et al. 2010). However the authors state participants had received a previous clinical diagnosis of 'autism spectrum disorder'. As the term 'autism spectrum disorder' is not a clinical diagnosis listed in diagnostic manuals and details of clinical diagnoses were not provided this study is limited by poor diagnostic clarity.

The weak central coherence theory has also been related to social impairment in those with autism, as weak central coherence renders an individual unable to process social information in complex social situations that require both local and global processing ability (Happé 2003). In prison the complexity of social situations is heightened by the prison subculture. Prisoners are expected to value the prisoner code of conduct and to guide their social conduct based on the values underlying the prisoner code with failure to do so resulting in negative consequences. Inability to predict the behaviour of others on account of the prison subculture conditioning social context is likely to result in an inability to adjust social behaviour for context. Therefore the person would be rendered unable to provide a behavioural response in keeping with the values of the prisoner subculture that would be socially accepted. This was demonstrated in the dislike by participant three and seven, and fear experienced by participant two, when they were forced into certain social situations in which they were unable to respond behaviourally in a manner appropriate for the prison social 
context. These situations included being locked in the prison yard and being unable to escape the presence of other prisoners. A further example was also being forcibly placed in a social situation such as cell sharing or being placed in a holding cell before transfer to court or to another centre. These situations subjected participants to social situations characterised by small talk which participant five, for example, found great difficulty with and subsequently responded to it in a socially inappropriate manner. The difficulties associated with this phenomenon were described by participants in a qualitative study exploring the social challenges of 18 adults with 'autism spectrum disorders' (Müller, Schuler \& Yates 2008). Engaging in 'chit-chat' for participants was bewildering and dreaded because such conversation did not appear to follow a predictable set of rules (Müller, Schuler \& Yates 2008). It is of note however that the study sample included two individuals with a 'formal diagnosis' of 'high-functioning autism' despite this term not being indicated in diagnostic manuals. Two participants had received an informal diagnosis of Asperger's Disorder only. Although it was claimed the majority of participants had received formal diagnoses, detail in relation to how the were obtained was not provided by the authors. Therefore the diagnostic clarity of the study sample is poor.

The inability for participants in the current study to adjust their social behaviour in response to the prison culture rendered them vulnerable to abuse from other prisoners. This was particularly the case for participants housed in the main locations of the prison where the experience of social demands were greater than what was experienced by those who were segregated from the main prison population. All of the participants in the current study spoke of experiencing some form of bullying from another prisoner during their incarceration. Forms of bullying experienced by participants included name calling, being stood over, physical abuse, and incidents of other prisoners executing dominance. Being stood over was a common experience for the participants in the current study and all but participant eight lacked the ability to navigate the complexity of this bullying behaviour through, for example, negotiation or defence. In the first case example presented by Paterson (2008) the person was also subject to bullying from other prisoners, and was unable at times to recognise nonverbal cues that were disingenuous in demeanour. It is plausible that the participants in the current study were subject to further forms of bullying and exploitation which they did not recognise as such and therefore failed to speak of during interviews. The 
misinterpretation of bullying has been examined in a study of 230 adolescents with 'Autism Spectrum Disorders' attending special needs schools in the Netherlands (Roekel, Scholte \& Didden 2010). In this study teachers reported a greater prevalence of bullying and victimisation than the participants themselves suggesting a lack of recognition of being bullied by the participants. Further adolescents who had high self and teacher report victimisation scores were more likely to misinterpret non-bullying behaviour as bullying. The prevalence of bullying and victimisation for participants in this study was between 6 and 46\% (Roekel, Scholte \& Didden 2010). However, it is of note that the authors have detailed that 35 participants had a diagnosis of 'Autism Spectrum Disorder' based on DSM-IV criteria despite such a diagnosis not being listed in the DSM-IV. The findings should also be considered in light of the fact that more than half of the sample $(n=123)$ had a diagnoses of PDD-nos, therefore having sub-threshold behaviours across the triad of impairment.

The difficulties that persons with autism have with emotional processing may result in their reactions to experiencing bullying or abuse in prison being beyond that which would be expected of neurotypical prisoners. Difficulties with emotional processing for persons with autism are related to deficits in theory of mind where the individual has impaired ability to infer and express thoughts and emotions (Hill, Berthoz \& Frith 2004; Losh \& Capps 2006). Rather, persons with autism have a tendency to focus on the external as opposed to inner event (Hill, Berthoz \& Frith 2004). This was evidenced in the participants of the current study. For example, the reaction of participant five to being hit by another prisoner, rather than express feelings of anger for example, was to seek justice in the form of formal charges against the attacker. This was despite such an act being considered minor and not warranting further attention within the confines of the prison culture. And for both participant two and participant five their reaction to experiencing an incident of bullying was to go against the prisoner code of conduct by reporting it to correctional staff, even though they had awareness that doing so had negative implications for them. The reporting of the incidents for these participants in all likelihood enabled them a means to express their feelings using concrete thought by focusing on the external event.

Difficulties with emotional processing may also explain the aggressive responses of the participants in the current study to the distress and frustration they experienced in 
the context of social interactions. For example, participants three, four and seven responded to being called names with physical aggression, and participant seven spoke of reacting aggressively when he was required to argue his version of sportrelated events. These participants did not perceive their aggressive reactions to be out of order. In discussing the challenges associated with adolescents and adults diagnosed with Asperger's Disorder being aggressors, Tantam (2003) highlighted that it is not uncommon for such individuals to perceive their acts of aggression to be justified in certain situations, such as when they feel they have been unfairly treated by others. Similarly both individuals presented in the case examples by Paterson (2008) also demonstrated aggressive outbursts to other prisoners. The aggressive outbursts for the first individual were associated with the agitation he experienced when in social situations, and for the second individual his aggression was in response to frustration he experienced. However, examples of situations in prison that caused him frustration were not identified. Both of these individuals got into trouble with prison authorities as a result of their aggression (Paterson 2008). Aggression is not uncommon in children and adolescents with autism. In a study of 176 children with DSM-IV-TR diagnosed Autistic Disorder, Asperger's Disorder, and PDD-nos, using an informant rated 18-item questionnaire to identify and assess challenging behaviours, found that aggression towards others as a form of externalising challenging behaviour was evident in 50\% of the sample (Matson, Wilkins \& Macken 2009). Responding aggressively for the participants in the current study may also be related to theory of mind deficit, where the inability to empathise resulted in them being unable to consider the effects of their aggression on others. Aggressive behaviours in a person with autism are likely to worsen when the person is frustrated and/or anxious (Tantam 2003).

It has been suggested that aggressive behaviour towards others in persons with autism is associated with social related frustration, not only resulting from social impairment, but also resulting from social rejection from others (White et al. 2012). Social rejection was experienced by participants in the current study in the form of nonacceptance from other prisoners. It is therefore plausible that being socially unaccepted by other prisoners in general contributed to their experiences of social frustration and subsequent aggressive reactions in some social situations. This is supported by a study of 618 college students in the US where Autism Spectrum 
Quotient scores of participants (indicating the degree to which they had behavioural features associated with autism), and symptoms of social anxiety were strongly correlated and significantly associated ( $\mathrm{p}<.001$ ) with hostility (White et al. 2012). In this study Autism Spectrum Quotient scores were also correlated with other measures of aggression (physical, verbal, and anger), but were not associated with social anxiety (White et al. 2012). Hostility in this study, measured using the Buss and Perry Aggression Questionnaire, was defined as "the tendency to believe that one does not receive fair treatment" and hence was related to the perception that one is being socially rejected (White et al. 2012, p. 5). However the study sample was nonclinical (i.e. individuals who did not have a diagnosis of autism) and therefore needs to be interpreted in the context of autism with caution.

A further response to anxiety and distress caused by social-related demands for the participants in the current study was self-isolation and avoidance as maladaptive coping strategies. Participants sought to avoid social demands through eating and undertaking activities alone, requesting not to share a cell and having solitary working positions. In extreme circumstances the solitude of protection units was also sought by participants where the majority of time was spent locked in a cell alone. Similar participant behaviour was also presented in the study by Patterson (2008). In the first case example the person presented in this study spent the majority of his time in his cell, for which he gained approval from prison authorities to do so in order to avoid confrontations with other prisoners (Patterson 2008). In the second case the person also chose to spend his time in his cell and not associate with other prisoners on the unit to avoid social interactions with others. Paterson (2008) highlighted the actions of staff that encouraged these individuals to seclude themselves in their cells to be of no therapeutic value to the isolated individual. In the second case the person was also housed in a healthcare unit due to his vulnerability to being bullied. This added to his isolative behaviour as there were fewer implications of not following prison routines in healthcare than what he would have experienced in the main location of the prison. In healthcare he was allowed to choose to remain in the confinement of his cell. Similarly four of the eight participants in the current study were housed in isolation from the main prison location at time of interview. These locations were a mental health unit, developmental disability unit, segregation and a behavioural unit. Of the four participants housed in the main location of the prison, they spent the majority of 
their time in their cells and only one had a cell mate. By being placed in isolation by correctional authorities, or by choosing to isolate themselves, participants' were able to gain relief from bullying, being required to engage socially with others, and from crowded social scenarios.

A tendency for social withdrawal and avoidance in persons with autism has been suggested to be related to rejection from peers and social failure (Attwood 1998). Social withdrawal acts as a reinforcement of social phobia as the person avoids situations that will highlight their social skills deficits or situations that are likely to lead to social rejection (Bellini 2008). This is supported by a study of social anxiety in 52 children and adolescents with 'high-functioning autism' and Asperger's Disorder, that found participants reported an increase in social anxiety and behavioural avoidance as they grew older (Kuusikko et al. 2008). Similarly a qualitative study exploring the social experiences of 18 adults with 'autism spectrum disorder' found all but one participant experienced intense isolation that increased as they became older and more conscious of being 'different' to their peers (Müller, Schuler \& Yates 2008). However, both these studies are limited by poor diagnostic clarity of study sample as discussed previously. It is of note that participants in the current study spoke of perceiving themselves as being different to the other prisoners, and isolation was used to avoid socialising with peers. Long term social isolation and rejection are likely to be contributing factors to symptoms of anxiety and depression in persons with autism (Müller, Schuler \& Yates 2008; Tantam 2000). Further to this, it has been suggested that persons with autism who are sensitive to hyper-arousal are at increased likelihood of feeling overwhelmed by social interactions (Bellini 2008). As a result, the experience of negative peer interactions and subsequent social anxiety is increased (Bellini 2008). This is supported by a study of 50 individuals aged 6 to 17 years with DSM-IV diagnosed Asperger's Disorder that found positive relationships between anxiety and hypersensitivity to sensory stimuli (Pfeiffer et al. 2005). Sensory modulation, anxiety and adaptive behaviours were measured using the parent report instruments: the Sensory Profile, the Adolescent/Adult Sensory Profile, the Revised Children's Manifest Scale Adapted Parents Version, and the Adaptive Behaviour Assessment System. A significant positive correlation $(\mathrm{p}<.000)$ between sensory hypersensitivity and anxiety was found, and hypersensitivity was significantly inversely correlated $(p<.05)$ to social skills (Pfeiffer et al. 2005). Sensory stimuli, 
leading to hyper-arousal for persons with autism, in the correctional environment include large numbers of prisoners in small enclosed spaces. This was evidenced by the distress experienced by participant two and seven when locked out into the crowded prison yard. Other sources of sensory stimuli include the noise of prisoners talking and officers shouting orders. This was evidenced by participants' four and five dislike of other prisoners because they talk too much and by participant six negatively experiencing muster as for him this routine was about officers shouting orders. Prison doors and gates slamming may also be a source of sensory stimuli, for persons with autism, in the correctional environment.

Isolation provided relief from social demands for the participants in the current study, and like the individuals in the case studies presented by Patterson (2008), enabled a way for correctional authorities to manage a vulnerable prisoner as a way to protect them from being bullied, abused and exploited. However, the actual therapeutic value of isolation as a coping mechanism is questionable, as it may arguably worsen symptoms of distress and anxiety. Situational experiences such as isolation and bullying have been associated with psychological distress in incarcerated individuals. For example, the psychological distress of incarcerated young offenders aged 16 to 21 years in Scotland was examined in four groups of prisoners: prisoners under strict suicidal supervision $(n=25)$, prisoners housed in protection units $(n=25)$, prisoners who were self-identified victims of bullying housed in the main location of the prison $(n=25)$, and a comparison group of prisoners housed in the main location of the prison with no known history of experiencing victimisation or bullying $(\mathrm{n}=25)$ (Biggam \& Power 1999). Psychological distress was measured using the Hospital Anxiety and Depression Scale and the Beck Hopelessness Scale. Mild to moderate depression was found in the suicidal supervision group and victims of bullying group, mild to moderate anxiety was found in the suicidal supervision group, victims of bullying group and the protection unit prisoners group, and clinical levels of distress using the Beck Hopelessness scale was also found in the suicidal supervision group, victims of bullying group and the protection unit prisoners group. Normal levels of depression, anxiety and hopelessness was found in the comparison group. It is of note that the depression score of the suicidal supervision group was the only score that differed significantly from the other groups. Whilst a high incidence of psychological distress can be expected in suicidal prisoners, this study highlights the psychological distress 
experienced by other prisoners who are subject to social isolation such as victims of bulling housed in the main locations of prisons and prisoners isolated on protection units. Further a qualitative study using focus group method of 31 prisoners in the UK to explore the influence of environmental factors on prisoner mental health concluded that long periods of isolation led to the experience of intense anxiety, frustration and anger (Nurse, Woodcock \& Ormsby 2003). In this study the prisoners subject to long periods of isolation were remand prisoners as work and programs were not available to them and prisoners housed in segregation units for their own protection. However, it is of note that the prisoners in these studies did not have autism. The short and long term psychological effects of housing a prisoner with autism in isolation are unknown.

\subsection{Comparing participant experience with the neurotypical experience of incarceration}

The discussion so far has focused on how the experiences of incarceration for the participants in the current study are attributable to the impairments associated with autism. However, it is fruitful to explore how the participant experiences compare to the neurotypical experience of incarceration as portrayed in the literature. The neurotypical experience of incarceration, as detailed in the literature review, is characterised by deprivation and loss of freedom and the adjustment to a prisoner subculture that is defined by hypermasculinity, hierarchies and a prisoner code of conduct.

Personal autonomy that is restricted by being forced to surrender control to imposed prison routines, such as being made to work, attend muster, and spending time locked in a cell have been identified as deprivations experienced by incarcerated individuals without autism (Bereswell 2004; Korn 1994; de Viggiani 2007). For the participants in the current study their experiences with imposed prison routines were about being deprived of their ability to regain control of their world. Participants sought to impose their own routines to provide structure in their environment in their attempts to seek predictability and sameness. However, enforced changes to prison routines often caused great distress as they were left unable to follow their self-imposed routine. Regular imposed transfers meant disruptions to self-imposed routines and 
consequences of such were distress and anxiety. It is of note that anxiety has also been associated with a lack of officer support in relation to adjustment to and awareness of prison routines in neurotypical prisoners (Biggam \& Power 1997). For the participants in the current study, anxiety was associated with the lack of uniformity of prison routines. This was due to the routines being imposed differently by different correctional officers and an inability to, on occasions, comprehend and therefore follow prison routines. Receiving contradictory information from officers has also been highlighted by neurotypical prisoners (de Viggiani 2007).

Regular movements between prisons have also been described by neurotypical prisoners to make adjustment to routines difficult and negatively impact on their ability to develop relationships (de Viggiani 2006). Neurotypical prisoners have access to structured work programs, such as those provided by industries. Therefore they arguably have a more structured environment in comparison to prisoners who do not have access to such structured work programs due to their seclusion from the main prison population. For example, the majority of participants in the current study did not have access to work programs provided by industries because they were housed in healthcare or protection units. Other participants worked only as a sweeper where regularity and structure was lacking. Underemployment in the prison system has been described to result in boredom, idleness, apathy and lack of motivation in neurotypical prisoners (de Viggiani 2007).

The greatest loss of liberty endured by the majority of participants in the current study was the long periods of time locked in their cells. Five of the eight participants in the current study had at some point during their incarceration been housed in isolation from other prisoners for their own protection against bullying and victimisation. This meant being locked in their cells for the majority of their day rather than being able to attend work/training programs, activities or associate with other prisoners. Three of these participants had been fortunate enough to have been housed in isolation on a closed unit, i.e. health care or behavioural units, and were therefore confined to the unit rather than their cell, but were still excluded from mainstream prison activities such as working. Segregating at-risk prisoners has been a way of managing vulnerable prisoners for many decades (Carlton 2009). However long-term confinement of neurotypical prisoners has been identified to be detrimental to their mental health, 
specifically increasing problems such as anxiety, depression, irritability and aggression (Carlton 2009; Haney 2003; de Viggiani 2007). The unexpected lock-ins experienced by the participants in the current study compare to the neurotypical experience. But for the participants in the current study, unlike neurotypical prisoners whose focus was on loss of liberty, the unexpectedness of the lock-ins was more the cause of distress and anxiety.

Being subject to an authoritarian management style whilst incarcerated has been identified as part of the neurotypical experience of incarceration, with the enforcement of prison routines and rules being highlighted as a source of conflict with prison staff (Ashkar \& Kenny 2008; Johnson \& Chernoff 2002; de Viggiani 2007). Correctional officers exerting control through giving orders was also a source of negative interactions for participants in the current study. Participants in the current study additionally experienced conflict with officers giving orders as directions given were not in a clear and explicit format. This is evidenced by participant five who was repeatedly getting into trouble for not following routine.

The physical environment of prison has been associated with a loss of privacy for incarcerated individuals. Characteristics of the physical environment accounting for this include overcrowding, locked doors and gates and constant surveillance (Ashkar \& Kenny 2008; Doyle 2003; Korn 1994; de Viggiani 2007). Being in constant close proximity to others, including sharing a cell, has been described to be a highly stressful aspect of the incarceration experience by neurotypical prisoners (de Viggiani 2006). For the participants in the current study their loss of privacy meant being unable to avoid the social demands associated with being surrounded by other prisoners. This was a source of anxiety and distress for participants as, for example, they were subjected to other prisoners attempting to make small talk with them when sharing a cell, when locked in temporary holding cells, or when locked out into the prison yard. A number of participants at some point during their incarceration were subject to constant surveillance in the form of constant observation by officers under safe cell conditions. This experience for participants however was focused on the disruption this caused to their self-imposed routines, or to the lengthy periods of being locked in, rather than on a loss of their privacy. 
It has been theorised that prisoners engage in an adaptive process to cope with the deprivations associated with incarceration which accounts for the formation of the prisoner subculture (Sykes \& Messinger 1960). The prisoner subculture is characterised by hierarchies of the dominant and masculine exploiting and abusing the fearful and vulnerable prisoners in order to achieve superordinate status (Kupers 2005; Newton 1994). Male prisoners are known to compensate for deprivations experienced and enforced submission to prison routines (and the enforcers of the routines) through hypermasculinity in the form of exerting dominance and power over the weak and vulnerable (Newton 1994). As a result of this dominance the experience of bullying and victimisation by neurotypical prisoners is common (Ireland 2000; South \& Wood 2006). The majority of the participants in the current study were able to recognise that they were vulnerable to bulling for being different, for not standing up for themselves, and for having mental health issues. Their impaired ability to initiate and sustain friendships also meant they were unable to associate with influential peers who may have provided some form of protection from being bullied. In order to cope with prison, neurotypical prisoners have described their attempts in prison to not be perceived as weak by other prisoners in order to avoid being targeted by bullies. An ethnographic study in a UK prison found such attempts to include putting on a false façade of being tough and confident, and engaging in 'prison talk' (such as offensive humour, sexist and homophobic banter and macho talk) as a way of becoming socially accepted (de Viggiani 2006). Adopting a confident façade and overtly expressing masculinity was also expressed by neurotypical participants in a qualitative study of seven prisoners in Australia (Korn 1994). A person with autism is likely to have difficulty understanding the complexity of this hierarchical-based social system and consequently be unable to align themselves with the social values required for successful integration. This is evident in the participants in the current study who made no attempts to become socially accepted as a way of avoiding being bullied. Rather participants responded with aggression and isolated themselves as a way to cope. Further to this, underlying the prisoner subculture is a distinct set of values that relate to a form of loyalty to other prisoners (Clemmer 1958). Prisoners who do not follow this code of conduct are subject to further abuse from other prisoners (de Viggiani 2006). Three of the participants in the current study spoke of incidents where they told on another prisoner to correctional staff for wrong doing; breaking the prisoner code of loyalty by doing so. This demonstrates that these values are likely to 
conflict with the logic of a prisoner with autism and therefore render them unable to abide by them, whereas a neurotypical individual would be able to see the abstract logic to these values and predict the implications of not following them. Therefore prisoners with autism are more likely to be subject to increased confrontations with other prisoners for not following the prisoner code.

The types of bullying and victimisation experienced by the participants in the current study included name calling, being stood over, physical abuse, and theft. Literature relating to the neurotypical experience of incarceration also identifies these forms of bullying in addition to sexual abuse and exploitation (Banbury 2004; Connell \& Farrington 1996; Edgar 2005; Ireland 2000; Ireland \& Archer 1996; Nagi, Browne \& Blake 2006; O’Donnell \& Edgar 1998; Power, Dyson \& Wozniak 1997; Wolff \& Shi 2009). Like the participants in the current study, the most common form of bullying experienced by neurotypical prisoners is verbal harassment and name calling (Ireland \& Archer 1996; Maitland \& Sluder 1998; de Viggiani 2006). The forceful taking of belongings, as experienced by the majority of participants in the current study, has also been identified as the second most experienced form of bullying by prisoners following verbal abuse (Ireland \& Archer 1996). No participant in the current study spoke of experiencing sexual abuse with the exception of one participant whose cell sharing experience with a sex offender resulted in his cell mate exposing his genitalia to him. A significant portion of sexual abuse in prisons is known to take place in the prisoners' cell during the evening and night when the cell door is locked (Banbury 2004). Therefore possible reasons for the participants not disclosing experiences of sexual abuse include the potentiality that they were less likely to experience such due to being housed in isolation or on protection units, or being in a single cell. It is also plausible that the participants in the current study didn't feel comfortable telling the interviewer, who was a young female, of any sexually related abuse they may have experienced during their incarceration. Reluctance to discuss incidents of being victim to coercive sexual behaviour has been found in neurotypical prisoners (Banbury 2004). For the most vulnerable participants in the current study attempts were made by correctional authorities to protect them from bullying by placing them in isolation away from the main locations of prison. Participant four for example, continued to experience bullying despite being placed in a protection unit. It is likely that persons with autism are more vulnerable to bullying and victimisation than neurotypical 
prisoners due to social impairment, social naivety, and social misunderstandings. In the absence of research comparing the prevalence of bullying in those with and without autism it is not known for certain, but it is known that incidents of such is higher in prisoners with intellectual disabilities who are known to be more vulnerable.

There appears to be similarities in how persons with autism experience incarceration to how incarceration is experienced by persons with intellectual disabilities. In a review of the literature Linhorst, Bennet and McCutchen (2003) described the incarceration experience for offenders with developmental disabilities (detailed as 'mental retardation' and 'learning disabilities') to be characterised by being assaulted, victimised and exploited by other prisoners, where difficulties adjusting to prison routines due to not understanding what was expected of them was common. However unlike prisoners with autism, those with a learning disability receive support in adjusting to prison life from prison-based disabilities services. If the prisoner with autism does not have a co-existing intellectual disability they are unlikely to fit the criteria for assistance from such services. This is supported by the current study that found only three of the eight participants were identified in the prison-based disability service register, and only one of the 13 identified potential participants who were not included as they did not meet inclusion criteria were identified on the disability service register.

Whilst it is clear that the participants in this study did experience aspects of incarceration that were comparable to what would be experienced by neurotypical individuals as described above, it is clear that much of the anxiety experienced related directly to the incompatibility of their autism-related impairments and the prison environment and would therefore be unique to prisoners who have autism or autismlike traits. This phenomenological study gives us insight into a world of unpredictability experienced by incarcerated persons with autism, in which their lifeworld is insinuated by anxiety. The anxiety experienced was a direct implication of being unable to impose sameness in an unpredictable environment that was subject to constant change. Participants also experienced social-related anxiety as a consequence of their communication and social impairments rendering them unable to successfully negotiate the unpredictable and complex social situations and structures that they were subject to in prison. 
Communication and social impairments in persons with autism are likely to worsen when they are anxious. This includes a decreased ability to comprehend and express verbal communication, increased repetitive and ritualistic behaviours and increased social blunders (Tantam 2003). Therefore, taking this into consideration, it is plausible that the effects of increased anxiety on incarcerated persons with autism would include altercations with correctional staff as they are unable to comprehend and follow instructions or orders given. Further implications of increased anxiety include difficulties engaging in prison-based programs and routines as a result of ritualistic behaviours taking priority in order to alleviate anxiety. In addition to this, increased anxiety associated with misinterpreted social related incidents leads to altercations with other prisoners. This is consistent with the findings in the current study where the types of stress resulting in anxiety were associated with change and disruption to routine, confusion with prison routines and instructions given by officers, confusion and worries relating to complex social situations and being prevented from their undertaking their self-imposed routines.

Similar stressors and triggers of anxiety for persons with autism were identified in a recent qualitative study of parent perspectives on the nature of anxiety in their children with autism (Ozsivadjian, Knott \& Magiati 2012). Focus groups were held with 17 parents of 19 children in the UK aged 7 to 17 years old with an existing diagnosis, made by local clinical services, of ‘Autism Spectrum Disorder’ (Asperger’s Disorder ( $n=5)$, 'high-functioning autism' $(n=6)$, atypical autism $(n=1)$, and 'ASD or autism’ $(n=7)$. Triggers to anxiety identified by parents were: change or disruption to routine due to unpredictability; social or language related triggers such as not knowing how they were expected to behave in social situations and difficulties with perspective-taking; specific fears or phobias; sensory triggers such as loud noises and too many voices; triggers relating to obsessions such as being prevented from doing preferred activities; and triggers related to high expectations in performance (Ozsivadjian, Knott \& Magiati 2012). Parents reported that in their children anxiety manifested in challenging behaviour (such aggression and self-harm), avoidance or withdrawal, arousal (hyperactivity), sensory behaviour (such as nail biting or shouting), obsessional and repetitive behaviours, somatic indicators (such as disruption to sleep), and cognitive indicators (verbal expression of thoughts relating to 
worries) (Ozsivadjian, Knott \& Magiati 2012). The authors of this study presented their findings in a theoretical model adapted from a model of clinical anxiety in autism by Wood and Gadow (2010). The findings from the current research have enabled further adaption of this model to represent the anxiety experienced by incarcerated adults with autism (see figure 1 below).

Figure 1: Illustrated model of anxiety experienced by incarcerated persons with autism
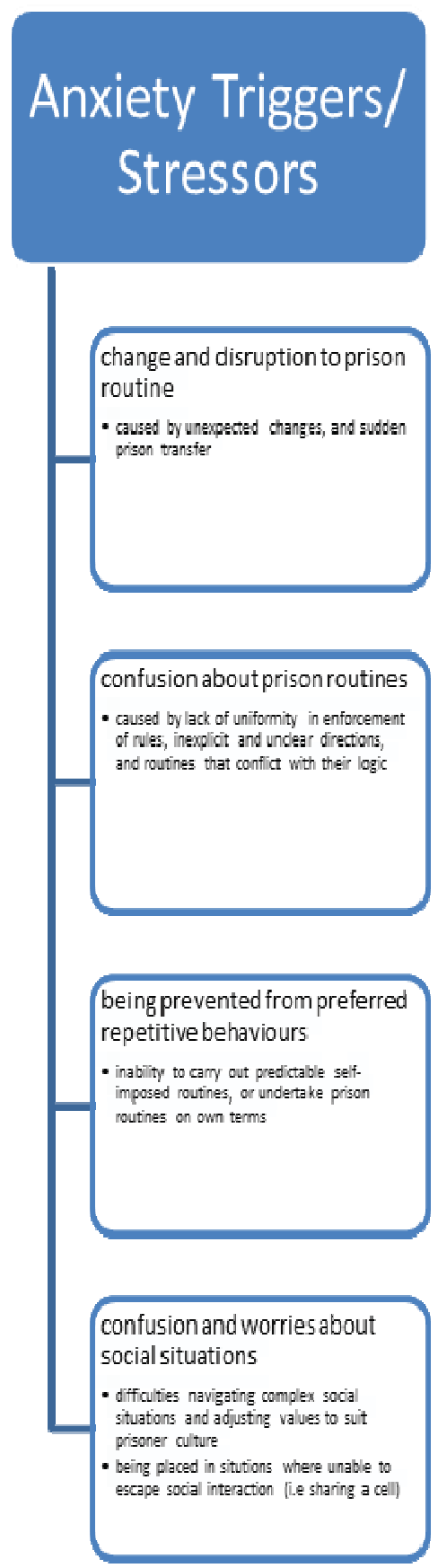
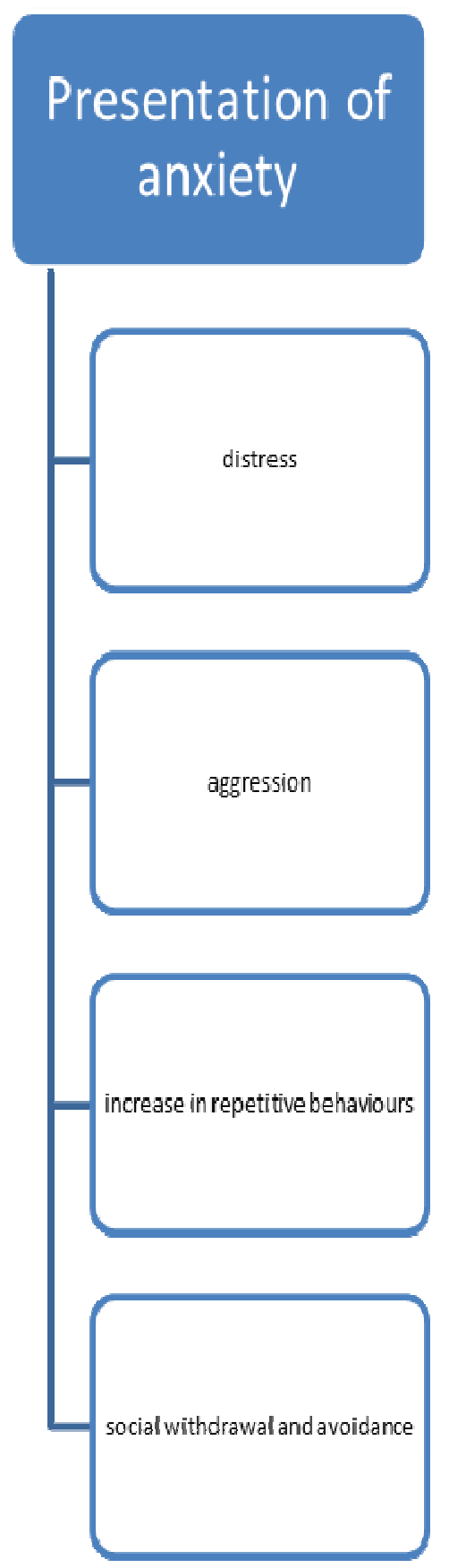

Impact of anxiety

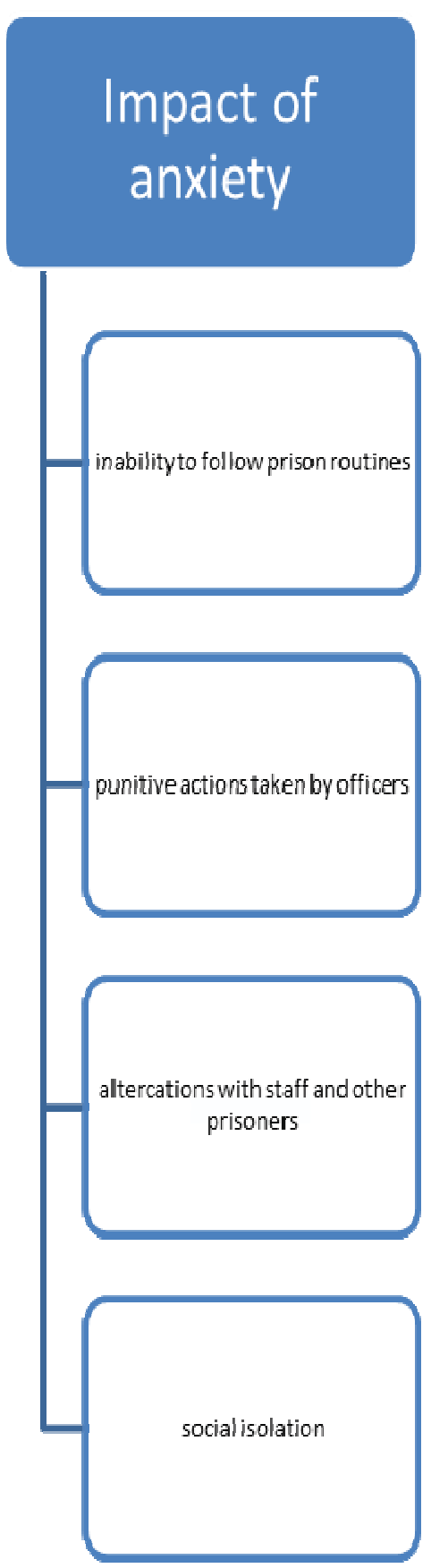




\subsection{Limitations}

Difficulties in the current study were experienced in relation to the inclusion of participants. A number of potential participants were excluded due to difficulties experienced by the researcher in meeting with them prior to their release from prison. Negotiating access to potential participants was at times a lengthy process involving both health and correctional staff, and obtaining security-related permissions for each potential participant. During this period, three potential participants were granted bail and released, and one participant was released after serving a short sentence. The prisoner population is well known to be transient in nature with a significant proportion of remand prisoners (i.e. unsentenced prisoners who may be released from prison under bail conditions or without a sentence), and prisoners who receive a short sentence. Statistics provided in the 2011 Prisoner Census indicate that $26.5 \%$ of prisoners for the period of 2009/2010 were on remand, and a further $7 \%$ of prisoners for this period were serving a sentence of less than nine months (Corben 2011). Difficulties related to accessing prisoner participants in research has been identified in the literature where factors such as sudden prisoner transfers and prisoner releases impact on both gaining and maintaining access to participants (Byrne 2005; Quina et al. 2007). The impact of frequent movements on access to potential participants was evidenced in the current study where, on five occasions, the interviewer attended a correctional centre as arranged, but was unable to meet with the potential participant due to them being in current transit to another correctional centre, being at court, or occupied with visitations with family or legal staff.

The identification of participants for inclusion in the study was made difficult by poor recording of incarcerated persons with autism on health and disability databases. This is evidenced by the poor consistency of recorded persons on the databases. For example, identified persons with autism in prison should, on the principles of best practice, be identified on all three databases searched (MHOAT, PAS and the CSNSW Disability Service Register). However of the participants included in the study ( $\mathrm{n}=8$ ) only one was identified on more than one database (PAS and Disability Register). The remaining participants were identified on one database only (PAS: $n=3$, MHOAT: $n=1$, Disability Register: $n=2$ ), with the exception of one participant who was not identified on any of the databases (this participant was referred to the 
researcher by another researcher). It is of note that the initially identified participants who appeared to meet inclusion criteria but on closer inspection did not were also subject to poor identification on these databases (PAS only: $n=6$, MHOAT only: $n=1$, PAS and Disability Register: $\mathrm{n}=1$ ).

The rigorous inclusion criteria in the current study was problematic as there were a number of potential participants identified who appeared to meet the inclusion criteria but, after consenting for the researcher to examine their medical record to confirm a formal diagnosis of autism, it was apparent that the documentation of diagnoses was either incomplete or too informal to include the participants in the study. In total six participants were not able to be included in the study due to not having an adequately documented diagnosis of autism in their medical notes. Three of these individuals had told a health staff member on reception to the prison that they had a history of autism but this diagnosis had not been confirmed with the external provider. For two of the individuals, a diagnosis of autism had been suggested by a prison-based medical officer or psychiatrist but had not been confirmed. The parent of the remaining individual had written to correctional authorities stating that her incarcerated son had autism but no confirmation of this diagnosis had been sought. This is suggestive of a number of issues: ineffective collaboration between prison health and external health providers (re: obtaining history and confirmation of diagnosis of autism made by external provider); limited awareness of autism by health staff and the need to seek confirmation of a diagnosis; inability for a previously undiagnosed person with autism to receive a diagnosis as an adult in prison (potentially related to inability to obtain/non-existence of developmental histories, and inexperience/non-expertise of prison-based psychiatrists and mental health nurses in the field of autism). Alternatively these individuals were provided with mental health care in prison for symptoms of mental health disorders associated with autism i.e. depression and anxiety-related disorders, mostly pharmacological in nature. It is also of note that this was also the case for participating individuals in the study. This supports that there is a probable high rate of incarcerated individuals with autism who remain either undiagnosed or misdiagnosed as suggested in a number of recent reviews (Cashin \& Newman 2009; Gómez de la Cuesta 2010; Mouridsen 2012). The need for health professionals working with offenders to receive education in the behavioural characteristics and cognitive profile of those with autism has been highlighted in order 
for appropriate service provision to be available, including diagnosis of autism in the cases of previously undiagnosed individuals (Cashin \& Newman 2009; Gómez de la Cuesta 2010; Mouridsen 2012; Robinson et al. 2012; Tiffin, Shah \& le Couteur 2007).

A further limitation of the current study was the potential impact of the lack of privacy experienced during the conduct of participant interviews on participants' disclosure of their experiences. Prisons are renowned for having limited provision of rooms that can be used for research that offer complete confidentiality (i.e. free from other prisoners or officers, free from interruptions) (Paternelj-Taylor 2005). The researcher was aware of this prior to commencing participant interviews and therefore actions were taken to ensure interviews were undertaken in a room free from other people.

However, as expected, on some occasions it was requirements stipulated by correctional officers for the door to the interview room to remain open in order to ensure the safety of the researcher was preserved. All but two participant interviews took place in the prison health centre with the level of privacy varying dependant on the busyness of the centre at that time (i.e. presence of visiting health specialists, multiple concurrent clinics running, and number of other prisoners, officers and health staff in the vicinity). Interruptions occurred during one participant interview on multiple occasions as health staff entered the room to take items from the room, and also by passing correctional staff that stopped to greet the participant through the doorway to the room. The interview with another participant was interrupted as the participant was made to leave the room to attend muster by correctional staff. Busy health centres meant noise disturbances from prisoners, staff and radios held in possession by correctional staff. The security classification associated with one participant additionally required the presence of an officer to be sat just outside the door to the room with a visual view of the prisoner, to which the conversation inside the room would have been heard. For the two participants who were not interviewed in the health centres, officers too were present directly outside the interview room to which the door had to remain open as the interview was taking place in a nonpatrolled area (i.e. areas of the prison wing where no prisoners or officers were normally scheduled at that time). 
Limited room availability to hold participant interviews has been identified by a number of researchers who have written about their experiences of conducting research with prisoners (Drake 1997; Quina et al. 2002). Whilst participants were made fully aware that the interview was being undertaken within hearing distance of an escorting officer, the consequence of this limited privacy was that the participants' may have been restricted in their disclosure of their experiences in fear of retribution from correctional staff if they had said something that could have been perceived as incriminating towards them. The requirement for some prisoners to be escorted for participation in research by prison officers has been identified to impact on access to, and the recruitment of, research participants (Paternelj-Taylor 2005).

\subsection{Recommendations and conclusion}

The current study highlighted the difficulties faced by prisoners with autism. The findings suggest that prisoners with autism experience environment-related stress and anxiety and are vulnerable to bullying and exploitation from other prisoners. The ability for prisoners with autism to adjust to prison routines is made difficult by being frequently moved around, not only inside individual correctional centres, but around the entire state correctional system. Struggles comprehending directions given by correctional staff further add to the difficulties prisoners with autism face in adjusting to prison routines.

The current study additionally highlighted the minimal, if any, provision of support available to prisoners with autism that address specifically their autism-related needs. Therefore support needs associated with communication, social and anxiety related difficulties were not addressed, or not recognised, by health or correctional staff. This was likely due to a lack of awareness, held by nursing and correctional staff, of autism in general and how incarceration may impact on an individual with autism. This limited awareness was also a likely contributing factor to the high incidence of potential participants having their external provider-made diagnoses not followed-up by nursing staff on their reception to prison.

In light of the difficulties associated with incarceration faced by the participants in the current study, a number of recommendations have made. Firstly, consideration needs 
to be given to the placement of prisoners with autism within the correctional system. Concerns relating to their increased vulnerability to being exploited and abused by other prisoners, and prison-specific stressors that cause distress and anxiety in this population group (changes/disruptions to routines, confusion related to routines, being prevented from preferred repetitive behaviours, and social relate confusion and worries) should be factored into the decisions made regarding where the individual is best placed within the correctional system. Placements, where possible, should provide stability to the prisoner with autism by allowing them to remain on the same unit/wing throughout their sentence.

All prisoners go through an induction process on entering prison to aid their adjustment to routines. This process is not repeated for each new correctional centre a prisoner is transferred to as it is assumed initial knowledge and experience will be generalised to other correctional centres; an ability lacking in individuals with autism. Prisoners with autism therefore require specific support provision to aid their adjustment to prison routines when transferred to different correctional centres. As their knowledge and experience from one centre is not likely to be transferred to another centre, they are at increased risk of experiencing distress, confusion, and anxiety as they strive to predict what it is they should be doing.

Prisoners with autism would benefit from both health and correctional staff having an increased awareness of the triad of impairment and the cognitive theories associated with autism (weak central coherence, theory of mind deficits, and executive dysfunction). This would enable staff to tailor their interactions with prisoners with autism to better suit their needs. This would be of specific benefit to the promotion of effective communication between a prisoner with autism and both health and correctional staff. For example, ensuring instructions given to persons with autism are clear, explicit and with only one instruction given at a time for that to be processed prior to giving another instruction, is likely to reduce prisoner-staff altercations that result from prisoners not following orders due to being unable to understand what is being requested of them. Visuals aids are also likely to be useful in supporting instructions given to prisoners with autism, such as a handbook pictorially illustrating that which is expected of them for certain routines such as muster and visitation. 
Increased and improved knowledge and awareness of the behavioural characteristics of autism by both correctional and health staff would also improve the identification of persons with autism in the correctional centre. In addition to this development of health staff knowledge concerning the challenges relating to the diagnosis, and misdiagnosis, of autism in the offender population would also be of benefit in the identification of prisoners with autism who are yet to receive a formal diagnosis. Further a formal protocol needs to be put in place to ensure prisoners with autism who claim to have received a diagnosis of autism by an external health provider to have confirmation of their diagnosis sought. Similarly a formal protocol is needed for the appropriate assessment of prisoners presenting with the behavioural characteristics of autism who have not had contact with an external health provider. The assessment of prisoners with autism, or prisoners who potentially have autism, may require referral to specialist external health providers where such expertise is lacking by prison-based staff. Further, consistency in the identification of persons with autism on relevant health and correctional databases (MH-OAT, PAS and CSNSW Disability Register for prisoners in NSW) would aid the identification of such persons who require tailored support by both health and correctional services whilst incarcerated.

The therapeutic value of strategies, such as self-isolation or imposed isolation in segregated units, to cope with distress and anxiety associated with communication and social impairments, is questionable as long-term isolation may worsen the experience of psychological distress. Whilst this method of managing individuals with autism in prison appears to be an easy fix for this vulnerable population, experiences of social isolation are likely to be detrimental to their health and well being as social impairments are exacerbated and symptoms of social anxiety, depression and psychosis worsen. Potential mechanisms for reducing social isolation and anxiety for incarcerated persons with autism are detailed below.

Providing for and offering social activities that are structured and appropriate to the participation of prisoners with autism may promote social inclusion of this prisoner group. These activities should be predictable in terms of their content (same activity in same order with same people where possible) and predictable in terms of when the activity is undertaken (same day/time each week). Prisoners with autism should be encouraged to participate in social interaction on a one-to-one or small group basis. 
This would enable an effective means of positive social interaction without the distressing experience associated with large groups (i.e. large groups of prisoners) (Müller, Schuler \& Yates 2008). If such activities are convened and facilitated by correctional or health staff this will relieve individuals with autism of the onus of initiating social interaction. Providing a peer mentor to facilitate social interactions in prison-based activities may also be of benefit to a prisoner with autism. For example, the allocation of a suitable neurotypical prisoner (who is agreeable to the role and has undergone specifically designed training for the task) who can accompany the prisoner with autism to prison-based sport or work activities to facilitate social interaction through the promotion of social inclusion and modelling context-specific social behaviours. This could be a paid working role for the prisoner acting as a peer mentor. The provision of an additional induction process for prisoners with autism that includes one-on-one instruction in the use of prison-specific social skills may also aid prisoners with autism from a social impairment perspective. For example, social skills related to the navigation of complex social situations found in the prison environment including stand-over behaviours, and the prisoner code.

The social support needs of incarcerated persons with autism may also be addressed by the appointment of a mental health nurse to provide case management to these individuals. Effective case management would include individualised support provision addressing social and communication needs (including prison-related social issues such as the unwritten prisoner code), and the identification and monitoring (including comprehensive and complete documentation) of support needs during incarceration. It is proposed that the provision of such would not only reduce the heightened distress and anxiety currently experienced by incarcerated persons with autism but promote social inclusion by enabling these persons to participate in prison activities available to neurotypical prisoners and to be housed in mainstream locations of prisons as opposed to being housed in isolation in segregation or protection units. Case management provided by mental health nurses for incarcerated persons for autism would also enable support to be provided to those persons with autism who currently do not receive additional support from the CSNSW Disability Service as they do not meet the criteria for this service (those who do not have a co-morbid intellectual disability). 
Examination of JH\&FMHN medical records of the potential participants revealed a commonality relating to a lack of external service provider correspondence. The majority of records contained medical information pertaining to their incarceration period only. Some of medical records had the inclusion of external provider information and records relating to physical health needs. However, records which related to the participants' history of mental health disorders and/or experiences with mental health community service providers was non-existent (with the exception of $\mathrm{n}=5$ participants who were able to be included in the study). Therefore the majority of individuals who were identified for potential inclusion in this study did not have a formally documented diagnosis of autism in their medical record. This would inevitably impact on the ability for prison-based health service providers to recognise, acknowledge and address the support needs of these individuals. It is recommended that collaboration between prison- and community-based health service providers is improved, with it being standard practice for any incarcerated persons claiming to have autism on reception to prison to be followed up with community services for confirmation of the diagnosis and identification of individual support needs. The appointment of a mental health nurse to case manage incarcerated persons with autism would ensure the responsibility of such actions are incorporated into the case manager's role, including liaison with appropriate community services to ensure community-based services are available to the individual when released from prison. It is further recommended that an audit is undertaken of current JH\&FMHN medical records to identify persons with autism currently incarcerated who require further investigation of their diagnosis (i.e. collaboration with external providers to obtain mental health and diagnostic histories).

Finally, further research is required to better understand the psychological effects of confinement and isolation on persons with autism. An evaluation of interventions to support persons with autism in prison, including ways to promote inclusion in the prison community, would also be valuable for this prisoner population. 


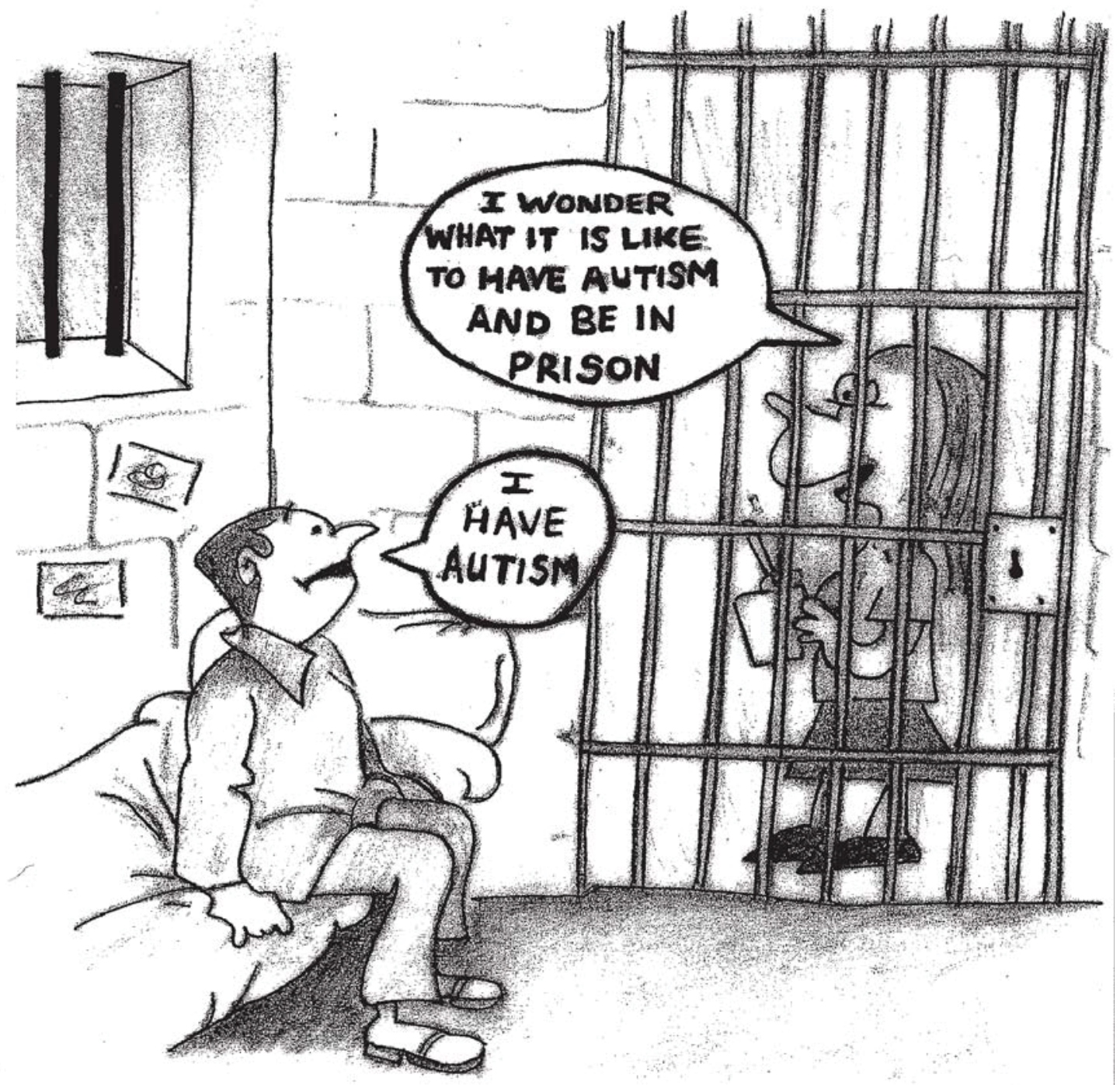




\title{
Appendix II
}

\section{JUSTICE HEALTH | NSWOHEALTH}

Ref: GEN 37/07

Doc: $5475 / 09$

\author{
Ms Claire Newman \\ Research Officer \\ Justice Health Professorial Unit \\ Suite 302, Level 2, Westfield Office Tower \\ 152 Bunnerong Road \\ PAGEWOOD NSW 2035
}

Dear Ms Newman

\section{Re A hermeneutic phenomenological study of the lived experience of incarceration for those with autism}

The Committee considered your request to amend the original application of this project out of session and decided to grant approval to the modifications.

According to the National Statement on Ethical Conduct in Research Involving Humans, a regular report is required on all approved projects. You will be required to report on your progress, by 31 July 2010. The report template will be emailed to you.

Additionally, researchers must immediately report anything which might warrant review of the approval, including:

a) Serious or unexpected adverse effects on participants;

b) Proposed changes in the protocol; or

c) Unforeseen events that might affect continued ethical acceptability of the project.

You are also requested to inform the Human Research \& Ethics Committee if the research project is discontinued prematurely.

The National Statement on Ethical Conduct in Human Research is available on http://www.nhmrc.gov.au/publications/synopses/_files/e72.pdf, for your information.

Please note that though Justice Health ethics approval has been granted, the administrative requirements regarding the conduct of the study are yet to be considered by Justice Health. For advice on receiving Justice Health administrative approval and support, please contact Ms Devon Indig, Head of Research, Centre for Health and Research in Criminal Justice on (02) 83723010.

Should you require further information, please do not hesitate to contact me on (02) 83723000 . Yours sincerely

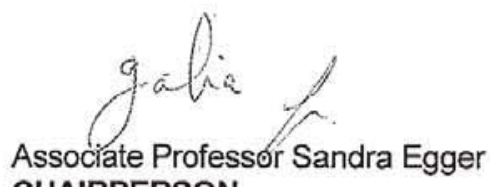

CHAIRPERSON

HUMAN RESEARCH \& ETHICS COMMITTEE

27 July 2009 


\section{NSW Department of Corrective Services}

Claire Newman

Research Nurse

Justice Health Professional Unit

Suite 302, Level 2

152 Bunnerong Rd

EASTGARDENS NSW 2036

\section{Dear Claire}

I refer to your research application titled "A hermeneutic phenomenological examination of the lived experience of incarceration for those with autism".

I also refer to the letter signed by Commissioner Ron Woodham, dated 19 April 2009, conditionally approving your research application.

The Executives of the Corrective Services Ethics Committee have reviewed the application amendments which now includes the steps to be taken in identifying inmates with autism. The Executives have also received advise from Anne Langford, Manager Disability Services stating that you have now produced an acceptable consent form to be used in this study.

The Executives are satisfied that you have met the conditions of approval. You are now free to commence your research project.

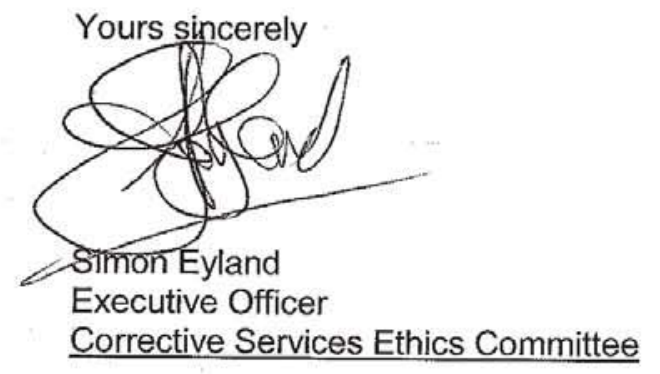

May 2009 
14 October 2009

Professor Andrew Cashin

Nursing, Midwifery and Health

KG05.02.19

UNIVERSITY OF TECHNOLOGY, SYDNEY

Dear Andrew,

UNIVERSITY OF

UTS HREC 2009-241 - CASHIN, Professor Andrew, WATERS, Dr Cheryl (for NEWMAN, Ms Claire, MA student) - "A hermeneutic phenomenological examination of the lived experience of incarceration for those with autism" [External Ratification: NSW Department of Corrective Services Ethics Committee HREC approval - 08/19871 01/05/2009 to 01/05/2010].

Thank you for your response to my email dated 17/09/09. Your response satisfactorily addresses the concerns and questions raised by the Committee, and I am pleased to inform you that your external ethics clearance is now ratified.

Your UTS clearance number is UTS HREC REF NO. 2009-241R

Please note that the ethical conduct of research is an on-going process. The National Statement on Ethical Conduct in Research Involving Humans requires us to obtain a report about the progress of the research, and in particular about any changes to the research which may have ethical implications. This report form must be completed at least annually, and at the end of the project (if it takes more than a year). The Ethics Secretariat will contact you when it is time to complete your first report.

I also refer you to the AVCC guidelines relating to the storage of data, which require that data be kept for a minimum of 5 years after publication of research. However, in NSW, longer retention requirements are required for research on human subjects with potential long-term effects, research with long-term environmental effects, or research considered of national or international significance, importance, or controversy. If the data from this research project falis into one of these categories, contact University Records for advice on long-term retention.

If you have any queries about your ethics clearance, or require any amendments to your research in the future, please do not hesitate to contact the Ethics Secretariat at the Research and Innovation Office, on 0295149772.

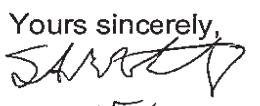

$$
\text { per. }
$$

Professor Jane Stein-Parbury

Chairperson

UTS Human Research Ethics Committee 


\title{
Appendix III
}

\section{JUSTICE HEALTH $\mid$ STATEWDE SERVIE}

\author{
Participant Information Sheet
}

This is for you to keep

STUDY:

(short title)

INVESTIGATORS:

PURPOSE OF THE STUDY:

BENEFITS OF THE STUDY:

WHAT WOULD BE EXPECTED OF YOU?

DISCOMFORTS/ RISKS:

\section{An examination of the experiences of imprisonment as described by individuals with autism}

\author{
Claire Newman, Research Nurse, Justice Health and Masters of Nursing (Hons) \\ student, University of Technology Sydney \\ Professor Andrew Cashin, Southern Cross University \\ Dale Owens, Justice Health
}

The study aims to understand how people with autism experience being in gaol. We would like you to take part in this research study.

This study will help in understanding how to support people with autism in prison

If you are happy to take part in the study you will be asked to sign the consent form. One of the researchers then will look in your medical notes. This is because you need have a diagnosis of autism or Asperger's disorder written in your notes to be interviewed. Unfortunately if the medical diagnosis is not clear we can not go on.

If the notes have the diagnosis clearly written you would be expected to meet with one of the researchers and have an interview about what prison is like for you. This will take about one hour

There should be no discomfort for you if you take part in this study. However, if you did get upset we will ask you if you want to stop doing the study with us. We can also tell you who you can talk to about the upset feeling. We can organise for you to talk to a nurse if you feel you would like extra support. If you are Aboriginal or Torres Strait Islander, we can arrange for you to talk to an Indigenous Health Worker on the telephone if you wish.

CONFIDENTIALITY: The interview will be recorded. Your name will be given a code and therefore will not be on any of the recordings that we do and will not be anything that we write down. 
YOUR

PARTICIPATION:

RESULTS OF THE STUDY

PERSONS TO CONTACT
This is to make sure that other people are not able to find out who you are. All recorded information will be copied onto a computer with these codes. In this way only the researchers will know your identity. The codes to the data will be locked in a cabinet in a separate location from your name. We will write a report but make sure that no one will be able to find out who you are. The data will be destroyed 5 years after the project has been finished.

We want you to decide whether you want to be in this study. If you want to take part in this study, but change your mind later on, that's OK. Whether you say yes or no you will still get the same service from Justice Health and the Department of Corrective Services.

The researchers will write about what they have found in a report and also in a journal article. What has been found will also be written in a document for the university.

If you have any questions about the project you can contact these people:

Claire Newman (Researcher) - (02) 83723003

Professor Andrew Cashin (Researcher) - (02) 66203156

Dale Owens (Researcher) - (02) 97003158

Secretary of the Research Ethics Committee of Justice Health - (02) 83723000

Carolyn Richie, Department of Corrective Services Ethics Committee - (02) 83461254

UTS Human Research Ethics Committee - (02) 95149772

UTS Supervisors of Claire Newman:

Professor Andrew Cashin - (02) 66203156

Cheryl Waters - (02) 95145741 


\section{Appendix IV}

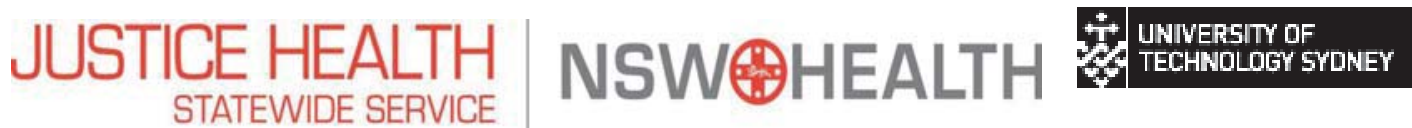

Project: The experiences of gaol as described by people with autism

Chief Researcher: Ms Claire Newman

Co-researcher: Professor Andrew Cashin

Co-researcher: Mr Dale Owens

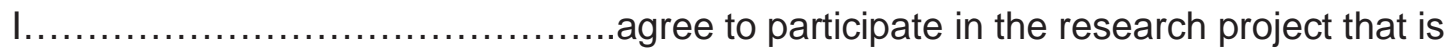
looking at the experiences that people with autism have in gaol.

The study has been explained to me.

I understand that the researcher will talk to me about my experiences in gaol.

This will be audio-recorded but without my name on it.

I will have to talk to the researcher for about 30 minutes.

But I can stop sooner if I want to.

I do not have to answer any questions if I do not want to.

I know that no-one will mind if I decide that I do not want to take part in the study.

I can pull out of the study at any time.

The researchers have agreed not to tell anyone my name or any other personal details.

It is OK for the researchers to look in my medical notes.

If I have any questions about this study I can speak to the research team.

I have read or have had read to me, this consent form.

If I have any questions about the study I can contact the Chief researcher Claire Newman on (02) 83723003.

PARTICIPANT (signature)

DATE

WITNESS (signature)

DATE. 


\section{Appendix V}

Publications arising from this thesis:

1. Cashin, A. \& Newman, C. 2009, 'Autism in the criminal justice system: A review of the literature', Journal of Forensic Nursing, vol. 5, pp. 70-75.

2. Newman, C., Cashin, A. \& Waters, C. 2010, 'A modified hermeneutic phenomenological approach toward individuals who have autism', Research in Nursing \& Health, vol. 33, pp. 265-271. 


\section{Reference List}

Allen, D., Evans, C., Hider, A., Hawkins, S., Peckitt, H. \& Morgan, H. 2008, 'Offending behaviour in adults with Asperger's Syndrome', Journal of Autism and Developmental Disorder, vol. 38, pp. 748-758.

American Psychiatric Association (APA) 2000, Diagnostic and statistical manual of mental disorders fourth edition text revision, APA, Washington, D.C.

American Psychiatric Association (APA) 2010, Proposed draft revisions to DSM Disorders and Criteria, viewed 26 April 2011, $<\underline{\text { http://www.dsm5.org/ProposedRevisions }>}$

Annells, M. 1996, 'Hermeneutic phenomenology: philosophical perspectives and current use in nursing research', Journal of Advanced Nursing, vol. 23, pp. 705-713.

Ashkar, P.J. \& Kenny, D.T. 2008, 'Views from the inside: Young Offenders' subjective experiences of incarceration', International Journal of Offender Therapy and Comparative Criminology, vol. 52, pp. 584-597.

Asperger, H. 1944, ‘Die ‘Autistischen Psychopathen’ im Kindesalter (The autistic psychopathy of childhood)', Archiv fur Psychiatrie und Nervenkrankheiten (Archives of Psychiatric and Nervous Diseases), vol. 117, pp. 76-136.

Attwood, T. 1998, Asperger's Syndrome: A guide for parents and professionals, Jessica Kingsley Publishers, London.

Australian Advisory Board on Autism Spectrum Disorders 2007, The Prevalence of Autism in Australia - can it be established from existing data? Author, Australia.

Australian Bureau of Statistics (ABS) 2009, National Health Survey: Summary of Results, ABS Catalogue Number 4364.0, Australian Bureau of Statistics and Australian Government Publishing Service, Canberra.

Baird, G., Cass, H. \& Slonims, V. 2003, 'Diagnosis of autism’, British Medical Journal, vol. 327, pp. 488-493.

Barnbaum, D.R. 2008, The ethics of autism: Among them, but not of them, Indiana University Press, Indiana.

Banbury, S. 2004, 'Coercive sexual behaviour in British prisons as reported by adult ex-prisoners', The Howard Journal, vol. 43, no. 2, pp. 113-130. 
Baron-Cohen, S. 1989, 'Perceptual role taking and protodeclarative pointing in autism', British Journal of Developmental Psychology, vol. 7, pp. 113-127.

Baron-Cohen, S., Scott, F.J., Allison, C., Williams, J., Bolton, P., Matthews, F.E. \& Brayne, C. 2009, 'Prevalence of autism-spectrum conditions: UK schoolbased population study', The British Journal of Psychiatry, vol. 194, no. 6, pp. 500-509.

Baron-Cohen, S., Wheelwright, S., Cox, A., Baird, G., Charman, T., Swettenham, J., Drew, A. \& Doehring, P. 2000, 'Early identification of autism by the CHecklist for Autism in Toddlers (CHAT)', Journal of the Royal Society of Medicine, vol. 93, pp. 521-525.

Barry-Walsh, J. \& Mullen, P. 2004, 'Forensic aspects of Asperger’s Syndrome’, The Journal of Forensic Psychiatry \& Psychology, vol. 15, no. 1, pp. 96-107.

Beaumont, R. \& Newcombe, P. 2006, 'Theory of mind and central coherence in adults with high-functioning autism or Asperger syndrome’, Autism, vol. 10, pp. 365-382.

Bellini, S. 2004, 'Social skill deficits and anxiety in high-functioning adolescents with autism spectrum disorders', Focus on Autism and Other Developmental Disabilities, vol. 19, pp. 78-86.

Bellini, S. 2006, 'The development of social anxiety in adolescents with autism spectrum disorders', Focus on Autism and Other Developmental Disabilities, vol. 21, pp. 138-145.

Bender, T.K. 1999, 'Martin Heidegger: Between Good and Evil', Clio: A Journal of Literature History \& the Philosophy of History, vol. 28, no. 2, pp. 227-231.

Benner, P. 1994, Interpretative Phenomenology. Embodiment, Caring, and Ethics in Health and Illness, Sage Publications, London.

Bereswill, M. 2004, 'Inside-out: Resocialisation from prison as a biographical process. A longitudinal approach to the psychodynamics of imprisonment', Journal of Social Work Practice, vol. 18, no. 3, pp. 315-336.

Bettelheim, B. 1967, The empty fortress: Infantile autism and the birth of the self, The Free Press, New York.

Biggam, F.H. \& Power, K.G. 1997, 'Social support and psychological distress in a group of incarcerated young offenders', International Journal of Offender Therapy and Comparative Criminology, vol. 41, no. 3, pp. 213-230. 
Biggam, F.H. \& Power, K.G. 1999, 'A comparison of the problem-solving abilities and psychological distress of suicidal, bullied, and protected prisoners', Criminal Justice and Behaviour, vol. 26, no. 2, pp. 196-216.

Bilder, D., Pinborough-Zimmerman, J., Miller, J. \& McMahon, W. 2009, 'Prenatal, perinatal, and neonatal factors associated with autism spectrum disorders', Pediatrics, vol. 123, pp. 1293-1300.

Bishop, D. 2003, 'Autism and specific language impairment: categorical distincition or continuum?', Autism: Neural Basis and Treatment Possibilities, vol. 251, pp. 213-234.

Blattner, W. 2006, Heidegger's Being and Time, Continuum International Publishing, London.

Bolton, P., Murphy, M., Macdonald, H., Whitlock, B., Pickles, A. \& Rutter, M. 1997, 'Obstetric complications in autism: Consequences or Causes of the Condition?', Journal of the American Academy of child \& Adolescent Psychiatry, vol. 36, no. 2, pp. 272-281.

Bosch, G. 1970, Infantile autism: A clinical and phenomenological-anthropological investigation taking language as the guide, Springer-Verlag, New York.

Brewer-Smyth, K. 2008, 'Ethical, Regulatory, and Investigator considerations in prison research', Advances in Nursing Science, vol. 31, no. 2, pp. 119-127.

Brugha, T. Cooper, S.A., McManus, S., Purdon, S., Smith, J., Scott, F.J., Spiers, N. \& Tyrer, F. 2012, Estimating the prevalence of autism spectrum conditions in adults: Data quality and methodology document, The NHS Health and Social Care Information Centre, United Kingdom.

Byrne, M.W. 2005', 'Conducting research as a visiting scientist in a women’s prison’, Journal of Professional Nursing, vol. 21, no. 4, pp. 223-230.

Carlton, B. 2009, 'Proliferating coercive control and crisis: the official uses and abuses of modern high-security in Australia', Prison Service Journal, vol. 183, pp. 3-12.

Cashin, A. 2005, ‘Autism: Understanding conceptual processing deficits', Journal of Psychosocial Nursing and Mental Health Services, vol. 43, no. 4, pp. 22-30.

Cashin, A. 2006, 'Two terms- one meaning: The conundrum of contemporary nomenclature in autism', Journal of Child and Adolescent Psychiatric Nursing, vol. 19, no. 3, pp. 137-144. 
Cashin, A. 2008, 'Narrative Therapy: A psychotherapeutic approach in the treatment of adolescents with Asperger's Disorder', Journal of Child and Adolescent Psychiatric Nursing, vol. 21, no. 1, pp. 48-56.

Cashin, A. \& Barker, P. 2009, 'The triad of impairment in autism revisited', Journal of Child and Adolescent Psychiatry, vol. 22, no. 4, 189-193.

Cashin, A., Gallagher, H., Newman, C. \& Hughes, M. 2012, ‘Autism and the cognitive processing triad: A case for revising the criteria in the Diagnostic and Statistical Manual', Journal of Child and Adolescent Psychiatric Nursing, vol. 25, pp. 141-148.

Cashin, A. \& Newman, C. 2009, 'Autism in the criminal justice system: A review of the literature', Journal of Forensic Nursing, vol. 5, pp. 70-75.

Cashin, A. \& Waters, C. 2006, 'The under-valued role of over regulation in autism: Chaos Theory as a metaphor and beyond', Journal of Child and Adolescent Psychiatric Nursing, vol. 19, no. 4, pp. 224-230.

Cass, H., Gringras, P., March, J., McKendrick, I., O’Hare, A., Owen, L. \& Pollin, C. 2008, 'Absence of urinary opioid peptides in children with autism', Archives of Disease in Childhood, vol. 93, pp. 745-750.

Centre for Disease Control and Prevention 2007, Surveillance Summaries MMWR 2007;56 (No.ss-1), viewed 15 September 2007, $<$ http://www.cdc.gov/mmwr/pdf/ss/ss5601.pdf>

Chamberlain, B., Kasari, C. \& Rotheram-Fuller, E. 2007, 'Involvement or isolation? The social networks of children with autism in regular classrooms', Journal of Autism and Developmental Disabilities, vol. 37, pp. 230-242.

Chopper 2000, motion picture, First Look Pictures, Australia.

Clemmer, D. 1958, The Prison Community, Rinehart \& Company, New York.

Cohen, M.Z., Kahn, D.L. \& Steeves, R.H. 2000, Hermeneutic phenomenological research: A practical guide for nurses. Sage Publications, California.

Colle, L., Baron-Cohen, S. \& Hill, J. 2007, 'Do children with autism have a theory of mind? A non-verbal test of autism vs. specific language impairment', Journal of Autism and Development Disorders, vol. 37, pp. 716-723.

Connell, A. \& Farrington, D.P. 1996, 'Bullying among incarcerated young offenders: developing an interview schedule and some preliminary results', Journal of Adolescence, vol. 19, pp. 75-93. 
Constantino, J.N., Zhang, Y., Frazier, T., Abbacchi, A.M. \& Law, P. 2010, ‘Sibling recurrence and the genetic epidemiology of autism', The American Journal of Psychiatry, vol. 176, no. 11, pp. 1349-1357.

Cool Hand Luke 1967, motion picture, Warner Bros.-Seven Arts, United States.

Corben, S. 2011, NSW Inmate Census 2011, Statistical Publication No.28.

Correctional Services New South Wales, Sydney.

Correctional Services New South Wales (CSNSW) 2011, Facts \& Figures, CSNSW, Sydney.

Correctional Services New South Wales (CSNSW) 2012, Operations Procedures Manual: Section 6 Escort,. CSNSW, Sydney.

Crotty, M. 1996, Phenomenology and nursing research, Churchill Livingstone, Melbourne.

Crotty, M. 1998, The foundations of social research: Meaning and perspective in the research process, Allen \& Unwin, Sydney.

Deer, B. 2011, 'How the case against the MMR vaccine was fixed', British Medical Journal, vol. 342, viewed 8 August 2011, $<\underline{\text { http://www.bmj.com/content/342/bmj.c7452.full }>}$

Dein, K. \& Woodbury-Smith, M. 2010, 'Asperger syndrome and criminal behaviour’, Advances in Psychiatric Treatment, vol. 16, pp. 37-43.

Dennis, M., Lazenby, A.L. \& Lockyer, L. 2001, 'Inferential language in high-function children with autism', Journal of Autism and Developmental Disorders, vol. 31, no. 1 , pp. 47-54.

Dodd, S. 2005, Understanding Autism. Elsevier Australia, Sydney.

Doyle, J. 2003, 'Custody and caring: Innovations in Australian correctional mental health nursing practice', Contemporary Nurse, vol. 14, no. 3, pp. 305-311.

Drake, V.K. 1998, 'Process, perils, and pitfalls of research in prison', Issues in Mental Health Nursing, vol. 19, pp. 41-52.

Dreyfus, H. 1991, Being-in-the-world: A commentary on Heidegger's Being and Time, Division I. MIT Press, New Baskerville.

Edgar, K. 2005, 'Bullying, victimization and safer prisons', Probation Journal, vol. 52, pp. 390-400.

Eigsti, I. \& Bennetto, L. 2009, 'Grammaticality judgments in autism: Deviance or delay’, Journal of Child Language, vol. 36, pp. 999-1021. 
Elder, J.H., Shankar, M., Shuster, J., Theriaque, D., Burns, S. \& Sherrill, L. 2006, 'The gluten-free, casein-free diet in autism: Results of a preliminary doubleblind clinical trial', Journal of Autism and Developmental Disorders, vol. 36, no. 3, pp. 413-420.

Eyal, G., Hart, B., Onculer, E., Oren, N. \& Rossi, N. 2010, The Autism Matrix: The social origins of the autism epidemic. Polity Press, Cambridge.

Everall, I.P. \& LeCouteur, A. 1990, 'Firesetting in an adolescent boy with Asperger's syndrome', The British Journal of Psychiatry, vol. 157, pp. 284-287.

Faulkner, P.L. \& Faulkner, W.R. 1997, 'Effects of organizational change on inmate status and the inmate code of conduct', Journal of Crime and Justice, vol. 20, no. 1 , pp. 55-72.

Feinstein, A. 2010, A History of Autism. Wiley-Blackwell, United Kingdom.

Fombonne, E. 2003, ‘Epidemiological surveys of autism and other pervasive developmental disorders: An update', Journal of Autism and Developmental Disorders, vol. 33, no. 4, pp. 365-382.

Foster, T. 1975, 'Make-believe families: A response of women and girls to the deprivations of imprisonment', International Journal of Criminology \& Penology, vol. 3, pp. 71-78.

Frith, U. 2008, Autism: A very short introduction, Oxford University Press, Oxford.

Frith, U. 1991, Autism and Asperger Syndrome, Cambridge University Press, Cambridge.

Gadamer, H.G. 1989, Truth and Method, 2nd edn, trans. J. Weisheimer, \& D. Marshall, Continuum, New York.

Gadamer, H.G. 1988, 'The discrediting of prejudice by the enlightenment', in K. Muller-Vollmer (ed.), Hermeneutics reader: texts of the German tradition from the enlightenment to the present, Continuum International Publishing, London, pp. 257-292.

Gaes, G.G. \& McGuire, W.J. 1985, 'Prison violence: The contribution of crowding versus other determinants of prison assault rates', Journal of Research in Crime and Delinquency, vol. 22, no. 1, pp. 41-65.

Gardener, H., Spiegelman, D. \& Buka, S. 2011, 'Perinatal and neonatal risk factors for autism: A comprehensive meta-analysis', Pediatrics, vol. 128, pp. 344355. 
Geanellos, R. 1998, 'Hermeneutic philosophy. Part I: implications of its use as methodology in interpretative nursing research’, Nursing Inquiry, vol. 5, pp. 154-163.

Ghaziuddin, M. 2010, 'Brief report: Should the DSM V drop Asperger Syndrome?', Journal of Autism and Developmental Disorders, vol. 40, pp. 1146-1148.

Ghaziuddin, M. 2005, Mental health aspects of autism and Asperger's Syndrome, Jessica Kingsley Publishers, London.

Gillott, A. \& Standen, P.J. 2007, 'Levels of anxiety and sources of stress in adults with autism', Journal of Intellectual Disabilities, vol. 11, no. 4, pp. 359-370.

Gjevik, E., Eldevik, S., Fjæran-Granum, T. \& Sponheim, E. 2011, ‘Kiddie-SADS reveals high rates of DSM-IV disorders in children and adolescents with autism spectrum disorders', Journal of Autism and Developmental Disorders, vol. 41, pp. 761-769.

Goines, P. \& Van de Water, J. 2010, ‘The immune system’s role in the biology of autism', Current Opinion in Neurology, vol. 23, pp. 111-117.

Gómez de la Cuesta, G. 2010, ‘A selective review of offending behaviour in individuals with autism spectrum disorders', Journal of Learning Disabilities and Offending Behaviour, vol. 1, no. 2, pp. 47-58.

Gray, C.A. 1994, The New Social Story Book, Future Horizons, Arlington, TX.

Gray, C. \& Attwood, T. 1999, 'The discovery of Aspie criteria by Attwood and Gray’, The Morning News, vol. 11, no. 3, pp. 18-28.

Green, S. \& Ben-Sasson, A. 2010, ‘Anxiety disorders and sensory over-responsivity in children with autism spectrum disorders: is there a casual relationship?', Journal of Autism and Development Disorders, vol. 40, pp. 1495-1504.

Haney, C. 2003, 'Mental health issues in long-term solitary and "supermax" confinement', Crime and Delinquency, vol. 49, pp. 124-155.

Happé, F. 1995, 'The role of age and verbal ability in the theory of mind task performance of subjects with autism', Child Development, vol. 66, pp. 843855.

Happé, F. 2003, 'Cognition in autism: one deficit or many?’, in G. Bock \& J. Goode (eds), Autism: neural basis and treatment possibilities, Wiley, Chichesterm, pp.198-212. 
Happé, F. \& Frith, U. 2006, ‘The weak coherence account: Detail-focused cognitive style in autism spectrum disorders', Journal of Autism and Developmental Disorders, vol. 36, no. 1, pp. 5-25.

Happé, F. \& Ronald, A. 2008, 'The 'fractionable autism triad': A review of evidence from behavioural, genetic, cognitive and neural research', Neuropsychology Review, vol. 18, pp. 287-304.

Hare, D., Gould, J., Mills, R. \& Wing, L. 1999, A preliminary study of individuals with Autistic Spectrum Disorders in three special hospitals in England, The National Autistic Society at the Centre for Social and Communication Disorders, Kent.

Heidegger, M. 1927/1962, Being and Time, trans. J. Macquarie \& E. Robinson, Harper \& Row, New York.

Heidegger, M. 1959/1971, On the way to language, trans. P. Hertz, Harper \& Row, New York.

Heidegger, M. 1971/1975, Poetry, Language, Thought, trans. A. Hofstadter, Harper \& Row, New York.

Hensley, E. \& Briars, L. 2010, 'Closer look at autism and the measles-mumps-rubella vaccine’, Journal of the American Pharmacists Association, vol. 50, no. 6, pp. 736-741.

Hill, E.L. 2004, ‘Executive dysfunction in autism’, Trends in Cognitive Sciences, vol. 8, no. 1, pp. 26-32.

Hill, E., Berthoz, S. \& Frith, U. 2004, 'Cognitive processing of own emotions in individuals with autistic spectrum disorder and in their relatives', Journal of Autism and Developmental Disorders, vol. 34, no. 2, pp. 229-235.

Holroyd, A. 2007, 'Interpretative hermeneutic phenomenology: Clarifying understanding', Indo-Pacific Journal of Phenomenology, vol. 7, no. 2, pp. 112.

Howlin, P. 2003, 'Outcome in high functioning adults with autism with and without early language delays: Implications for the differentiation between autism and Asperger syndrome', Journal of Autism and Developmental Disorders, vol. 33, pp. 3-13.

Howlin, P. 2004, Autism and Asperger syndrome: Preparing for adulthood, Routledge, London. 
Hudry, K., Leadbitter, K., Temple, K., Slonims, V., McConachie, H., Aldred, C., Howlin, P. \& Charman, T. 2010, 'Preschoolers with autism show greater impairment in receptive compared with expressive language abilities’, International Journal of language \& Communication Disorders, vol. 45, no. 6, pp. 681-690.

Huey, M.P. \& Mcnulty, T.L. 2005, ‘Institutional conditions and prison suicide: Conditional effects of deprivation and overcrowding', The Prison Journal, vol. 85, pp. 490-514.

Hurlbutt, K. \& Chalmers, L. 2002, ‘Adults with autism speak out: Perceptions of their life experiences', Focus on Autism and Other Developmental Disabilities, vol. 17, no. 2, pp. 103-111.

Hurley, R., Losh, M., Parlier, M., Reznick, S. \& Priven, J. 2007, ‘The broad autism phenotype questionnaire', Journal of Autism and Developmental Disorders, vol. 37, pp. 1676-1690.

Husserl, E. 1929/1950, Cartesian Meditations: An introduction to Phenomenology, trans. D. Cairns, Kluwer Academic Publishers, The Netherlands.

Indig, D., Topp, L., Ross, B., Mamoon, H., Border, B., Kumar, S. \& McNamara, M. 2010, The 2009 NSW Inmate Health Survey, Justice Health, Sydney.

International Centre for Prison Studies 2011, World Prison Brief 2011, viewed 20 May 2012,

<www.prisonstudies.org/info/worldbrief/wpb_country_print.php?country=1 $92>$

Ireland, J.L. 2000, “"Bullying” among prisoners: A review of the research’, Aggression and Violent Behavior, vol. 5, no. 2, pp. 201-215.

Ireland, J. \& Archer, J. 1996, 'Descriptive analysis of bullying in male and female adult prisoners', Journal of Community \& Applied Social Psychology, vol. 6, pp. 37-47.

Jiang, S. \& Winfree, T. 2006, 'Social support, gender, and inmate adjustment to prison life: insights from a national sample', The Prison Journal, vol. 86, pp. 32-55.

Johnson, M.E. 2000, 'Heidegger and meaning: implications for phenomenological research’, Nursing Philosophy, vol. 1, pp.134-146.

Johnson, R. \& Chernoff, N. 2002, ““Opening a vein”: Inmate poetry and the prison experience', The Prison Journal, vol. 82, pp. 141-167. 
Kamio, Y. \& Toichi, M. 2000, 'Dual access to semantics in autism: Is pictorial access superior to verbal access?', Journal of Child Psychology and Psychiatry, vol. 41, no. 7, pp. 859-867.

Kamp-Becker, I., Smidt, J., Ghahreman, M., Heinzel-Gutenbrunner, M., Becker, K. \& Remschmidt, H. 2010, 'Categorical and dimensional structure of autism spectrum disorders: The nosologic validity of Asperger Syndrome', Journal of Autism and Developmental Disorders, vol. 40, pp. 921-929.

Kana, R.K., Keller, T.A., Cherkassky, V.L., Minshew, N.J. \& Just, M.A. 2006, 'Sentence comprehension in autism: thinking in pictures with decreased functional connectivity’, Brain, vol. 129, pp. 2484-2493.

Kanner, L. 1943, ‘Autistic disturbances of affective contact', Nervous Child, vol. 2, pp. 217-250.

Karkhaneh, M., Clark, B., Ospina, M.B., Seida, J.C., Smith, V. \& Harding, L. 2010, 'Social Stories ${ }^{\mathrm{TM}}$ to improve social skills in children with autism spectrum disorder: A systematic review’, Autism, vol. 14, pp. 641-662.

Kenworthy, L., Black, D.O., Harrison, B., Rosa, A. \& Wallace, G.L. 2009, ‘Are executive control functions related to autism symptoms in high-functioning children?', Child Neuropsychology, vol. 15, no. 5, pp. 425-440.

Kim, J.A., Szatmari, P., Bryson, S.E., Streiner, D.L. \& Wilson, F.J. 2000, 'The prevalence of anxiety and mood problems among children with autism and Asperger Syndrome', Autism, vol. 4, pp. 117-132.

Kjelgaard, M.M. \& Tager-Flusberg, H. 2001, ‘An investigation of language impairment in autism: Implications for genetic subgroups', Language and Cognitive Processes, vol. 16, no. 2, pp. 287-308.

Kleinman, J., Marciano, P.L. \& Ault, R.L. 2001, 'Advanced theory of mind in highfunctioning adults with autism', Journal of Autism and Developmental Disorders, vol. 31, no. 1, pp. 29-36.

Knivsberg, A., Reichelt, K.L., Høien, T. \& Nødland, M. 2002, ‘A randomised, controlled study of dietary intervention in autistic syndromes', Nutritional Neuroscience, vol. 5, no. 4, pp. 251-261.

Knivsberg, A., Reichelt, K.L., Nødland, M. \& Høien, T. 1995, ‘Autistic syndromes and diet: a follow-up study', Scandinavian Journal of Educational Research, vol. 39, no. 3, pp. 223-236. 
Koch, T. 1995, 'Interpretative approaches in nursing research: the influence of Husserl and Heidegger', Journal of Advanced Nursing, vol. 21, pp. 827-836. Kockelmans, J.J. 1967, Phenomenology: The philosophy of Edmund Husserl and its interpretation, Doubleday Anchor Books, New York.

Kogan, M.D., Blumberg, S.J., Schieve, L.A., Boyle, C.A., Perrin, J.M., Ghandour. R.M., Singh, G.K., Strickland, B.B., Trevathan, E. \& van Dyck, P.C. 2009, 'Prevalence of parent-reported diagnosis of autism spectrum disorder among children in the US, 2007', Pediatrics, vol. 124, pp. 1395-1403.

Kohn, Y., Fahum, T., Ratzoni, G. \& Apter, A. 1998, 'Aggression and sexual offense in Asperger's syndrome', The Israel Journal of Psychiatry and Related Sciences, vol. 35, no. 4, pp. 293-299.

Kolevzon, A., Gross, R. \& Reichenberg, A. 2007, 'Prenatal and perinatal risk factors for autism', Archives of Pediatric and Adolescent Medicine, vol. 161, pp. 326-333.

Korn, N. 1994, Life behind bars: Conversations with Australian male inmates, New Holland, Sydney.

Kupers, T.A. 2005, 'Toxic masculinity as a barrier to mental health treatment in prison', Journal of Clinical Psychology, vol. 61, no. 6, pp. 713-724.

Kuusikko, S., Pollock-Wurman, R., Jussila, K., Carter, A.S., Mattila, M., Ebeling, H., Pauls, D.L. \& Moilanen, I. 2008, 'Social anxiety in high-functioning children and adolescents with autism and Asperger syndrome', Journal of Autism and Developmental Disorders, vol. 38, pp. 1697-1709.

Långström, N., Grann, M., Ruchkin, V., Sjöstedt, G. \& Fazel, S. 2009, ‘Risk factors for violent offending in autism spectrum disorder: A national study of hospitalized individuals', Journal of Interpersonal Violence, vol. 24, no. 8, pp. 1358-1370.

Laverty, S.M. 2003, 'Hermeneutic phenomenology and phenomenology: A comparison of historical and methodological considerations', International Journal of Qualitative Methods, vol 2, no. 3, viewed 3 October 2010, $<$ http://www.ualberta.ca/ iiqm/backissues/2_3final/pdf/Laverty.pdf >

Leonard, V.W. 1989, 'A Heideggerian phenomenological perspective on the concept of the person', Advances in Nursing Science, vol. 11, no. 4, pp. 40-55.

Levy, F. 2007, 'Theories of autism', Australian and New Zealand Journal of Psychiatry, vol. 41, no. 11, pp. 859-868. 
Levy, M. 2005, 'Prisoner health care provision: reflections from Australia', International Journal of Prisoner Health, vol. 1, no. 1, pp. 65-73.

Lind. S.E. \& Bowler, D.M. 2009, 'Language and theory of mind in autism spectrum disorder: The relationship between complement syntax and false belief task performance', Journal of Autism and Developmental Disorders, vol. 39, pp. 929-937.

Linhorst, D.M., Bennett, L. \& McCutchen, T. 2003, 'Practicing social justice with persons with developmental disabilities who enter the criminal justice system’, Social Thought, vol. 22, no. 2, pp. 221-235.

Liss, M., Saulnier, C., Fein, D. \& Kinsbourne, M. 2006, 'Sensory and attention abnormalities in autistic spectrum disorders', Autism, vol. 10, pp. 155-172.

Locke, J., Ishijima, E.H., Kasari, C. \& London, N. 2010, 'Loneliness, friendship quality and the social networks of adolescents with high-functioning autism in an inclusive school setting', Journal of Research in Special Educational Needs, vol. 10, no. 2, pp. 74-81.

Lomangino, K. 2010, ‘AAP: Insufficient evidence for diet-based therapies in autism', Clinical Nutrition Insight, vol. 36, no. 3, pp. 7-8.

Lopez, B.R., Lincoln, A.J., Ozonoff, S. \& Lai, Z. 2005, 'Examining the relationship between executive functions and restricted, repetitive symptoms of autistic disorder', Journal of Autism and Development Disorders, vol. 35, no. 4, pp. 445-460.

Lopez, K. \& Willis, D. 2004, 'Descriptive Versus Interpretive Phenomenology: Their contributions to nursing knowledge’, Qualitative Health Research, vol. 14, no. 5, pp. 726-735.

Lord, C.E., Risi, S. \& Pickles, A. 2004, 'Trajectory of language development in autism spectrum disorders', in M. Rice \& S. Warren (eds), Developmental language disorders: from phenotypes to etiologies, Erlbaum, Mahwah, NJ, pp. 7-29.

Losh, M. \& Capps, L. 2006, 'Understanding of emotional experience in autism: insights from the personal accounts of high-functioning children with autism’, Developmental Psychology, vol. 42, no. 5, pp. 809-818.

Losh, M., Childress, D., Lam, K. \& Piven, J. 2008, 'Defining key features of the broad autism phenotype: a comparison across parents of multiple- and 
single- incidence autism families’, American Journal of Medical Genetics Part B (Neuropsychiatric Genetics), vol. 147B, pp. 424-433.

Losh, M., Esserman, D., Anckarsäter, H., Sullivan, P.F. \& Lichtenstein, P. 2012, 'Lower birth weight indicates higher risk of autistic traits in discordant twin pairs’, Psychological Medicine, vol. 42, pp. 1091-1102.

Loth, E., Gómez, J.C. \& Happé, F. 2008, ‘Event schemas in autism spectrum disorders: The role of theory of mind and weak central coherence', Journal of Autism and Developmental Disorders, Vol. 38, pp. 449-463.

Love, C. \& Morrison, E. 2002, 'Forensic Psychiatric Nursing Struggling to Happen, Failing to Thrive', Forensic Nurse, viewed 19 October 2005, $<$ http://www.forensicnursemag.com/articles/281feat1.html?wts=200510191 22343\&hc>

Maitland, A.S. \& Sluder, R.D. 1998, 'Victimization and youthful prison inmates: an empirical analysis', The Prison Journal, vol. 78, pp. 55-73.

Manolitsi, M. \& Botting, N. 2011, 'Language abilities in children with autism and language impairment: using narrative as a additional source of clinical information', Child Language Teaching and Therapy, vol. 27, no. 1, pp. 3955.

Matson, J.L., Wilkins, J. \& Macken, J. 2009, ‘The relationship of challenging behaviours to severity and symptoms of autism spectrum disorders', Journal of Mental Health Research in Intellectual Disabilities, vol. 2, pp. 29-44.

Mattila, M., Hurtig, T., Haapsamo, H., Jussila, K., Kuusikko-Gauffin, S., Kielinen, M., Linna, S., Ebeling, H., Bloigu, R., Joskitt, L., Pauls, D.L. \& Moilanen, I. 2010, 'Comorbid psychiatric disorders associated with Asperger syndrome/ high-functioning autism: A community- and clinic-based study', Journal of Autism and Developmental Disorders. vol. 40, pp. 1080-1093.

Mawson, D., Grounds, A. \& Tantam, D. 1985, 'Violence and Asperger’s syndrome: a case study', The British Journal of Psychiatry, vol. 147, pp. 566-569.

Mercier, C., Mottron, L. \& Belleville, S. 2000, ‘A psychosocial study on restricted interests in high-functioning person with pervasive developmental disorders’, Autism, vol. 4, pp. 406-425.

Miles, J.H. 2011, 'Autism spectrum disorders: A genetics review', Genetics in Medicine, vol. 13, no. 4, pp. 278-294. 
Miller, C.A. 2006, 'Developmental relationships between language and theory of mind', American Journal of Speech-Language Pathology, vol. 15, pp. 142154.

Millward, C., Ferriter, M., Calver, S. \& Connell-Jones, G. 2008, ‘Gluten- and caseinfree diets for autistic spectrum disorder', Cochrane Database of Systematic Reviews, Issue 2, viewed 2 February 2012, < http://onlinelibrary.wiley.com/doi/10.1002/14651858.CD003498.pub3>

Moran, D. 2000, Introduction to phenomenology, Routledge, London.

Morrison, J.C. 1970, 'Husserl and Brentano on Intentionality', Philosophy and Phenomenological Research, vol. 31, no. 1, pp. 27-46.

Moser, D., Arndt, S., Kanz, J., Benjamin, M., Bayless, J., Reese, R., Paulsen, J. \& Flaum, M. 2004, 'Coercion and informed consent in research involving prisoners', Comprehensive Psychiatry, vol. 45, no. 1, pp. 1-9.

Mouridsen, S.E. 2012, 'Current status of research on autism spectrum disorders and offending', Research in Autism Spectrum Disorders, vol. 6, pp. 80-86.

Muhle, R., Trentacoste, S.V. \& Rapin, I. 2004, 'The genetics of autism', Pediatrics, vol. 113, no. 5, pp. 472-486.

Muller-Vollmer, K. 1988, Hermeneutics reader: texts of the German tradition from the enlightenment to the present, Continuum International Publishing, London.

Müller, E., Schuler, A. \& Yates, G. 2008, 'Social challenges and supports from the perspective of individuals with Asperger syndrome and other autism spectrum disabilities’, Autism, vol. 12, no. 2, pp. 173-190.

Murphy, D. 2010a, 'Understanding offenders with autism-spectrum disorders: what can forensic services do?', Advances in Psychiatric Treatment, vol. 15, pp. 44-46.

Murphy, D. 2010b, 'Extreme violence in a man with an autistic spectrum disorder: assessment and treatment within high-security psychiatric care', Journal of Forensic Psychiatry \& Psychology, vol. 21, no. 3, pp. 462-477.

Murphy, D. 2003, ‘Admission and cognitive details of male patients diagnosed with Asperger Syndrome detained in a Special Hospital: comparison with a schizophrenia and personality disorder sample', The Journal of Forensic Psychiatry \& Psychology, vol. 14, no. 3, pp. 506-524. 
Murray, D.S., Ruble, L.A., Willis, H. \& Molloy, C.A. 2009, 'Parent and teacher report of social skills in children with autism spectrum disorders', Language, Speech, and Hearing Services in Schools, vol. 40, pp.109-115.

Murrie, D.C., Warren, J.I., Kristiansson, M. \& Dietz, P.E. 2002, ‘Asperger’s syndrome in forensic settings', International Journal of Forensic Mental Health, vol. 1, no. 1, pp. 59-70.

Muskett, T., Perkins, M., Clegg, J. \& Body, R. 2010, 'Inflexibility as an interactional phenomenon: Using conversation analysis to re-examine a symptom of autism', Clinical Linguistics \& Phonetics, vol. 24, no. 1, pp. 1-16.

Nagi, C., Browne, K. \& Blake, J. 2006, ‘A descriptive analysis of the nature and extent of bullying at a category C prison', The British Journal of Forensic Practice, vol. 8, no. 2, pp. 4-9.

Newman, C., Cashin, A. \& Waters, C. 2010, ‘A modified hermeneutic phenomenological approach toward individuals who have autism', Research in Nursing \& Health, vol. 33, pp. 265-271.

Newman, S.S. \& Ghaziuddin, M. 2008, 'Violent crime in Asperger Syndrome: The role of psychiatric co-morbidity', Journal of Autism and Developmental Disorders, vol. 38, pp. 1848-1852.

Newman, T.M., Macomber, D., Naples, A.J., Babitz, T., Volkmar, F. \& Grigorenko, E.L. 2007, 'Hyperlexia in children with autism spectrum disorders', Journal of Autism and Developmental Disorders, vol. 37, pp. 760-774.

Newton, C. 1994, 'Gender theory and prison sociology: using theories of masculinities to interpret the sociology of prisons for men', The Howard Journal, vol. 33, no. 3, pp. 193-202.

Nurse, J., Woodcock, P. \& Ormsby, J. 2003, 'Influence of environmental factors on mental health within prisons: focus group study', British Medical Journal, vol. 327, pp. 480-485.

NSW Department of Attorney General and Justice 2011, 2010/11 Annual Report, Department of Attorney General and Justice, Sydney, viewed 23 May 2012, <http://www.correctiveservices.nsw.gov.au/_data/assets/pdf_file/0011/3363 59/ag-and-j-2010-11-annual-report.pdf>

O’Connor, K. \& Kirk, I. 2008, ‘Atypical social cognition and social behaviours in autism spectrum disorder: A different way of processing rather than 
impairment', Journal of Autism and Developmental Disorders, vol. 38, pp. 1989-1997.

O’Donnell, I. \& Edgar, K. 1998, 'Routine victimisation in prisons', The Howard Journal, vol. 37, no. 3, pp. 266-279.

Ooi, Y.P., Tan, Z.J., Lim, C.X., Goh, T.J. \& Sung, M. 2011, 'Prevalence of behavioural and emotional problems in children with high-functioning autism spectrum disorders', Australian and New Zealand Journal of Psychiatry, vol. 45, pp. 370-375.

Osborne, J. 1994, 'Some similarities and differences among phenomenological and other methods of psychological qualitative research', Canadian Psychology, vol. 35, no. 2, pp. 167-189.

Ozsivadjian, A., Knott, F. \& Magiati, I. 2012, 'Parent and child perspectives on the nature of anxiety in children and young people with autism spectrum disorders: a focus group study', Autism, vol. 16, no. 2, pp. 107-121.

Paley, J. 1997, ‘Husserl, phenomenology and nursing', Journal of Advanced Nursing, vol. 26, pp. 187-193.

Panksepp, J. 1979, ‘A neurochemical theory of autism’, Trends in Neuroscience, vol. 2, pp. 174- 177.

Paterline, B.A. \& Petersen, D.M. 1999, 'Structural and social psychological determinants of prisonization', Journal of criminal Justice, vol. 27, no. 5, pp. 427-441.

Paternelj-Taylor, C.A. 2005, 'Conceptualizing nursing research with offenders: Another look at vulnerability', International Journal of Law and Psychiatry, vol. 28, pp. 348-359.

Paterson, P. 2008, 'How well do young offenders with Asperger's syndrome cope in custody? Two prison case studies', British Journal of Learning Disabilities, vol. 36, pp. 54-58.

Paul, R. 1987, ‘Communication’, in D.J. Cohne \& A.M. Donnellan (eds), Handbook of Autism and Developmental Disorders, Wiley-Interscience, US, pp. 61-84.

Pearson, J., Nelson, P., Titsworth, S. \& Harter, L. 2011, Human Communication. McGraw-Hill, New York.

Peppé, S., McCann, J., Gibbon, F., O’Hare, A. \& Rutherford, M. 2007, ‘Receptive and expressive prosodic ability in children with high-functioning autism’, 
Journal of Speech, Language and Hearing Research, vol. 50, pp. 10151028.

Pfeiffer, B., Kinnealey, M., Reed, C. \& Herzberg, G. 2005, 'Sensory modulation and affective disorders in children and adolescents with Asperger's Disorder', The American Journal of Occupational Therapy, vol. 59, no. 3, pp. 335-345.

Power, K. G., Dyson, G. P. \& Wozniak, E. 1997, 'Bullying among Scottish young offenders: Inmates self-reported attitudes and behaviour', Journal of Community \& Applied Social Psychology, vol. 7, pp. 209-218.

Prisoner 1979-1986, video recording, Network Ten, Australia.

Quina, K., Garis, A. V., Stevenson, J., Garrido, M., Brown, J., Richman, R., Renzi, J., Fox, J. \& Mitchell, K. 2007, 'Through the bullet-proof glass: Conducting research in prison settings', Journal of Trauma \& Dissociation, vol. 8, no. 2, pp. 123-139.

Realmuto, G.M. \& Ruble, L.A. 1999, 'Sexual behaviours in autism: Problems of definition and management', Journal of Autism and Developmental Disorders, vol. 29, no. 2, pp. 121-127.

Reichelt, K.L., Knivsberg, A., Lind, G. \& Nødland, M. 1991, 'Probable etiology and possible treatment of childhood autism', Brain Dysfunction, vol. 4, pp. 308319.

Reichelt, K.L., Sælid, G., Lindback, T. \& Bøler, J.B. 1986, ‘Childhood autism: A complex disorder’, Biological Psychiatry, vol. 21, pp. 1279-1290.

Robertson, M. A., Sigalet, D.L., Holst, J. J., Meddings, J.B., Wood, J. \& Sharkey, K.A. 2008, 'Intestinal permeability and glucagon-like peptide-2 in children with autism: A controlled pilot study', Journal of Autism and Developmental Disorders, vol. 38, pp. 1066-1071.

Robinson, L., Spencer, M.D., Thomson, L.D., Stanfield, A.C., Owens, D.G., Hall, J. \& Johnstone, E.C. 2012, 'Evaluation of a screening instrument for autism spectrum disorders in prisoners', PLoS ONE, vol. 7, no. 5, viewed 20 June 2012, $<$ http://www.plosone.org/article/info\%3Adoi\%2F10.1371\%2Fjournal.pone. 0036078>

Roekel, E.V., Scholte, R.H.J. \& Didden, R. 2010, 'Bullying among adolescents with autism spectrum disorders: prevalence and perception', Journal of Autism and Developmental Disorders, vol. 40, pp. 63-73. 
Ronald, A. \& Hoekstra, R.A. 2011, 'Autism spectrum disorders and autistic traits: A decade of new twin studies’, American Journal of Medical Genetics Part B, vol. 156, pp. 255-274.

Rosengren, K.E. 2000, Communication: An Introduction, Sage Publications, London. Royal College of Psychiatrists 2006, Psychiatric services for adolescents and adults with autistic-spectrum disorders, Council Report CR136, Royal College of Psychiatrists, London.

Rutter, M. 2005, ‘Aetiology of autism: findings and questions’, Journal of Intellectual Disability Research, vol. 49, no. 4, pp. 231-238.

Sacks, O. 1986, The man who mistook his wife for a hat. Picador, London.

Sandyk, R. \& Gillman, M.A. 1986, 'Infantile autism: a dysfunction of the opioids?', Medical Hypotheses, vol. 19, pp. 41-45.

Schlosser, J.A. 2008, 'Issues in interviewing inmates: Navigating the methodological landmines of prison research', Qualitative Inquiry, vol. 14, no. 8, pp. 15001525.

Schofield, M. 2004, ‘Sampling in quantitative research’, in V. Minichiello, G. Sullivan, K. Greenwood \& R. Axford (eds), Research Methods for Nursing and Health Science, 2nd edn, Pearson Education Australia, NSW, Australia, pp. 176-205.

Schultz, R.T., Chawarska, K. \& Volkmar, F.R. 2006, 'The social brain in autism: perspectives from neuropsychology and neuroimaging', in S. Moldin \& J. Rubenstein (eds), Understanding autism: from basic neuroscience to treatment, Taylor and Francis, London, pp. 323-348.

Schwartz-Watts, D. 2005, 'Asperger's Disorder and Murder', The Journal of the American Academy of Psychiatry and the Law, vol. 33, pp. 390-393.

Scragg, P. \& Shah, A. 1994, 'Prevalence of Asperger's syndrome in a secure hospital’, British Journal of Psychiatry, vol. 165, pp. 679-682.

Shattock, P. \& Whiteley, P. 2002, 'Biochemical aspects in autism spectrum disorders: updating the opioid-excess theory and presenting new opportunities for biomedical intervention', Expert Opinion on Therapeutic Targets, vol. 6, no. 2, pp. $175-183$.

Shriberg, L.D., Paul, R., McSweeny, J.L., Klin, A., Cohen, D.J. \& Volkmar, F.R. 2001, 'Speech and prosody characteristics of adolescents and adults with 
high-functioning autism and Asperger Syndrome’, Journal of Speech, Language and Hearing Research, vol. 44, pp. 1097-1115.

Siegel, D.J., Minshew, N.J. \& Goldstein, G. 1996, 'Wechsler IQ profiles in diagnosis of high-functioning autism', Journal of Autism and Development Disorders, vol. 26, no. 4, pp. 389-406.

Simon, J. 2000, 'The 'Society of Captives' in the Era of Hyper-Incarceration', Theoretical Criminology, vol. 4, no. 3, pp. 285-308.

Siponmaa, L., Kristiansson, M., Jonson, C., Nyden, A. \& Gillberg, C. 2001, ‘Juvenile and young adult mentally disordered offenders: the role of child neuropsychiatric disorders', Journal of the American Academy of Psychiatry and the Law, vol. 29, pp. 420-426.

South, C.R. \& Wood, J. 2006, 'Bullying in prisons: The importance of perceived social status, prisonization, and moral disengagement', Aggressive Behavior, vol. 32, pp. 490-501.

Southall, C.M. \& Gast, D.L. 2011, ‘Self-management procedures: A comparison across the autism spectrum', Education and Training in Autism and Developmental Disabilities, vol. 46, no. 2, pp. 155-171.

Souza, K.A. \& Dhami, M.K. 2010, 'First-time and recurrent inmates’ experiences of imprisonment', Criminal Justice and Behavior, vol. 37, no. 12, pp. 13301342.

Spiker, M.A., Lin, E.C., Van Dyke, M. \& Wood, J.J. 2012, 'Restricted interests and anxiety in children with autism', Autism, vol. 16, pp. 306-320.

Sykes, G. 1958, The Society of Captives, Princeton University Press, Princeton, NJ.

Sykes, G. \& Messinger, S. 1960, ‘The inmate social system’, in R.A. Cloward, D.R. Cressey, G.H. Grosser, R. McCleery, L.E. Ohlin, G.M. Sykes \& S.L. Messinger (eds), Theoretical studies in social organization of the prison, Social Science Research Council, New York, pp. 5-19.

Tager-Flusberg, H., Calkins, S., Nolin, T., Baumberger, T., Anderson, M. \& Chadwick-Dias, A. 1990, ‘A longitudinal study of language acquisition in autistic and Down syndrome children', Journal of Autism and Developmental Disorders, vol. 20, pp. 1-22.

Tager-Flusberg, H., Paul, R. \& Lord, C. 2005, 'Language and communication in autism', in F.R Volkmar, R. Paul, A. Klin \& D. Cohen (eds), Handbook of 
autism and Pervasive Developmental Disorders, 2nd edn, John Wiley \& Sons, New Jersey, pp. 335-364.

Tantam, D. 2000, 'Psychological disorder in adolescents and adults with Asperger syndrome’, Autism, vol. 4, pp. 47-62.

Tantam, D. 2003, 'The challenge of adolescents and adults with Asperger syndrome', Child and Adolescent Psychiatric Clinics of North America, vol. 12, pp. 143163.

Tiffin, P., Shah, P. \& le Couteur, A. 2007, 'Diagnosing pervasive developmental disorders in a forensic adolescent mental health setting', The British Journal of Forensic Practice, vol. 3, no. 3, pp. 31-40.

The Shawshank Redemption 1994, motion picture, Columbia Pictures, United States.

'Vaccine Court rules no connection between vaccines and autism’ 2009, Mental Health Weekly, vol. 19, no. 8, pp. 7-8.

Verhoeven, W.M., Egger, J.I. \& Feenstra, I. 2011, 'Genetic disorders and the autism spectrum’, Clinical Neuropsychiatry, vol. 8, no. 3, pp. 219-224.

de Viggiani, N. 2006, 'Surviving prison: exploring prison social life as a determinant of health’, International Journal of Prisoner Health, vol. 2, no. 2, pp. 71-89.

de Viggiani, N. 2007, 'Unhealthy prisons: exploring structural determinants of prison health', Sociology of Health \& Illness, vol. 29, no. 1, pp. 115-135.

Volden, J. \& Lord, C. 1991, 'Neologisms and idiosyncratic language in autistic speakers', Journal of Autism and Developmental Disorders, vol. 21, no. 2, pp. 109-130.

Wakefield, A.J., Murch, S.H., Anthony, A., Casson, D.M., Malik, M., Berelowitz, M., Dhillon, A.P., Thomson, M.A., Harvey, P., Valentine, A., Davies, S.E. \& Walker-Smith, J.A. 1998, 'Ileal-lymphoid-nodular hyperplasia, non-specific colitis, and pervasive developmental disorder in children', The Lancet, vol. 351, 637-641.

Waldram, J.B. 2007, 'Everybody has a story: Listening to imprisoned sexual offenders', Qualitative Health Research, vol. 17, no. 7, pp. 963-970.

Walenski, M., Tager-Flusberg, H. \& Ullman, M. 2006, 'Language in autism’, Chapter 9 In: Molden, S. \& Rubenstein, J. (Eds). Understanding autism: from basic neuroscience to treatment. Taylor and Francis; London, UK. pp. 175-203.

Watterson, K. 1996, Women in prison: inside the concrete womb, Northeastern University Press, Boston. 
White, S., Kreiser, N., Pugliese, C. \& Scarpa, A. 2012, 'Social anxiety mediates the effect of autism spectrum disorder characteristics on hostility in young adults', Autism, Published ahead of print, May 2012, <http://aut.sagepub.com/content/early/2012/05/03/1362361311431951>

White, S., Oswald, D., Ollendick, T. \& Scahill, L. 2009, ‘Anxiety in children and adolescents with autism spectrum disorders', Clinical Psychology Review, vol. 29, pp. 216-229.

Williams, K., MacDermott, S., Ridley, G., Glasson, E. \& John, W. 2008, 'The prevalence of autism in Australia: Can it be established from existing data?', Journal of Paediatrics and Child Health, vol. 44, pp. 504-510.

Wing, L. 1981, ‘Asperger’s syndrome: a clinical account’, Psychological Medicine, vol. 11, pp. 115-130.

Wing, L. \& Gould, J. 1979, 'Severe impairments of social interaction and associated abnormalities in children: Epidemiology and classificiation', Journal of Autism and Developmental Disorders, vol. 9, pp. 11-29.

Wing, L., Gould, J. \& Gillberg, C. 2011, 'Autism spectrum disorders in the DSM-V: Better or worse than the DSM-IV?', Research in Developmental Disabilties, vol. 32, no. 2, pp. 768-773.

Wing, L. \& Potter, D. 2002, 'The epidemiology of autistic spectrum disorders: Is the prevalence rising?', Mental Retardation and Developmental Disabilities, vol. 8, pp. 151-161.

Witt, K.A. \& Davis, T.P. 2006, 'CNS drug delivery: opioid peptides and the bloodbrain barrier', The American Association of Pharmaceutical Scientists Journal, vol. 8, no. 1, pp. 76-88.

Wojnar, D. \& Swanson, K. 2007, 'Phenomenology, An exploration', Journal of Holisitic Nursing, vol. 25, no. 3, pp. 172-180.

Wolff, K. 1984, ‘Surrender-and-catch and phenomenology’, Human Studies, vol. 7, pp. 191-210.

Wolff, N. \& Shi, J. 2009, ‘Type, source and patterns of physical victimization: A comparison of male and female inmates', The Prison Journal, vol. 89, pp. 172-191.

Wood, J.J. \& Gadow, K.D. 2010, 'Exploring the nature and function of anxiety in youth with autism spectrum disorders', Clinical Psychology: Science and Practice, vol. 17, no. 4, pp. 281-292. 
Woodbury-Smith, M., Clare, I., Holland, A.J., Kearns, A., Staufenberg, E. \& Watson, P.C. 2005, 'A case-control study of offenders with high functioning autistic spectrum disorders', The Journal of Forensic Psychiatry \& Psychology, vol. 16, no. 4, pp. 747-763.

Woodbury-Smith, M., Clare, I., Holland, A. J., Watson, P.C., Bambrick, M., Kearns, A. \& Staufenberg, E. 2010, 'Circumscribed interests and 'offenders' with autism spectrum disorders: a case-control study', Journal of Forensic Psychiatry \& Psychology, vol. 21, no. 3, pp. 366-377.

Woodham, R. 2004, 'Security in correctional systems', in S. O’Toole \& S. Eyland (eds), Corrections Criminology, Hawkins Press, Sydney, pp. 53-59.

World Health Organisation 1992. The ICD-10 Classification of Mental and Behavioural Disorders: Clinical Descriptions and Diagnostic Guidelines, World Health Organisation, Geneva.

World Health Organisation 1993. The ICD-10 Classification of Mental and Behavioural Disorders: Diagnostic Criteria for Research, World Health Organisation, Geneva. 